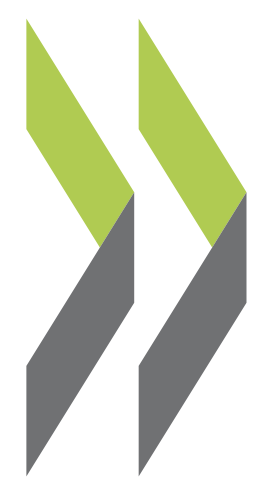

OECD Local Economic and Employment Development (LEED) Papers 2012/03

\title{
Skills for Competitiveness: Country Report for Canada
}

\section{Anil Verma}




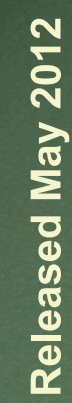

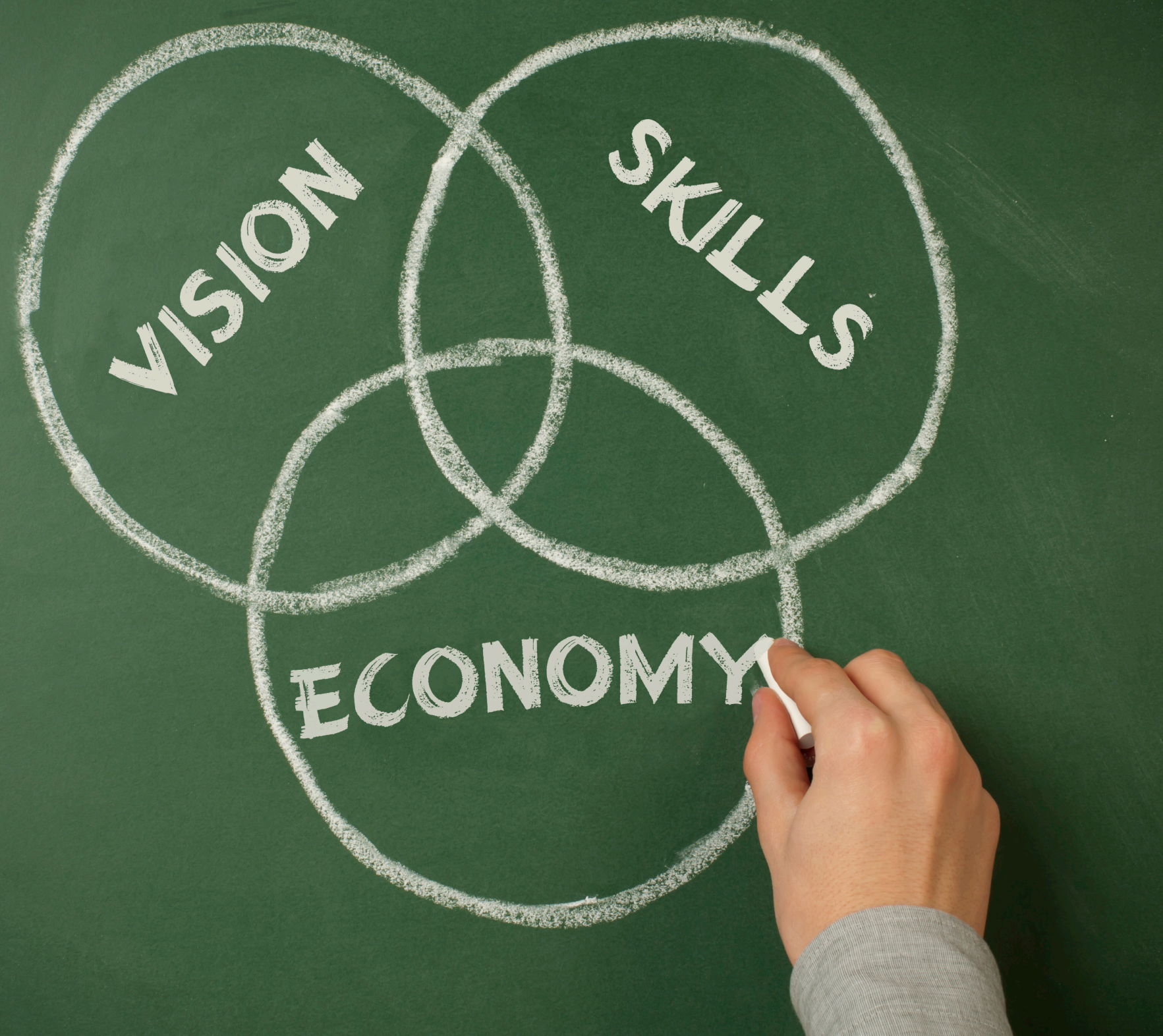

\section{Skills for Competitiveness}

Country Report for Canada

Anil Verma 
TABLE OF CONTENTS

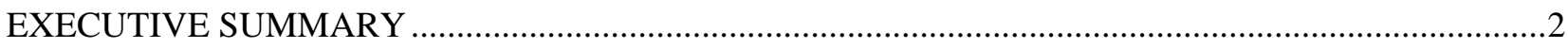

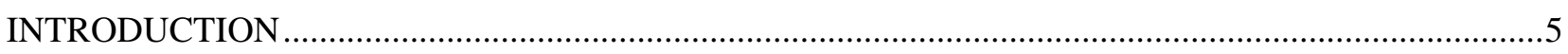

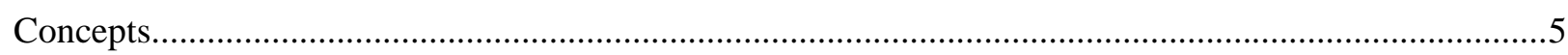

A LABOUR MARKET PROFILE: DEMAND AND SUPPLY OF HIGH-SKILL JOBS IN CANADA \&

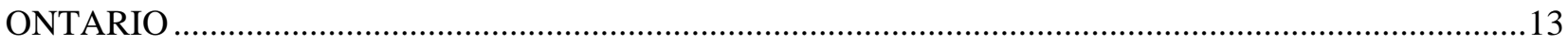

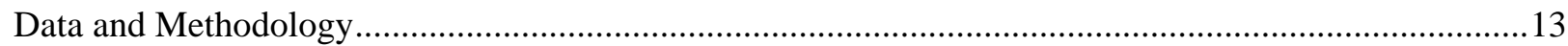

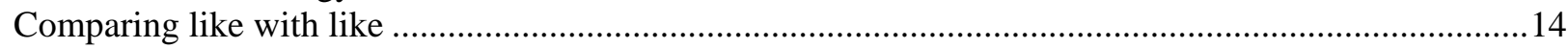

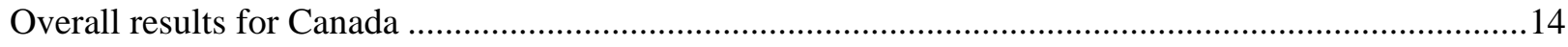

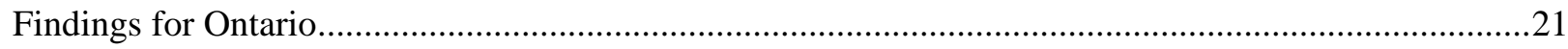

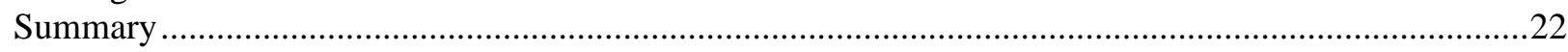

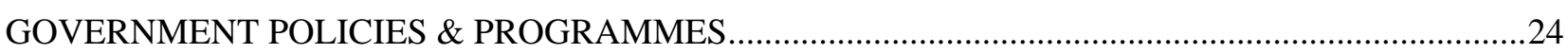

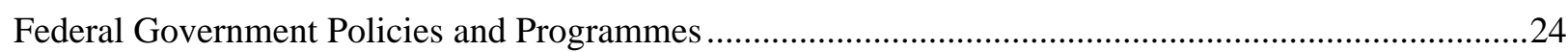

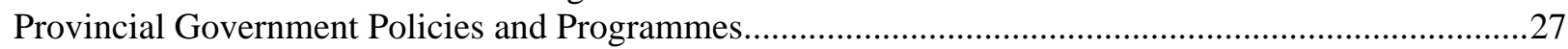

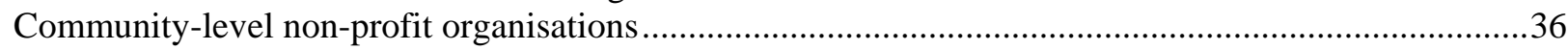

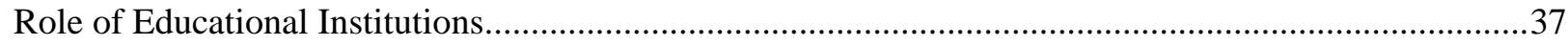

PARTNERSHIPS \& COLLABORATION: THE REGIONAL APPROACH …........................................41

The Niagara Region: Moving to a Higher Value-added Economy .............................................................41

The Waterloo Region: Moving to a Higher Value-added Economy ........................................................49

PARTNERSHIPS \& COLLABORATION: THE SECTOR APPROACH....................................................55

Case Study 1: The Ontario Food Processing Sector ….....................................................................55

Industry Case-study 2: Hotel Industry in Ontario.................................................................................62

Broader training and skills development in relation to tourism and hospitality ..................................67

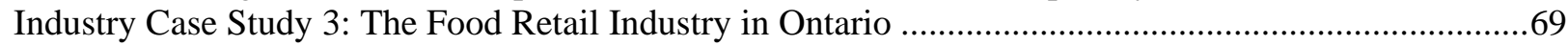

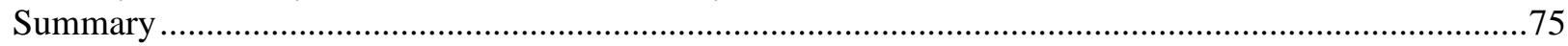

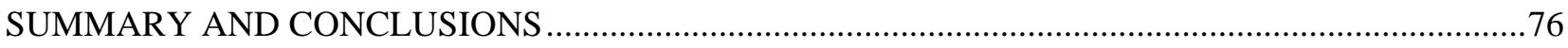

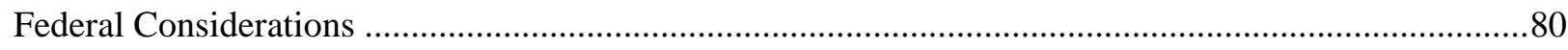

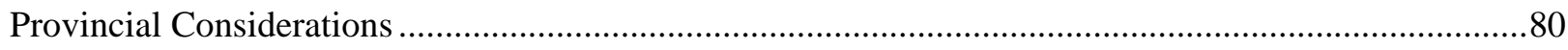

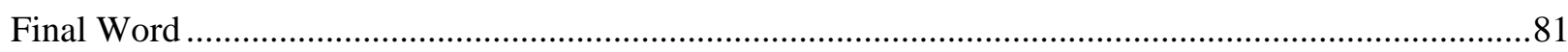

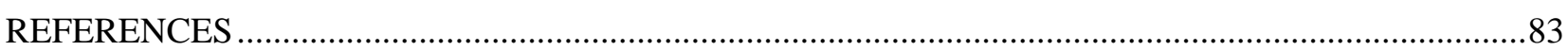




\section{EXECUTIVE SUMMARY}

This study conducted an investigation of how regions can move to a higher-skill, higher value-added equilibrium in Canada, drawing on Ontario as a case study example. ${ }^{1}$ Given the complexities of measuring such a shift this investigation examined the issue from different perspectives. It examined aggregate labour market data in order to map skills supply and demand at the level of employment insurance (EI) regions. This analysis is supplemented with an overview of institutions and policies that facilitate the shift to higher skills and higher value-added production in Ontario. Two geographical regions (Niagara and the Kitchener-Waterloo regions) and three industries within Ontario (food processing, hotels, food retailing) were examined in greater detail.

The institutional framework in Ontario for a shift towards a high value-added economy includes the federally-funded Sector Councils. In the Government of Ontario the following play a key role in increasing supply and demand for high skills: Ministry of Training, Colleges and Universities, Ministry of Economic Development and other region-specific and industry-specific (e.g., Ministry of Northern Development, Mines and Forestry; Ministry of Agriculture, Food and Rural Affairs) ministries including the Ministry of Research and Innovation.

The "local" dimension to policy interventions comes from quasi-government bodies, industry (or employer) associations, non-profit community organisations, labour unions, etc. At the local level, Ontario's policy infrastructure includes workforce planning boards, regional governments, regional industry associations, and non-profit organisations.

Most of the Provincial funding spent on training is for "downside" adjustment, i.e., to rehabilitate workers displaced by merger, closure, tech change or other disruptions. Monies spent on upgrading skills of current employees, so-called "upside" training, is much more limited in scope and in quantity. The policy issue for Canada is to consider how employers could be incentivised to invest more in the skills of their workforce. Our case studies illustrate a few examples of employers who have adopted a policy of investing in the skills of their employees through formal and on-the-job training.

Many employer groups especially at the national and industry level, such as the Canadian Manufacturers and Exporters and Canadian Food Processors among many others, support firms in becoming more competitive by investing in more value-added work and employee skills. Many region- or industry-specific university and college programmes in Ontario were established after being proposed by an educational institution with the support from relevant industry. This is done on a case-by-case basis rather than through centralised planning. Some colleges and universities have adopted region- or industry-

\footnotetext{
${ }^{1}$ The Province of Ontario was chosen for the study because not only is it the most populous of all Canadian provinces but it also has a well-diversified economy. To support more general application of the project findings, data was analysed on the supply and demand for skills for EI regions across Canada, and specific sectors were explored (tourism, retail and food processing) which are important to the Canadian economy as a whole. The findings can be considered by all levels of government in Canada that are involved training, skills and economic development policy.
} 
specific priorities but it is not a defining characteristic of educational programmes in general which tend to be focused around academic disciplines or occupations that cut across region and industry.

Non-profit community groups also provide key inputs by providing training and other services to employers, individuals and local governments. These organisations serve an integrative role at the local level by creating a forum for public-private regional economic development partnerships and by pooling community resources to address common concerns. They also serve as a major platform for building the local community's social capital.

The Niagara regional economy, anchored by tourism, hospitality, winemaking and light manufacturing, is diversifying to fill the loss of jobs in manufacturing by attracting both higher-tech manufacturing as well as start-ups in digital media. There are also efforts to add value to the traditional tourist trade by promoting "culinary" tourism. Local level networks are anchored by bodies such as the Niagara Workforce Planning Board, the Niagara Economic Development Corporation, educational institutions (Niagara College, Brock University) and industry associations (Grape Growers Ontario, local Chambers of Commerce, etc.). The Niagara region benefits from a well-defined geographical and industrial profile both of which have contributed to investments in social capital.

Regional coordination in the Kitchener-Waterloo-Cambridge area is anchored by community nonprofit organisations (e.g., Excellence in Manufacturing Canada, Communitech, and Canada's Technology Triangle), educational institutions (University of Waterloo, Wilfrid Laurier University, Conestoga College, University of Guelph) and industry associations (e.g., Association of Ontario Food Processers). The boundaries of this region are less clearly delineated (both an advantage and a disadvantage at the same time) and the regional economy is more diversified relative to the Niagara region. For social capital formation the geographical and industrial diversity translates into multiple networks rather a single large network.

Our research is unable to ascertain what proportion of Ontario industries come into contact with organisations and programmes described here. It is very likely that many companies undertake training and business improvement on their own without any contact with government or non-profit programmes. Although difficult to determine, it is important to assess the extent to which Ontario industry relies on external resources supplied by these programmes and organisations.

Although a significant variety of institutions exist in Ontario the likelihood of a response coordinated across all stakeholders at the local level is episodic at best. Ontario could improve its response to local needs by creating processes that require periodic consultations across all stakeholders at the local level.

Overall, it can be concluded that Ontario has an elaborate infrastructure for policy intervention. It consists of a variety of institutions representing different constituencies. However, the coordination at the local level is not as focused as some situations demand. Many firms are benefitting from the policies and programmes available to encourage and support firms to move to a high skill equilibrium. However, it is not possible to ascertain based on existing information, the share of Ontario's economy that is fully participating in this change. Institutions that help build social capital at the local level are the key to innovation and change in the direction of a high-skill equilibrium and while Ontario has some of this institutional infrastructure, more can be done to foster stronger institutions and processes.

Based on the discussion above the following initiatives are suggested for consideration:

\section{All levels of government in Canada}

a. Promote joined-up local level partnerships as a mechanism for moving areas toward a higher-skills equilibrium 
b. Broaden the definition and scope of innovation in policies and programmes to include product improvement, process improvement, higher-value product introduction, higher-value process introduction; and, target relatively low value-added sectors with high employment for funding innovations.

c. Foster community- and industry-level organisations that provide information, training and support for adoption of value-addition practices within small and medium-sized enterprises.

\section{Federal government} economy:

Improve labour market information to better track the shift towards a higher value-added, higher-skill

o Implement a workplace (establishment) survey like the former WES but in a modified form, that would track both demand- and supply-side practices for higher value-added products and processes and higher skills.

o Augment the reporting of monthly (or quarterly) employment statistics from the Labour Force Survey, with employment and unemployment broken down by occupational skill categories (e.g., creative, service, working) and by income categories.

\section{Provincial government}

a. Create a process (or forum) that would bring together local level bodies from both demand- and supply-side of the high-skill equilibrium on a regular basis. Currently, the two sides work in parallel and consult when deemed necessary.

b. Work closer with employers to understand what skills are in high demand and to bring about a better skills supply and demand match.

c. More focus could be placed on "upside" adjustment, where employment and training programmes are targeted to upgrade the skills of current employees. 


\section{INTRODUCTION}

The Skills for Competitiveness project aims to better understand the dynamics of moving high-wage economies from a low-value-added equilibrium to a high-value-added equilibrium in which the supply of higher skills is matched by a demand for higher skills. The project covers three countries (Canada, U.K. and Italy) and this report documents the evidence from Canada. More specifically, the Province of Ontario was chosen for the study because not only is it the most populous of all Canadian provinces but it also has a well-diversified economy.

We begin with a brief overview of concepts and methodology. ${ }^{2}$ This is followed by a review of policies, programmes and institutions in Ontario that facilitate and support the move towards higher skills on both the demand side and the supply side. This is followed by a brief description of initiatives by government, educational institutions, employers and community organisations. In the next two sections we describe the Ontario experience in creating a supply of and demand for high skills, using two separate approaches: by region and by industry sector. Although these approaches overlap they represent two important foci for policies targeted at investment, job creation and value-addition.

\section{Concepts}

Moving to a high-skill equilibrium is not only desirable but also necessary if Canada has to maintain and enhance its prosperity. Higher skills add more value to products and services and thereby can justify and sustain higher wages and consequently a higher standard of living. As the rest of the world develops economically and national economies become more connected with the global economy, Canada cannot afford to engage in low-value-added production with concomitant low skills and low wages. Therefore, understanding the dynamic of transitioning from a low-skill equilibrium to a higher-skill equilibrium at the regional level is important to ensuring economic growth and competitiveness.

Figure 1 below shows a typology of skills supply and demand at high and low ends. If we polarize skills into low and high levels, the possible combinations of skills supply and demand would generate four possible states of equilibrium or disequilibrium.

\footnotetext{
${ }^{2}$ This report presents only a very brief description of the conceptual framework that is common to all the sites of the project. It is suggested that this report should be read in conjunction with the OECD synthesis report that discusses the concepts driving the overall project.
} 
Figure 1. Moving from a low to high-skilled equilibrium (adapted from Green et al, 2003)

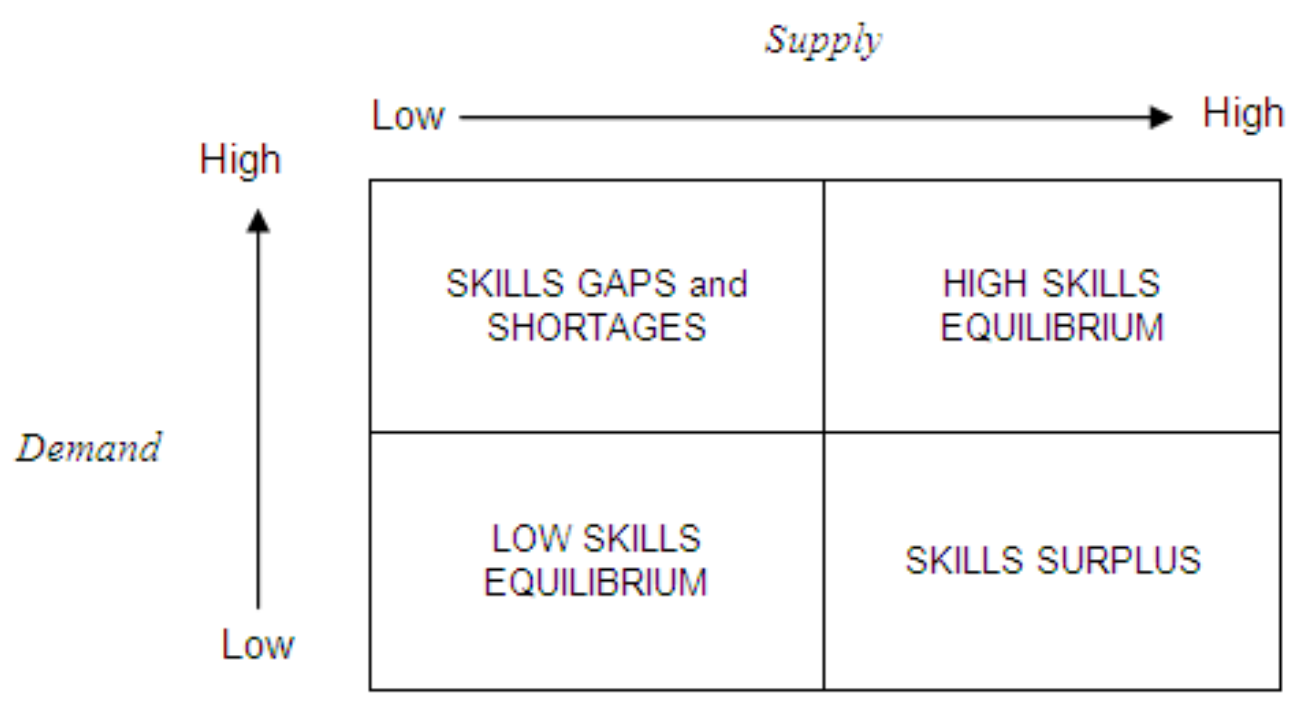

Source: OECD, 2009

In the top-left corner, demand for high skills is met by a supply of low skills, a situation that results in reported skills shortages. In the top-right corner, demand for high skills is met by an equal supply of high skills resulting in a high-skill equilibrium. This is the most desired destination of all high wage economies. At the bottom-left corner the demand for low skills is met by a supply of low skills resulting in a low-skill equilibrium - a situation that has existed historically but still persists in selected regions and industries in Canada. The challenge facing policymakers is to get the economy moving in a north-easterly direction towards the top-right corner. Lastly, in the bottom-right corner demand for low skills is met by a supply of high skills resulting in an economy where high skills available are not utilised. This leads to migration of talent, underemployment and attrition of human capital, all of which signal missed opportunities for creating prosperity.

Each of these four corners requires different policy responses. The scope of our study is to focus more specifically on moving to the top-right corner from any of the other three corners. Hence, we do not address directly issues such as brain-drain or underemployment of immigrants or older workers. Our interest lies in policies that encourage businesses to move to more value-added production on the demand side and on policies that encourage workers to acquire higher skills on the supply side.

Much has been written on the topic of moving to higher value-addition and skills needed to add greater value. At the national level there are examples like the rise of Asian economies such as Japan in the 1950s and the 1960s, then Singapore, Taiwan and Hong Kong in the 1970s and more recently, China, India and Brazil since the 1990s. In each of these cases, investing in skills has been central to their economic growth. The European Commission also funds regional development aimed at boosting the knowledge economy (i.e., a higher value-added economy) through targeted funds and incentives. ${ }^{3}$ In this report we do

3 The European Union's Regional Development programme is aimed at “increasing investment in human capital”, among other objectives, in regions that are less developed. Regional spending for 2007-13 accounts for over one third of the EU budget - or some $€ 350$ billion. There are three main funds for regional development: the European Regional Development Fund (ERDF) for general infrastructure, innovation, and investments; the European Social Fund (ESF) for vocational training projects, other kinds of employment assistance, and job-creation programmes; and, the Cohesion Fund for environmental and transport infrastructure projects and the development of renewable energy. This funding is for 15 countries 
not summarise these programmes or their evaluations but rather take note of the important lessons drawn from such experience. The underlying premise of these initiatives is that policy interventions can nudge a region towards greater value-added production.

The underlying process that accounts for a region's economy gradually moving from low value-added to higher value-added production can be understood in terms of producers' actions in response to competition and supply responses from the labour market to demand for production of value-added products. This process is generally triggered by new technologies or increased competition in the market that forces producers to use innovative and creative methods of production. Our discussion of this dynamic is organised into three areas: demand-side dynamics, supply-side dynamics, and institutional interventions. These generalisations form the basis for our investigation of the Ontario case.

\section{Demand-side Factors}

Firms and workplaces are generally aware of the need for and benefits of high-skill-high-value-added production. The management of the firm initiates change through introduction of innovation and new technology. Market forces of competition and rational behaviour of seeking greater returns on investment form the incentives for management to introduce change but ultimately, it is managerial choice and prerogative that decides if the firm is to move to higher value-added products. Hence, the quality of management in terms of its ability to anticipate changes in the industry and its vision of future possibilities become crucial in determining the speed and the extent to which an economy would move to a higher value-added equilibrium.

Management introduces change through a variety of practices. Some of these identified and popularised since the 1980s are:

- Business process re-engineering ${ }^{4}(\mathrm{BPR})$ is a method to improve the value each business process (e.g., handling customer complaints or billing accounts, etc.) adds to the key objectives of the organisation. BPR begins with the analysis of existing processes and ends with a re-design of workflows and key business processes. Triggered by the work of Hammer (1990), Hammer and Champy (1993), and Davenport and Short (1990), it became popular in identifying and eliminating non-value adding work rather than using technology for automating it. It allows a fundamental rethinking of how work is done in order to dramatically improve processes such as customer service, cut operational costs, and become world-class competitors.

- Benchmarking to global standards. Benchmarking is a technique for comparing one's own performance with high-performing peers in the industry. In general, peers are identified from the best performing firms or the most-admired firms in the industry. In such cases, it is also referred to as, "best practice" benchmarking. Geographical scope of peers can be defined as local, regional, national or international. Benchmarking can be performed as a one-time exercise or can be the basis for a periodic review of organisational processes (Boxwell 1994, Camp 1989).

- Six Sigma. Six Sigma is a technique for improving process quality originally developed by Motorola in the U.S. in 1986 and later adopted on a large scale and popularized by firms such as General Electric. The name Six Sigma derives from the statistical probability of an error rate (or a defect rate in the case of manufacturing) outside of six standard deviations from the mean. It

whose living standards are less than $90 \%$ of the EU average (12 newest EU members plus Portugal, Greece and Spain). Source: http://europa.eu/pol/reg/index_en.htm

\footnotetext{
${ }^{4}$ Also known by other names such as: business process management, business process redesign, or business process
} optimisation. 
translates into an error rate of precisely $0.00034 \%$ or 3.4 defects per million (Breyfogle 1999). Motorola and others firms have developed certification procedures for training people in Six Sigma techniques that result in various levels of certification such as black belt, green belt, etc. Currently, Six Sigma is used in many firms and different sectors of industry.

- Employee Involvement in workplace decision-making. Inspired by Japanese innovations such as quality circles and kaizen (Japanese word for "improvement", or "change for the better") and European developments in autonomous work teams, many firms in Canada and the U.S. began to introduce various forms of employee involvement in workplace decision-making. Some of the most popular forms have been quality circles, autonomous or semi-autonomous work teams, employee committees, taskforces, suggestion schemes, etc. (Cutcher-Gershenfeld, Kochan and Verma 1991; Walton 1979, 1985).

- Lean Manufacturing. Sometimes referred to as lean production, it is a paradigm rather than a specific technique applied initially to manufacturing but later expanded to services, that advocates systematic reduction of inputs (raw materials, labour, capital, etc.) while maintaining the same or higher output and better outcomes (quality, cost, productivity, delivery time, customer satisfaction, etc.). A lean manufacturing unit may practice any or all of the abovementioned techniques such as benchmarking, employee involvement, quality improvement techniques such as Six Sigma and Quality Circles, just-in-time inventory systems, continuous improvement, etc. ${ }^{5}$

Since these practices are generally associated with greater value-addition in firms, in this study we followed institutions and organisations in Ontario that promote such practices. An important caveat needs to be made in respect of these practices: they are all incremental processes to improve gradually the value added to goods or services being produced. They do not account for large-scale innovation that comes typically from technological breakthroughs. These practices can help add more value to existing product lines (Cole 2002) but they are not designed to spur technological innovation. Thus, their role is complementary, not substitutional, to technological innovation. There is some evidence that incremental improvements can lead to innovation despite the apparent logical differences between the two processes (Cole 2002, Cole and Matsumiya 2008).

It is also important to note that in many sectors and especially the low value-added and serviceintensive sectors that we focus on in this study such as food processing, food retail and hospitality, innovation takes place through hundreds of small incremental improvements rather than through a few large-scale technological breakthroughs. Therefore, management techniques described above are quite relevant for studying the dynamics of adding greater value to products through greater investment in skills.

\section{Supply-side Factors}

On the supply-side, change is needed at two levels to enable the firm to move to higher value-added production: firm (or workplace) level and the individual worker level. The firm seeking higher value-added production must upgrade its workforce with skills needed to enter new markets, new products, raise quality, lower costs and improve productivity. Skill formation for the upwardly mobile firm requires a combination of public and private investment in education and training. The institutional infrastructure to

\footnotetext{
${ }^{5}$ The "Lean" paradigm originated in the Japanese manufacturing industry but the term in English was first used in an article by John Krafcik, "Triumph of the Lean Production System," Sloan Management Review, Fall 1988, 30 (1): 41-52. The International Motor Vehicle Program (IMVP) at MIT provided a more comprehensive treatment of the lean system in: Jim Womack, Daniel Jones, and Daniel Roos, The Machine That Changed the World. New York: Free Press, 1990.
} 
deliver higher skills for the firm must exist in the region where the firm operates. Some regions do better than others. Firms can move people if the infrastructure is not available locally but this is generally found to be less efficient than locating the firm in the region where a strong skill formation infrastructure exists. This notion is well captured in Porter's $(1980,1985)$ idea of competitive industry "clusters" that exist within certain geographies. More recent work on the growth and prosperity of "creative" cities by Florida (2002, 2005) and others also supports the view that some regions are more attractive to firms because of their skills infrastructure, along with other factors. ${ }^{6}$

So, firms need to set up the right infrastructure and incentives for their workers to acquire better skills. Investment in firm-level training, both classroom and on-the-job, has been well documented as an essential ingredient in increasing value-added production. In addition to making training available to their employees, firms also need to integrate acquisition and utilization of higher skills into the employees' incentive systems. In other words the higher skills must be so integrated into their tasks that the connection between their skills and higher performance on the job is well established.

An economy seeking to move to a higher value-added level of production must persuade its workforce that future prosperity is inherently tied to higher education and higher skills. In Canada generally and in Ontario in particular, this translates into all of the following ${ }^{7}$ :

- persuading more young people to finish high school

- $\quad$ persuading more young people to pursue post-secondary education

- $\quad$ strengthening education in science and mathematics

- attracting more people to programmes in new areas of technology

In addition, there has emerged a growing emphasis in public policy on life-long learning because the knowledge frontier in almost every field of study is constantly changing and evolving. Without continuous learning and updating, skills can become out-dated more quickly than was the case in the past.

These changes, especially the ones in changing attitudes towards skill acquisition, are slow to take effect. Ideas about the value of education and the relevance of learning are influenced heavily by social interactions with family and friends. Hence, the task of influencing education and career decisions is quite difficult and needs sustained and significant policy inputs at multiple levels.

\footnotetext{
${ }^{6}$ Florida (2002) proposed the 3-T model of urban growth and success: technology, training and tolerance.

${ }^{7}$ These policies have evolved gradually over the years. Recent documents that affirm these policies can be found in Ministry of Education and Training (1996), "Future goals for Ontario Colleges and Universities. Discussion paper”; and, Bob Rae’s 2005 report, "Reaching higher: The McGuinty government plan for postsecondary education.” The Reaching Higher Plan included a commitment to substantially expand graduate education in Ontario. This initiative will increase the number of highly skilled and knowledgeable workers in Ontario, ensuring that Ontario remains economically competitive. The end-state target of 201112 will increase the number of graduate spaces (measured in Full-Time Equivalents - FTEs) by 62 per cent compared to 2002-03. Institutions have made significant progress towards meeting this target. The 2002 and 2004 annual reports of the Task Force on Competitiveness, Productivity and Economic Progress (accessed from www.competeprosper.ca) identified part of Ontario's prosperity gap as the result of lower levels of human capital, noting that fewer Ontarians are educated at the graduate level in comparison to peer jurisdictions in the United States. The key US jurisdictions produce 100 per cent more Master's and 33 per cent more doctoral graduates than Ontario.
} 


\section{Institutional Factors}

The role of institutions in fostering change and introducing innovation has attracted much attention in the past (Cole 1979, 1982). If markets were perfect, firms facing competition would innovate on their own without external input. In the neoclassical view, firms that do not respond to the innovation challenge would go out of business. This is a simplistic view of how the economy operates as a whole for at least two reasons: first, there are instances of market failures, and, second, the social costs of allowing firms to fail more often than they need to, are often too high and, hence, unacceptable. Previous research has documented the role that institutions play in spurring innovation. Cole $(1979,1982)$ examined evidence on the diffusion of innovations across United States, Japan and Sweden. These studies found that quality circles (QCs) spread in Japan because institutions such as the Japan Federation of Employers' Associations (Nikkeiren) and the Japan Union of Scientists and Engineers (JUSE) promoted its benefits and urged Japanese producers to adopt them. In Sweden, the employers federation (SAF) played a similar role. The diffusion process was considerably slower in the U.S. because of the absence, at least in the 1980s, of similar institutions.

A large variety of institutions can be involved in the process of promoting innovations and often their role can be complementary of each other. There are government-run programmes that would provide funding for equipment and training if the firm were to introduce new technology or other process innovations. There are employer organisations such as the SAF, Nikkeiren, Canadian Manufacturers and Exporters (CME) or the Conference Board of Canada. There are also community-level non-profit organisations that address investment and innovation issues. These organisations and their activities underscore the relevance of institutional inputs that are a resource to the individual firm moving on the path to more value-added production and more enhanced skills for its workforce.

Although an open economy adjusts constantly to the environment, institutions can and do play a significant role in facilitating the move to a higher-skill equilibrium. Policy interventions can be made to increase the demand as well the supply of higher skills (Figure 2). Stimulating demand for higher skills begins with producers increasing the value of their products, which can be accomplished in a variety of ways. One path to higher value is to improve product quality, price, delivery, etc., in incremental ways through continuous improvement. Another path would be to invest in research, design and development of new products using new technologies. Either way, these improvements and innovations would require workers to have better skills. The additional skills required can be "soft" skills in addition to functional or technical knowledge acquired through formal education and training. Soft skills refer to skills such as problem-solving, team work, communication and conflict resolution among others. On the supply-side, policies and programmes fund education and training in areas that are in demand. Additionally, campaigns are directed at people at different stages of their life-course to enhance their skills through further training and education. When the two trends intersect, i.e., both demand and supply of higher-skill jobs rise by the same amount we would get a higher-skill equilibrium.

The process described here can occur at an aggregate level of national economy or at a more disaggregate level of a region or sub-region (sometimes referred to as 'local' level). Achieving a high-skill equilibrium at a disaggregate level has become more challenging with increasing integration of local, national and international economies. So, for example, some occupational or industry-specific labour markets that used to be more localized have now expanded in scope. If the supply of high skills at the local level exceeds the demand for local skills, people would simply move to other regions and thus pre-empt investments that might have taken place to build demand for high skills in the region. Conversely, if demand exceeds supply of high skills other regions (nearby or far away) could supply those skills and thereby pre-empt investments in local infrastructure for increasing the supply of skills. Although recent developments in the global economy have moved us in the direction of less 'localization' of both supply and demand for high skills, it is important to keep in mind that there are still strong imperatives for 
managing labour markets at the local level. We have already mentioned above the work of Porter (1980, 1985) on clusters as the basis for economic development. These clusters tend to develop within certain geographic boundaries for a number of reasons. People are not always eager to move, especially, after they begin to raise families. Further, Florida's (2002, 2005) work on cities suggests that there is a life-style element that attracts creative talent to certain places. If people are attracted to New York City, for example, for its offering of the arts and theatre, it is time consuming and very expensive for other cities in the region to replicate these features in the short-run. Other infrastructural resources such as high quality educational institutions and research labs are similarly hard to replicate in the short-run to increase high skill supply. As long as these factors are still applicable, policy planning at the local level can be rewarding. Of course, the local focus needs to take into account the blurring of local boundaries that happens with increasing integration of regional, national and international markets.

\section{Box 1. Methodology}

The Province of Ontario was chosen for this study as an exemplar of the Canadian economy. In 2010, Ontario was Canada's largest province with a population of 13.2 million, accounting for $38.7 \%$ of the national population. It accounts for roughly $38 \%$ of the Canadian GDP. Its economy is among the most diversified of Canadian provinces with goods production accounting for $24 \%$ of the GDP (of which manufacturing accounts for $15 \%$ and the remaining $9 \%$ comes from primary industries).

A three-stage methodology has been employed to map and understand the dynamics of processes aimed at creating the demand for higher skills and a commensurate supply of higher skills in the province. The first stage involved analysing demand and supply proxies for various jurisdictions in Canada and Ontario. The second stage involved interviews with key informants in several government ministries, employer organisations, educational institutions, community organisations and selected "partnership" organisations such as labour-management councils. The third stage involved case-studies of selected regional and industry clusters. At the regional level, we examined the cases of the Niagara area and the Kitchener-Waterloo-Cambridge-Guelph area of Ontario. At the industry level, we examined the cases of the food-processing industry, the hospitality industry and the retail industry. 
Figure 2. A Model of Policy Interventions for a Shift to a High-skill Equilibrium

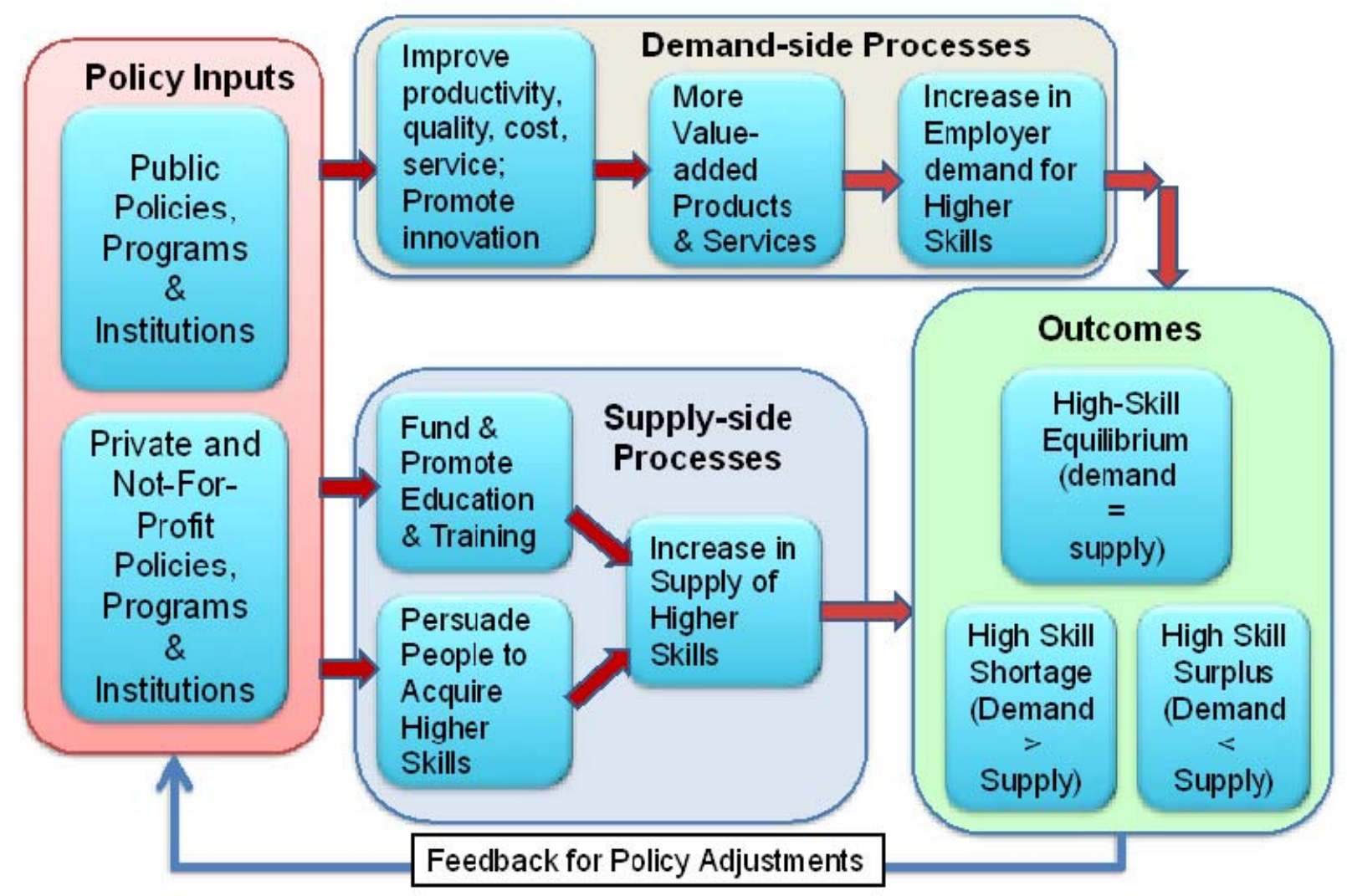




\section{A LABOUR MARKET PROFILE: DEMAND AND SUPPLY OF HIGH-SKILL JOBS IN CANADA \& ONTARIO ${ }^{8}$}

An aggregate look at the supply and demand of high-skill jobs can be undertaken using labour market data at the local level. In this section, we present a profile of such jobs by various regions of Canada and Ontario. The typology outlined earlier in Figure 1 is used as the framework for the analysis that follows.

\section{Data and Methodology}

The data used in the project is from the Canadian Census. For the first time this data was aggregated at the Employment Insurance (EI) region level thanks to the support of HRSDC. The 58 EI regions ${ }^{9}$ are designed to provide comparable EI benefits to Canadians residing in areas with homogeneous labour markets and similar unemployment levels. They therefore incorporate travel to work areas and are particularly useful for this analysis.

We have used data from the Census of 2001 and 2006, the two most recent surveys for which data are available publicly. This allows us to not only examine the relative supply and demand of jobs in these regions but also the changes that occur over five years between the surveys.

We computed proxies for skills supply and demand for each EI region and we plotted them on a scatter graph. Supply of skills is measured by the percentage of the population having post secondary education (University certificate, diploma or degree). Skills demand is measured by combining inflationadjusted income (weight=0.75) and the percentage of people employed in medium-to-high skilled jobs (weight $=0.25$ ). It should be pointed out that our reliance on incomes as a proxy for skill may distort the picture in the case of some regions that have a high proportion of primary sector jobs. Such jobs can command high salaries not necessarily because of the skill content but due to physical demands of work such as hazardous work and its remote location.

In order to make the variables comparable across regions, they were standardized using an inter-decile range method as follows:

$$
\begin{aligned}
& \text { Standardized Score for region } \mathrm{i}=\left(\mathrm{X}_{\mathrm{i}}-\mathrm{X}_{\mathrm{med}}\right) /\left(\mathrm{X}_{9 \mathrm{th}}-\mathrm{X}_{1 \mathrm{st}}\right) \\
& \text { Where, } \mathrm{X}_{\mathrm{i}}=\text { value for EI region } \mathrm{i} \\
& \mathrm{X}_{\mathrm{med}}=\text { Canadian median } \\
& \mathrm{X}_{9 \mathrm{th}}=9 \text { th decile } \\
& \mathrm{X}_{1 \text { st }}=1 \text { st decile }
\end{aligned}
$$

\footnotetext{
${ }^{8}$ The analysis reported in this section was performed by Michela Meghnagi, a Research Analyst at the OECD, Paris.

${ }^{9}$ Yukon, Northwest Territories and Nunavut have been excluded from the analysis. Therefore 55 EI regions were studied.
} 


\section{Comparing like with like}

It is important that policy makers are able to compare regions with similar overall characteristics. The data analysis therefore started with an exploration of the industrial base and degree of urbanisation of the chosen sub-regional areas.

In particular the basic elements which can assist in comparisons between similar regions are:

- Employment by industry. This variable identifies the percentage of the population in the labour force working in three main industrial categories: primary, secondary and services.

- Degree of urbanisation. EI regions were divided in urban and rural following the classification provided by HRSDC.

- Differentiating cities. As large urban centres have particularly complex skills ecosystems, they have been separated from other urban areas in the analysis. Following the classification of the OECD Directorate for Public Governance and Territorial Development, in Canada, Montreal, Toronto and Vancouver are considered as metropolitan areas.

Drawing on the above information, sub regions have been classified into 4 profiles; predominant primary, secondary or services sectors. Within these categories, sub- regions have been categorised according to their level of urbanisation.

After identifying the benchmarking groups it is possible to compute the supply and demand indices in two separate ways - either by comparing sub-regions within their benchmarking groups (alongside subregions with similar industrial characteristics and degree of urbanisation) or by comparing sub-regions across a country. In the first case the formula shown above applies only to the sub-regions belonging to the benchmarking group (e.g. sub-regions having a dominant primary sector); in the second case it applies to all sub-regions in the country. The following section includes results from both ways of computing the data in the different countries.

\section{Overall results for Canada}

\section{Comparison by benchmarking group}

In the graphs that follow, the standardised score for the supply proxy is plotted on the $\mathrm{X}$-axis and the standardized score for the demand proxy is plotted on the y-axis.

The following figures show scatter plots for Canada as a whole by primary (Figures $3 \& 4$ ), secondary (Figures $5 \& 6$ ) and service sectors (Figures $7 \& 8$ ). These charts generally suggest that high-skill equilibria characterise urban economies while relatively lower skill equilibria characterise rural regions. 
Figure 3. El regions in Canada with a strong primary sector, 2001

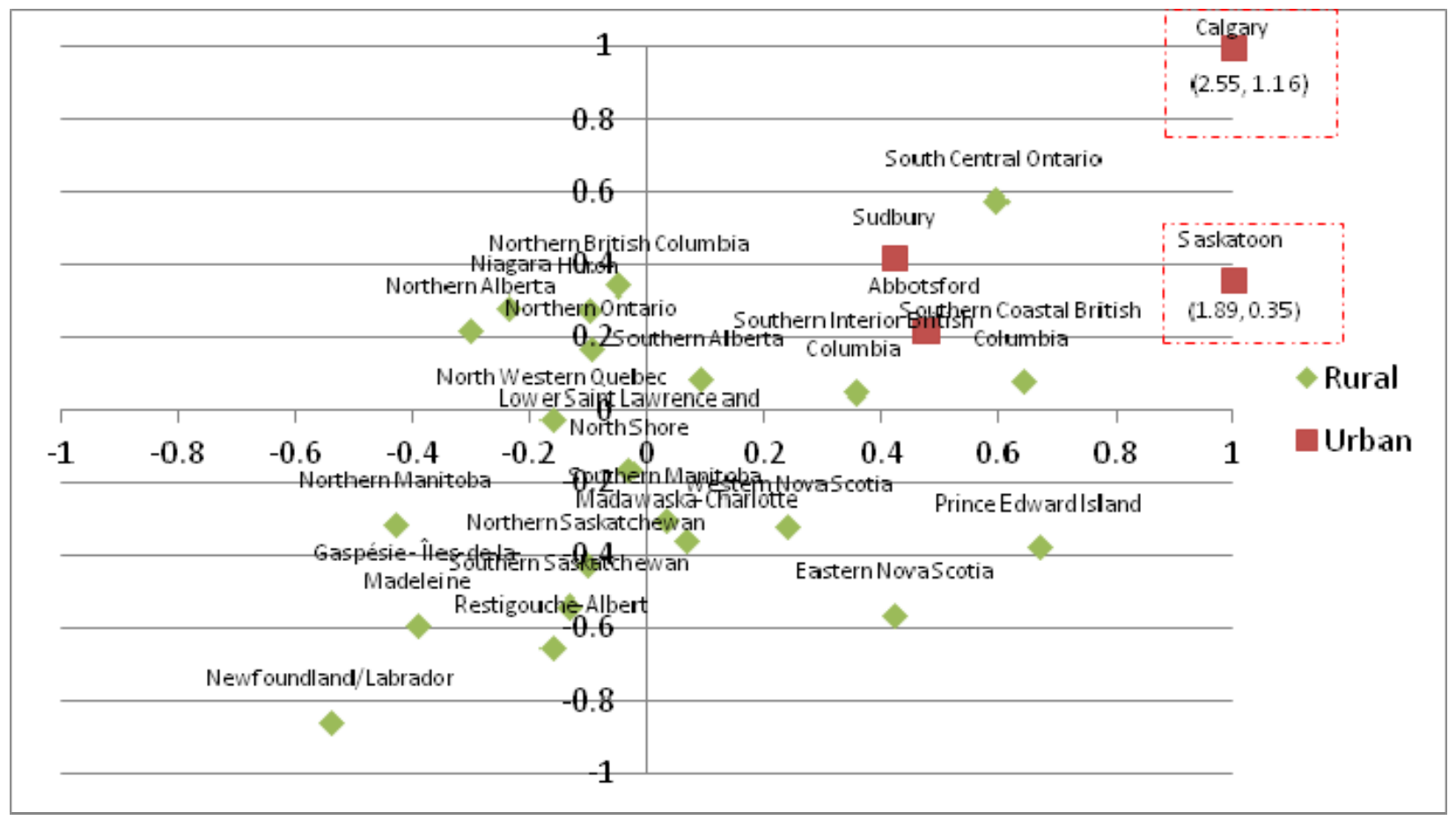

Figure 4. El regions in Canada with a strong primary sector, 2006

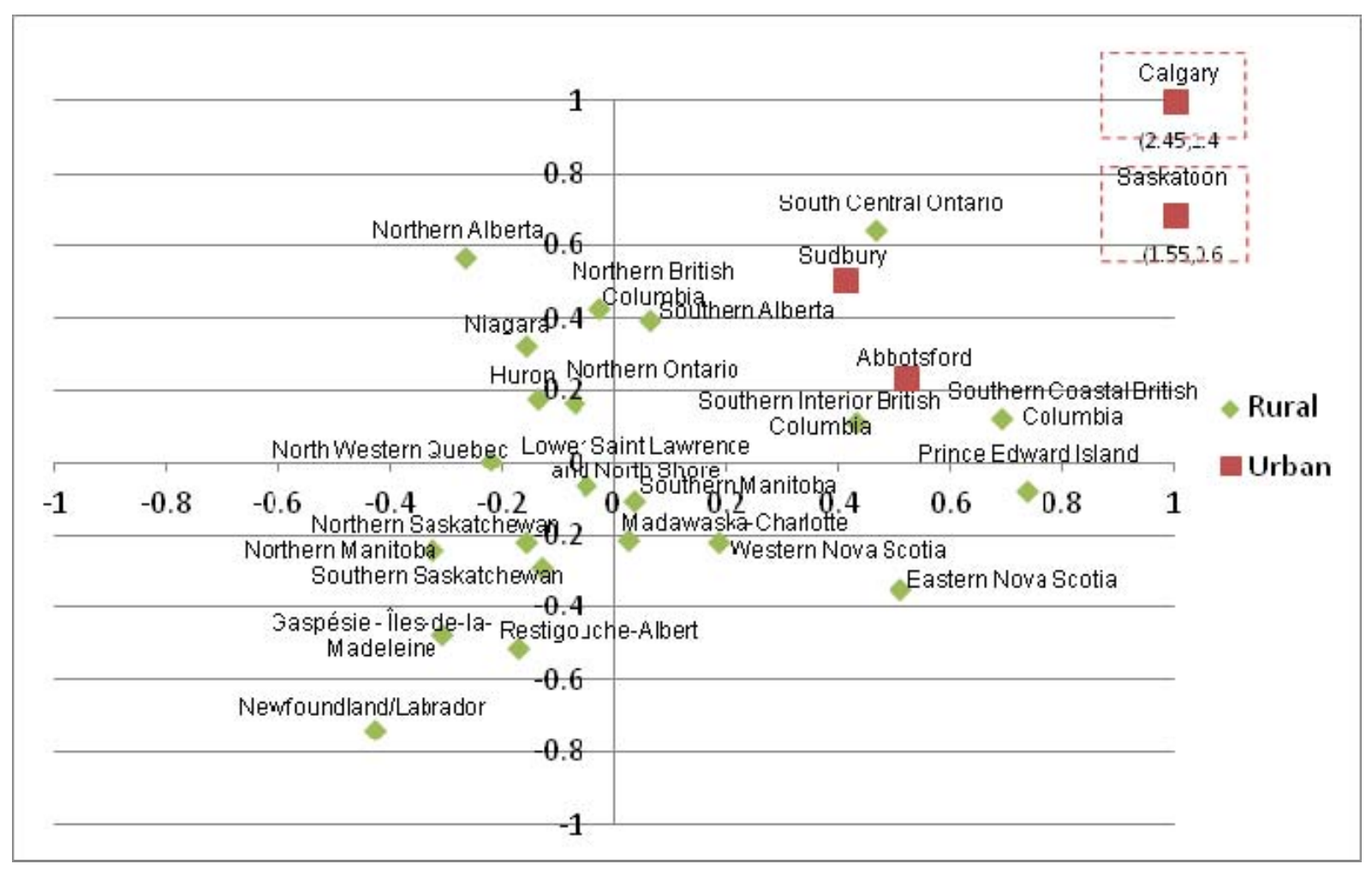


Figure 5. El regions in Canada with a strong secondary sector, 2001

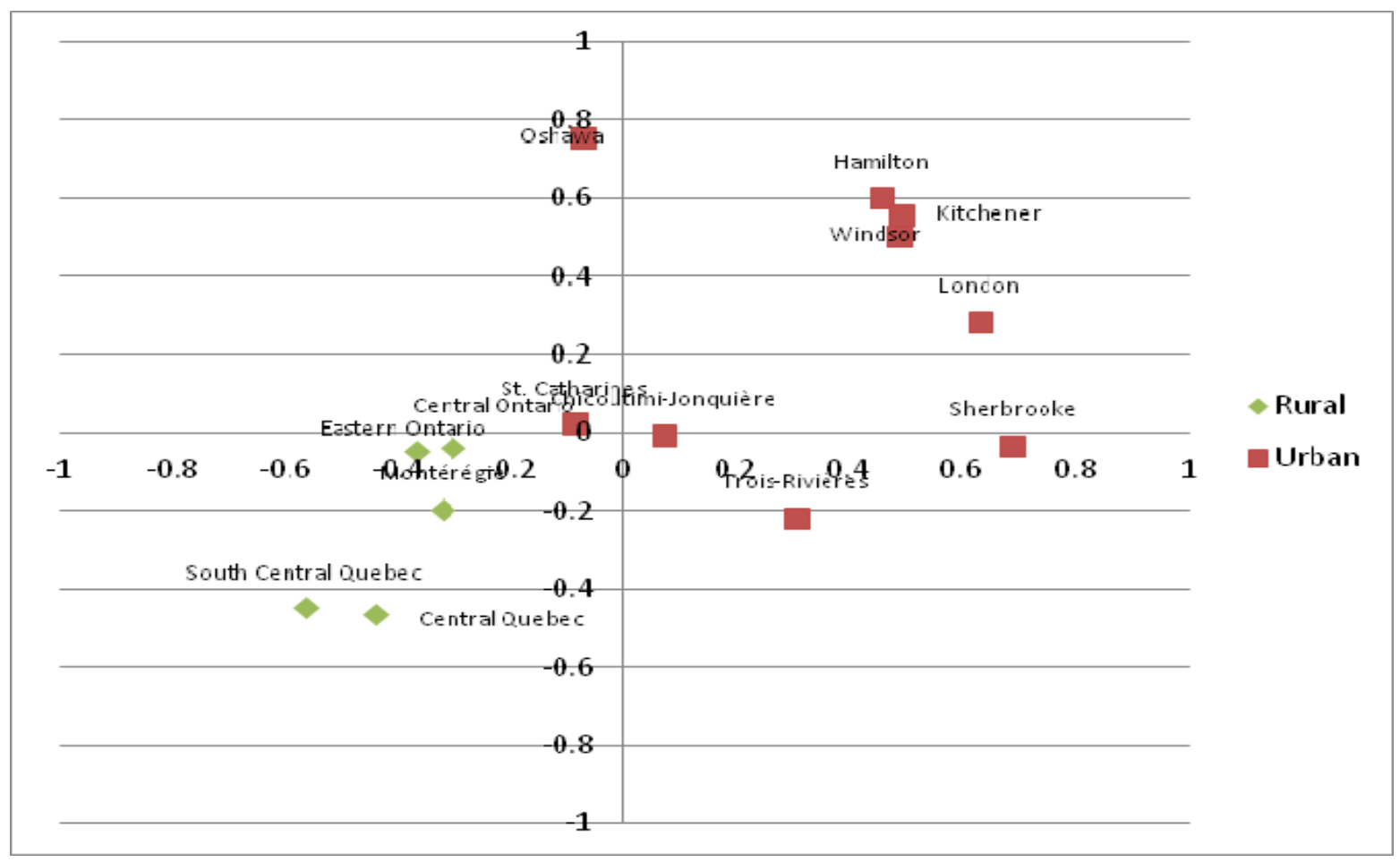

Figure 6. El regions in Canada with a strong secondary sector, 2006

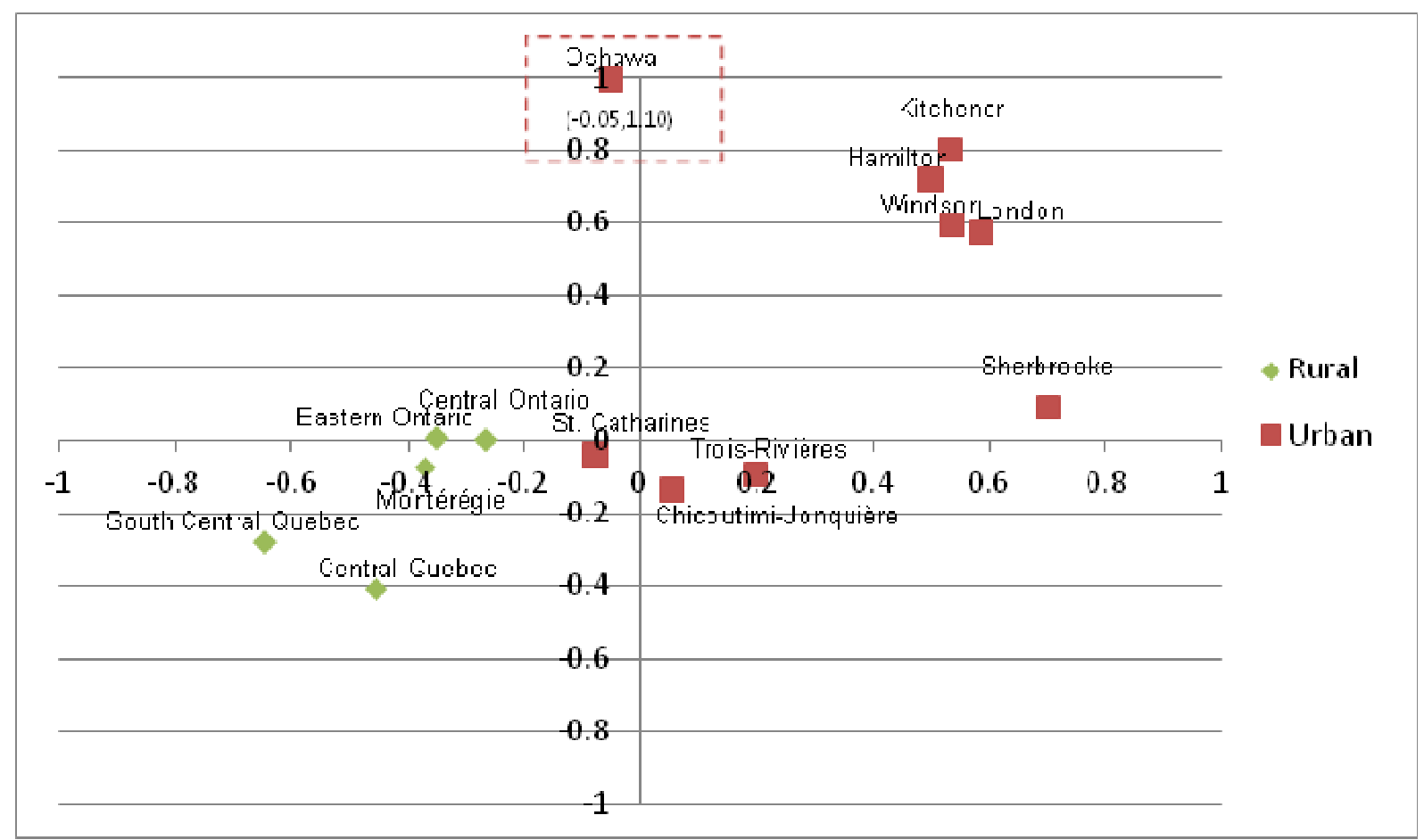


Figure 7. El regions in Canada with a strong service sector, 2001

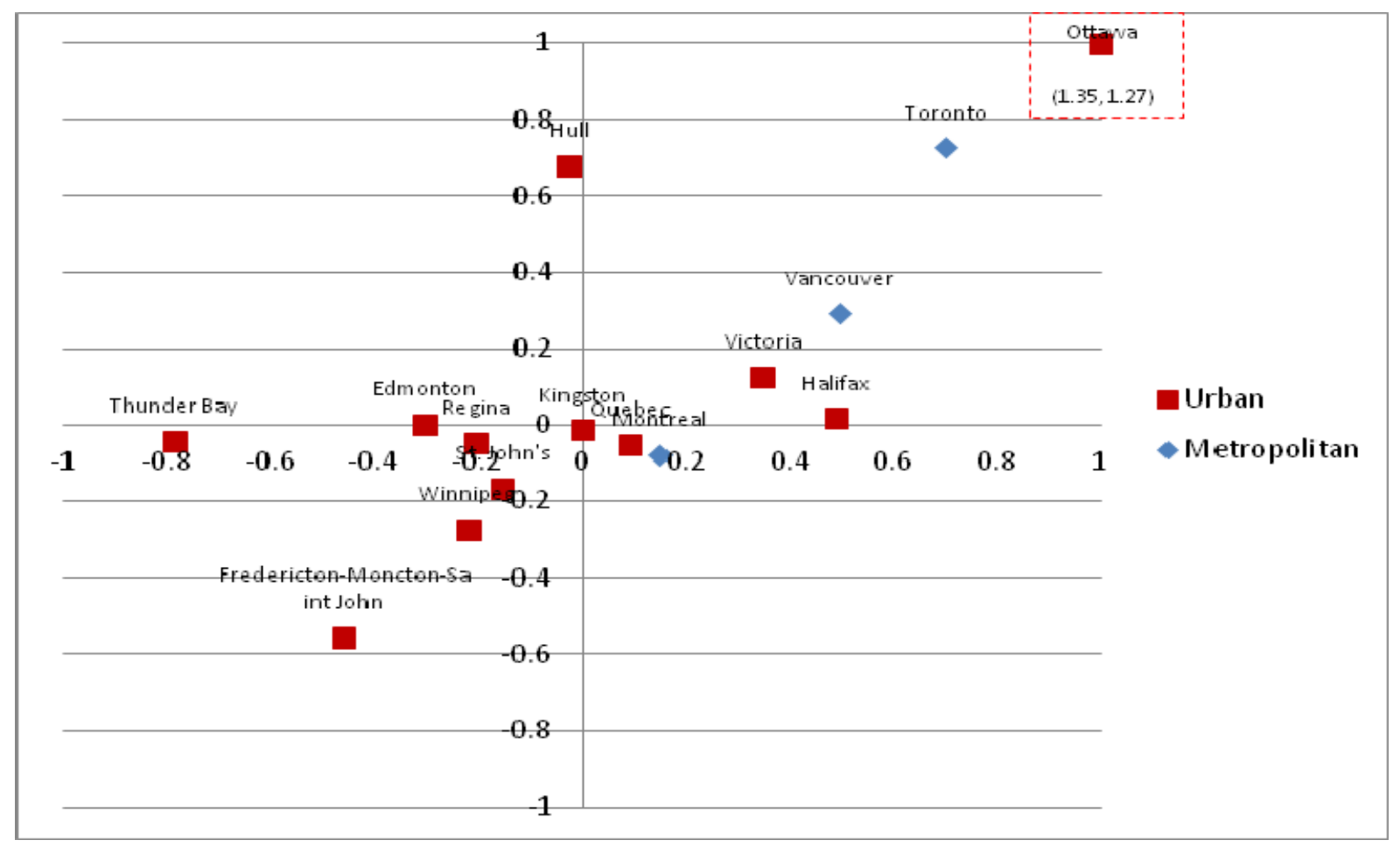

Figure 8. El regions in Canada with a strong service sector, 2006

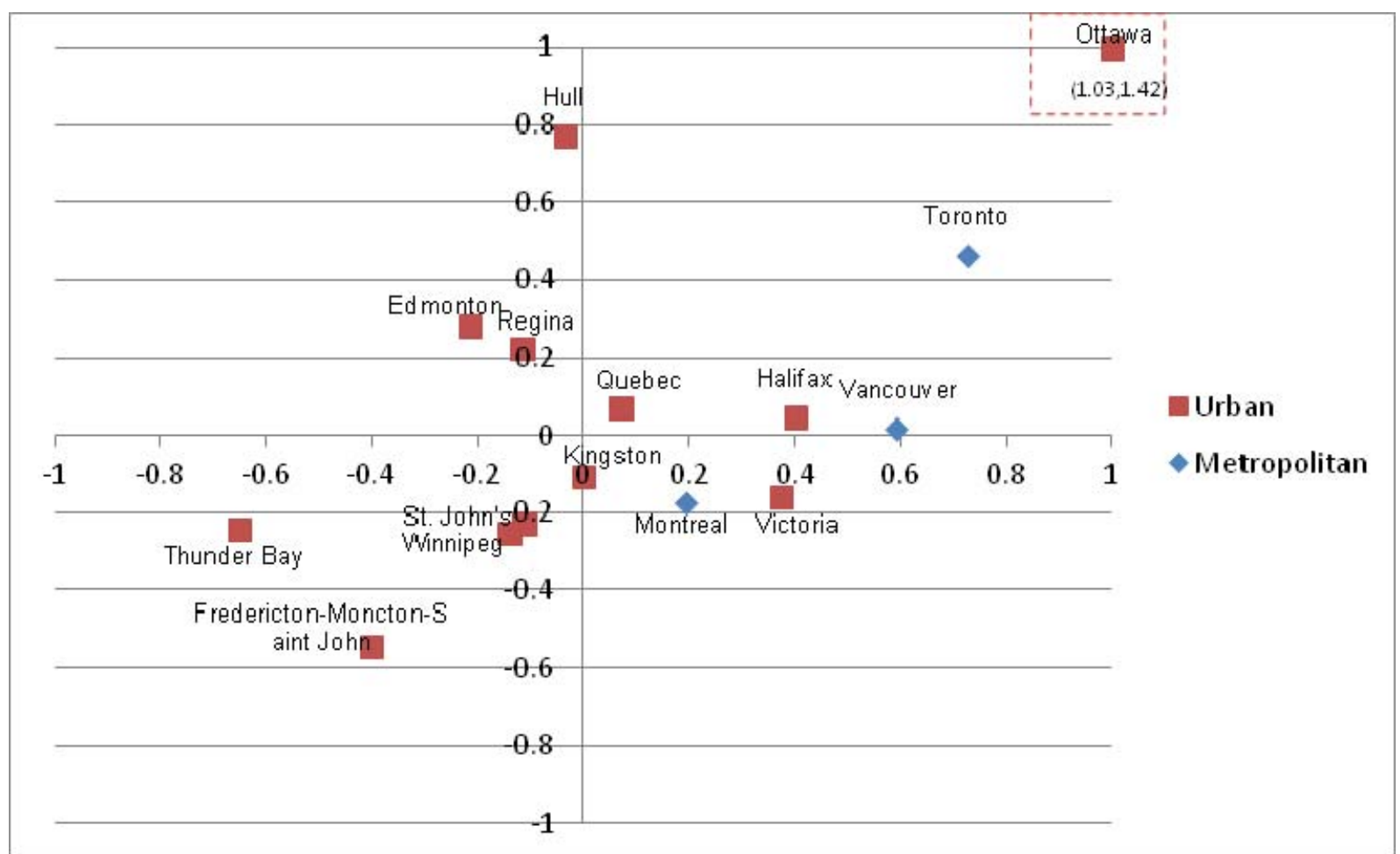


In Figures 3 and 4 that show regions where the primary sector is the main employer, cities such as Calgary, Saskatoon, Sudbury ${ }^{10}$ and Abbotsford appear to have a high-skill equilibrium. In contrast, most of the rural areas have a supply of and demand for jobs of lower skills. Some semi-urban areas such as southcentral Ontario with a greater variety of industries and a combination of both urban and rural areas also appear to have a high-skill equilibrium.

Prince Edward Island and Eastern Nova Scotia appear to be regions of excess supply in high skills. Demand for higher skills is lacking compared to the supply. The implication being that policies in these regions can be focused on stimulating demand for higher value-added products and services. In contrast, regions such as Northern Alberta and Niagara appear to have relatively excess demand for higher skills compared to the supply of skills. Policies in these regions could be aimed at increasing the supply of higher skills.

Where the secondary sector is the main employer (Figures 5 and 6), the pattern of urban areas is concentrated towards the higher end of the skill spectrum and rural areas towards the lower end. Some anomalies like Oshawa (high on demand for skills but only average on the supply of skills) can be explained by the heavy reliance of this region on highly-paid manufacturing jobs in the auto sector. Both 2001 and 2006 were boom years for the auto industry in Ontario. Sherbrooke (in Quebec), which has the opposite pattern of excess supply and only average demand for high skills, improved its demand for higher skills slightly between 2001 and 2006. These movements between the two census years are generally quite small. Further investigation of its statistical significance and the underlying factors responsible for these shifts is warranted before any definitive inferences can be made.

In regions where the service sector is the largest employer, large urban areas as Ottawa, Toronto and Vancouver are the furthest to the north-east in the first quadrant (Figures 7 and 8). Montreal and Quebec City show a small magnitude of excess supply. Both cities along with Kingston are near the origin implying a labour market equilibrium in jobs around the national average in terms of skills. Winnipeg and Fredericton-Moncton-St. John regions also fall along the diagonal but in the third quadrant implying a lower skill equilibrium compared to Ottawa and Toronto. Thunder bay, Edmonton and Regina are all average in terms of demand for skills but are short on average in terms of supply of skills. Thunder Bay, in particular, may have the skilled jobs but supplying the skills using local resources appears to pose a challenge.

\section{Trends over time}

Overall for Canada the median level of high-skill employment, i.e., the fraction of people employed in medium-to-high skilled jobs, rose from $14.3 \%$ to $14.7 \%$ between 2001 and 2006 . The median fraction of people with post-secondary education also rose from $12.6 \%$ to $16.3 \%$ during the same period. Based on this broad trend we may infer that both the demand and supply of high skills increased on average in Canada over this period. However, inflation-adjusted median income fell from \$24008 to \$22580. This trend did not keep up with the rising investment in human capital or creation of additional high-skill jobs. This discrepancy is puzzling and needs further investigation but it should be noted that Canada is not the only OECD country to experience a small decline in real incomes.

A more detailed look confirms the trends inferred from the change in median levels. All the 55 regions of Canada $^{11}$ for which we have data saw an increase in the proportion of people with postsecondary education. The increases in this proportion ranged from 15.7\% (Ottawa which at 30\% in 2001

\footnotetext{
${ }^{10}$ Sudbury's economy has been dominated by relatively high-paying mining sector jobs which can command high salaries not so much for their skills but also for hazardous work located in remote areas.

${ }^{11}$ Excluding the northern areas of Yukon, North Western Territories and Nunavut.
} 
was already quite high) to $34.2 \%$ (Newfoundland \& Labrador which was very low at $7.4 \%$ in 2001 ) increase between 2001 and 2006. The fraction of people employed in medium-to-high-skill jobs increased in all regions except four rural regions where it declined. Huron (Ontario) declined by a marginal $0.66 \%$ while Northern Alberta, Northern Saskatchewan and Northern Manitoba each declined by close to $4 \%$ over 2001-2006. Historically, these regions are known for people moving out as they get more education and find jobs outside the region.

Although real median income declined for Canada as a whole eleven regions registered an increase in median income with Quebec City, an urban region, registering a negligible $0.02 \%$ increase. The largest increases in median real income are to be found in Alberta: Northern Alberta (10.3\%), Southern Alberta (7.1\%) and Edmonton (5.7\%). All Saskatchewan regions (Saskatoon, Regina, Southern Saskatchewan and Northern Saskatchewan) also reported increases in real median income during 2001-2006.

Changes over the two census years (2001 vs 2006) can be visualized by plotting the net change in supply and demand proxies. Figure 9 shows a scatter plot of the regions in terms of change of the percentage of the population having post- secondary education in Canada (shown on the x-axis) and the change in employment in medium and high-skill occupations (shown on the y-axis). If increases in education are commensurate with increases in employment in higher skill occupations then it may be inferred that the Canadian economy is gradually moving to a higher skill equilibrium.

The scattergram shown in Figure 10 at first appears to show no obvious correlation between increases in education and employment in higher skill occupations. It seems clear that on average Canadian regions acquired more years of schooling between 2001 and 2006 and during this period the employment in higher skill occupations increased in most regions albeit at a rate slower than the increase in schooling. Regions falling above this line did better than the national average while regions below this line performed below national average.

Figure 9. Percentage change in post secondary education (x axis) and medium-high skilled occupations (y axis) in Canada, 2001-2006

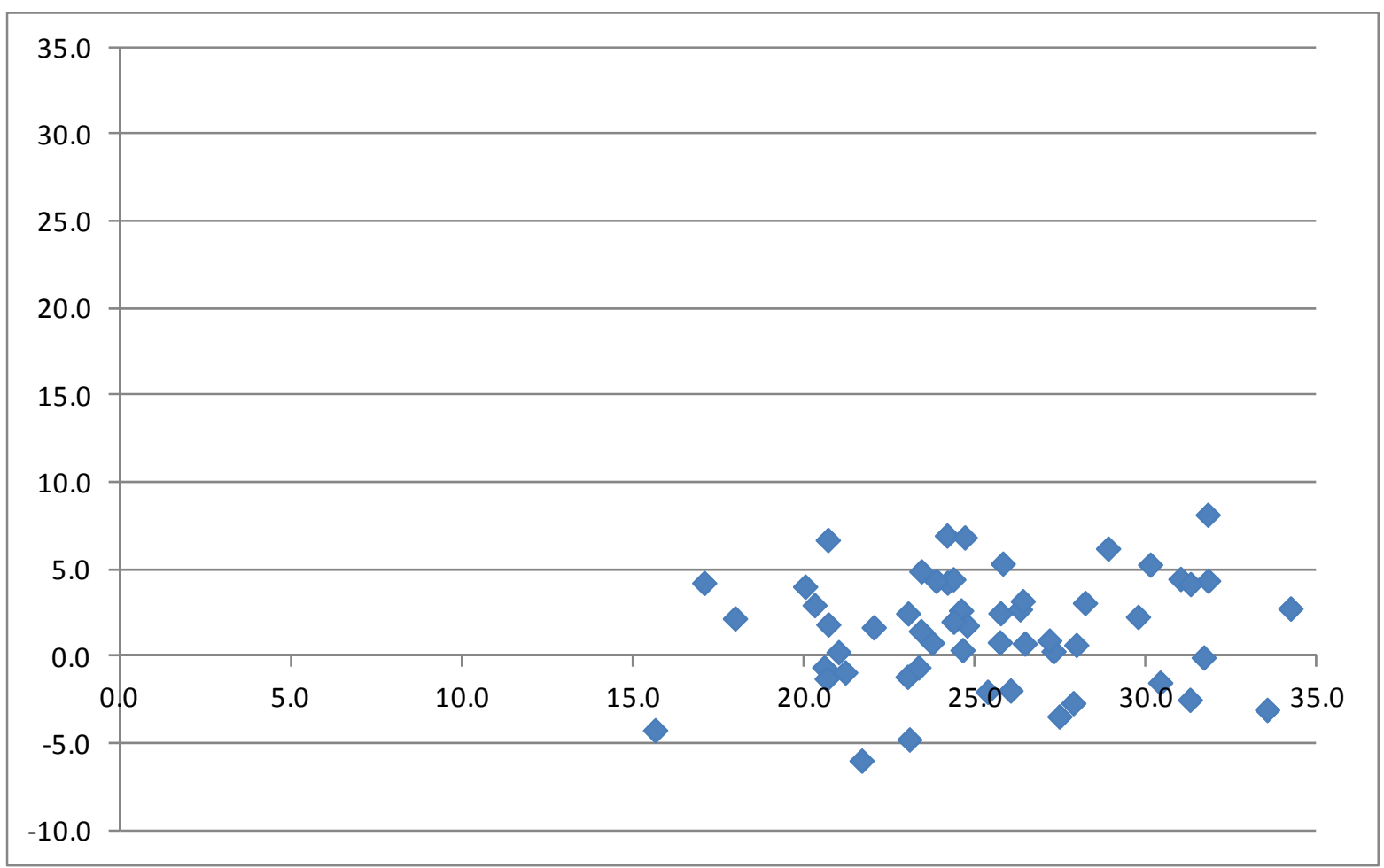


Similarly, we plot regions in terms of change in education versus change in inflation-adjusted income (Figure 11). A line drawn through the origin and fitted with these points has a slope slightly below zero, suggesting that while education increased on average real incomes declined. These results corroborate findings from other studies that have found that real incomes did not rise in the years in question. So, although the evidence supports the notion of movement towards a higher skill equilibrium, there is no support for this process in terms of real wages. These are aggregate data that are likely to hide real wage increases in certain occupations within the national average.

Figure 10. Percentage change in post secondary education ( $x$ axis) and median income $(y$ axis) in Canada, 2001-2006

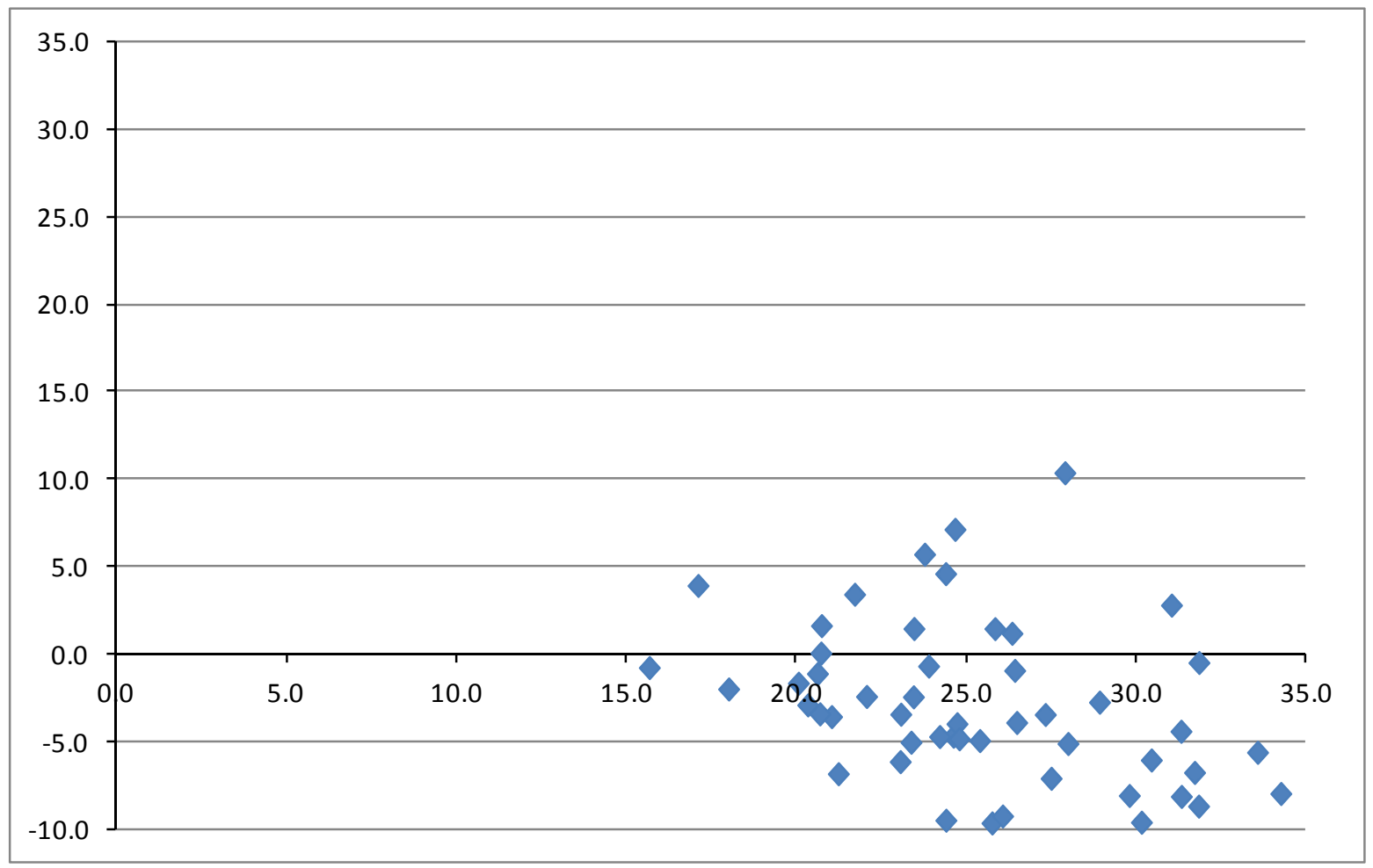

Lastly, a similar picture emerges from Figure 12, which plots regions of Canada in terms of increase in employment in higher skill occupations against increase in inflation-adjusted income. Once again, a line drawn through the origin and fitted with these points has a slope close to zero, suggesting that while employment in higher skill occupations increased over the 2001-06 period, the average income in these occupations registered a modest change. 
Figure 11. Percentage change in medium-high skilled occupations ( $x$ axis) and median income ( $y$ axis) in Canada, 2001-2006

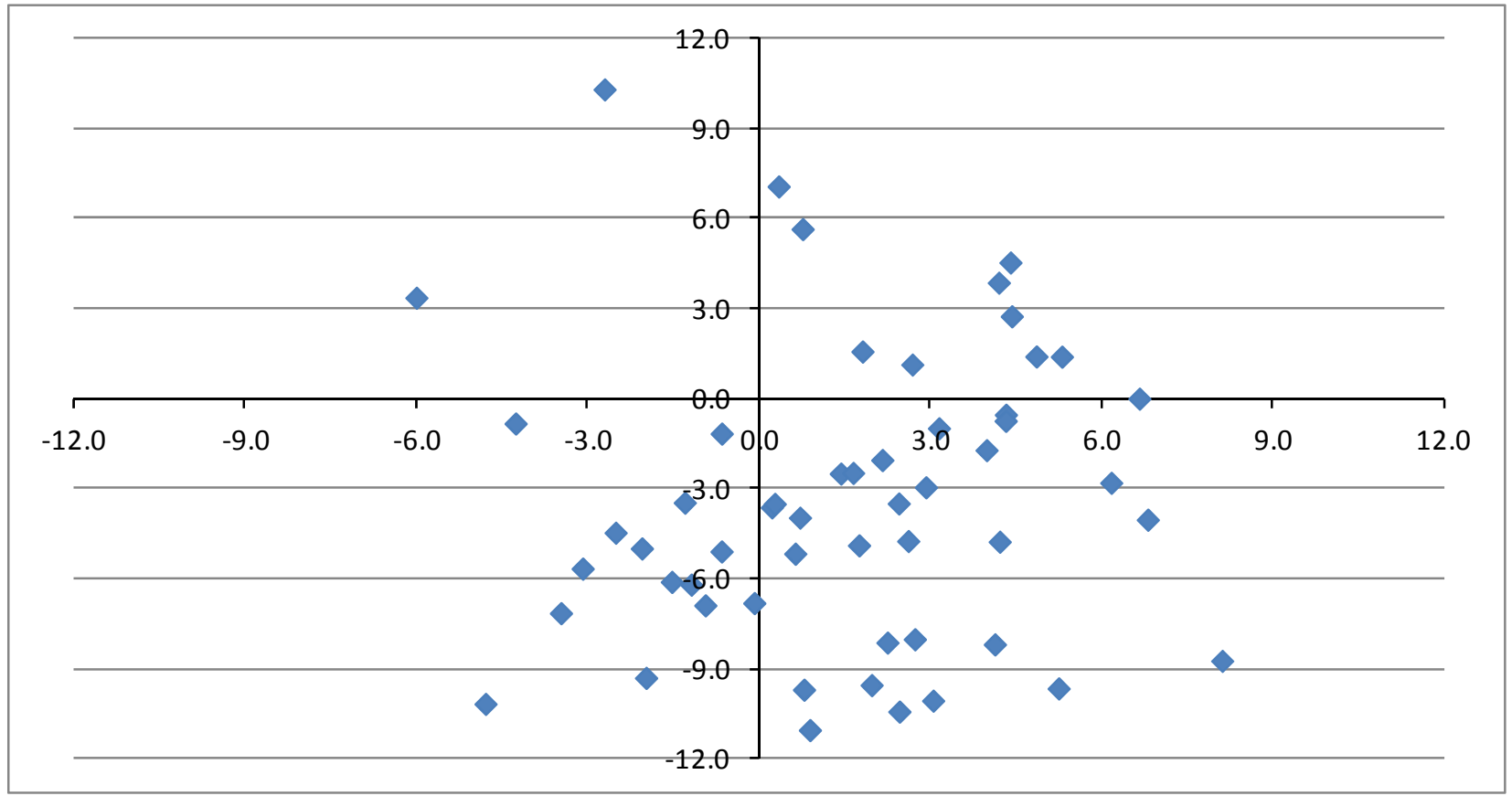

\section{Findings for Ontario}

Our emphasis is on Ontario where we can see that most cities fall in the first quadrant with Ottawa and Toronto in the north-east corner (Figures 12 \& 13). St. Catharines lies almost at the origin along with the rural area of central Ontario. Rural areas of Ontario fall in the fourth quadrant where skills supply is slightly below the Provincial average while demand for skills is average. Overall, Ontario's urban and rural areas both appear to be close to the national average in terms of value-added skills. This pattern largely holds between 2001 and 2006. 
Figure 12. Skills supply and demand in Ontario, 2001

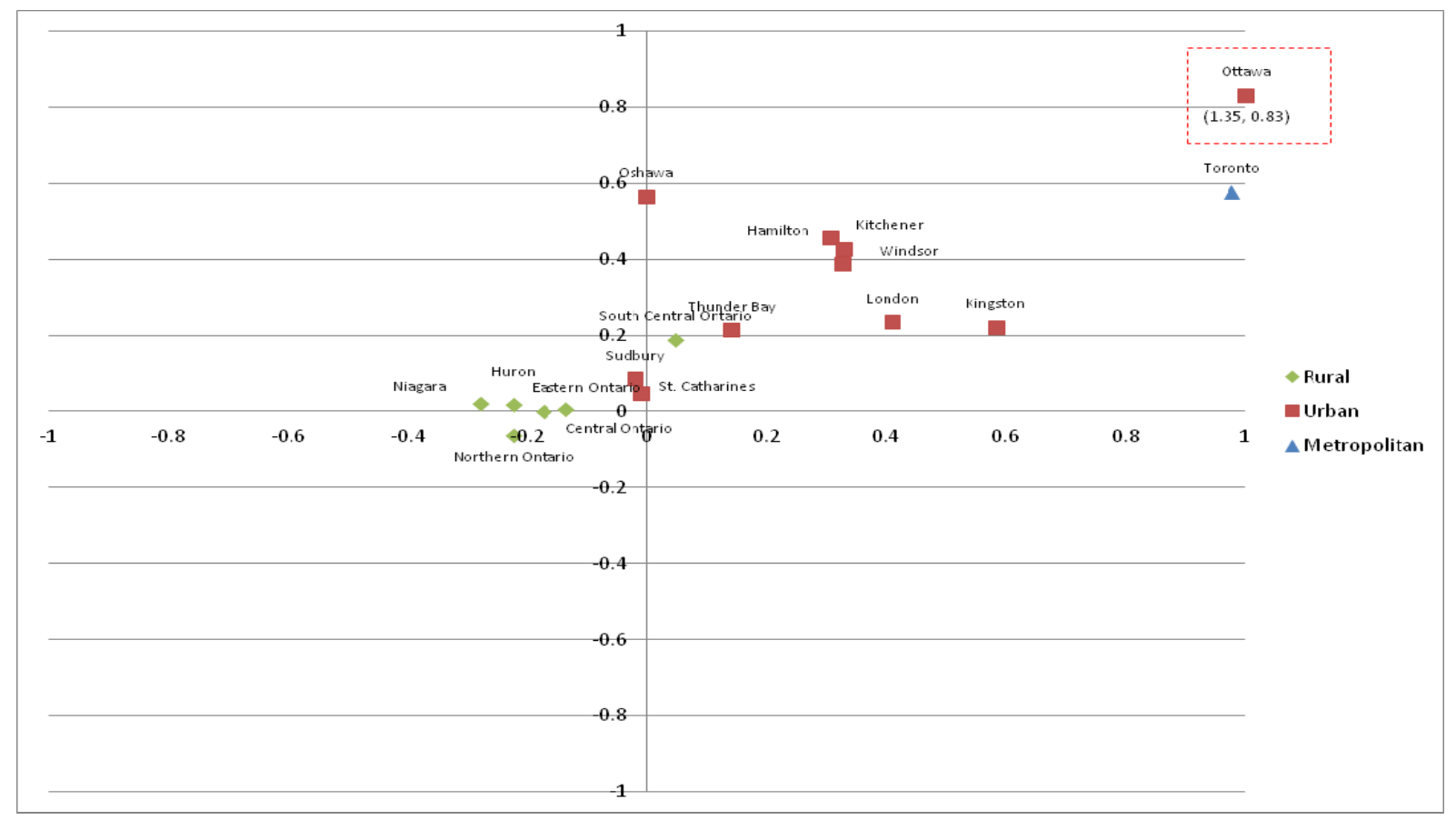

Figure 13. Skills supply and demand in Ontario, 2006

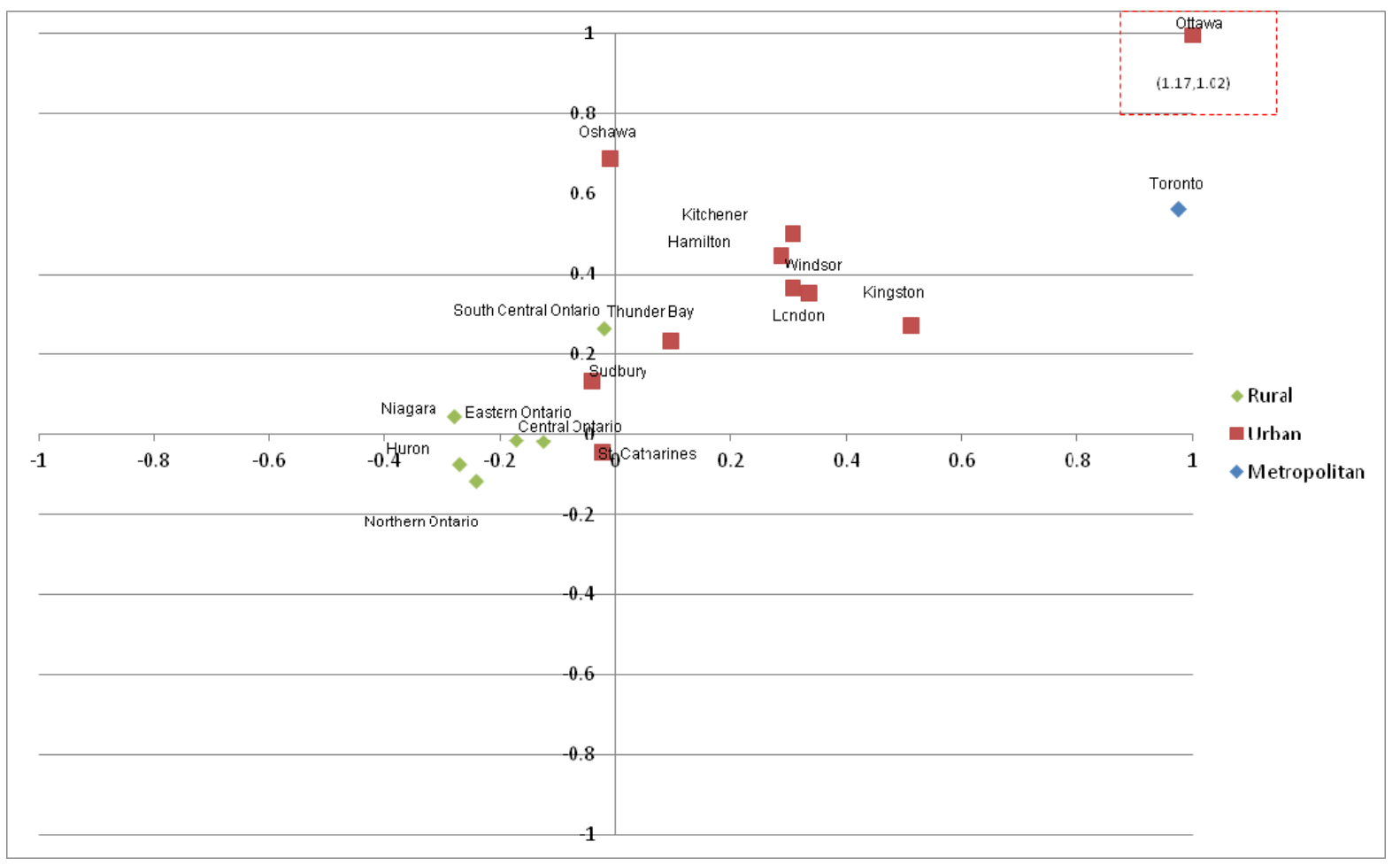

\section{Summary}

This analysis gives us a general idea of where the regions of Ontario stand in relation to the concept of a high-skill equilibrium. As expected, urban areas do better than rural ones. This would suggest that more 
policies should be specifically targeted at rural areas. Obviously, there are other local conditions that matter and if resources are scarce the question arises of whether regions more likely to respond to policy input should be targeted. These issues cannot be answered here or through purely economic analyses. Some aspects of targeted policies need political judgements that go beyond economic choice.

It should also be noted that the proxies used here are relatively crude. If policymakers were to find this analysis useful they could pursue this analysis with more rigour. It would be possible to construct more detailed and valid measures at a disaggregate level given more resources. Data at the sub-regional level are often hard to find and in this report we were not able to analyse disaggregate data at the establishment level. Other data on wages and benefits and other job characteristics would enable us to measure the demand and supply of higher skill jobs.

Lastly, we did track these data between 2001 and 2006 but data limitations do not allow us to fully interpret the progress a region made towards the goal of a high-skill equilibrium. We need to track these outcomes (e.g., supply and demand for high-skill jobs) over time if we want to correlate them with policy initiatives and other institutional inputs. Ultimately, we would want to know if what we do through policy and practices makes a difference. This question can be answered only by correlating these supply and demand proxies with policy inputs and market factors. Measuring policy inputs is a complex task for which we did not have the resources to retroactively collect data for the years 2001 and 2006. 


\section{GOVERNMENT POLICIES \& PROGRAMMES}

Government policies aimed at increasing demand for value-added production and supply of higher skills can be made at different levels: local, regional, provincial and federal. In this study we examined the scope and role of several government initiatives at all levels.

\section{Federal Government Policies and Programmes}

\section{Industry Canada (IC)}

Many departments in the Government of Canada contribute to formulation and execution of Canada's economic and business policy. But Industry Canada can be considered easily as the lead department to deliver programmes aimed at improving productivity and competitiveness of Canadian business. Industry Canada implements and oversees a wide variety of programmes and activities related to industry, science, technology and innovation, commerce, telecommunications, consumer affairs, corporations, competition and restraint of trade, weights and measures, bankruptcy and insolvency, intellectual property, investment, small business and tourism. In recent years, IC has played a key role in Canada's Economic Action Plan, including the Knowledge Infrastructure Programme. The annual business plan for 2011-12 lists 'Fostering the Knowledge-based Economy' as one of the four principal areas of its operation. ${ }^{12}$

\section{Scientific Research and Experimental Development Tax Credit Programme (SR\&ED)}

Introduced in the 1980s, the SR\&ED is a tax credit programme that plays a key role in encouraging Canadian companies to become more competitive. It is the single largest source for funding innovation in Canadian industry. In 2010, the SR\&ED programme provided nearly $\$ 5$ billion in investment tax credits (ITCs) to over 24,000 claimants. Of these, about $75 \%$ are small businesses. ${ }^{13}$

Activities such as developing prototypes, incremental improvement, and testing can be covered if they lead to innovation in a product or service. The programme is intended to encourage businesses of all sizes, particularly small to medium and start-up firms, to develop new, improved, or technologically advanced products, processes, principles, methodologies, or materials.

The Department of Finance is responsible for the legislation that governs the SR\&ED programme, while the Canada Revenue Agency is responsible for its administration. For Canadian-controlled private corporation the tax credit is 35\% of the first \$3 million in qualified expenditures, and $20 \%$ on amounts above this limit. For other Canadian corporations, proprietorships, partnerships, and trusts, the tax credit is $20 \%$. In addition, each province or territory may also provide a supplemental tax credit. In Ontario, British Columbia and Alberta, the additional tax credit is $10 \%$. Quebec has the highest tax credit at $37.5 \%$ followed by Manitoba at 20\%. New Brunswick, Newfoundland, Nova Scotia and Saskatchewan offer a $15 \%$ tax credit. ${ }^{14}$

An expert panel appointed by the federal government in 2011 to examine the effectiveness of government-funded innovation programmes, recommended a policy overhaul saying that the government spends too much money and fails to show any increase in innovation among Canadian companies. The

\footnotetext{
${ }^{12}$ Industry Canada. Annual Business Plan 2011-12. Accessed from www.ic.gc.ca/eic/site/ic1.nsf/eng/06582.html\#c4a

${ }^{13}$ McKenna, Barrie. “R \& D tax scheme too rich, government panel finds”. The Globe and Mail, 18 Oct 2011 : B.1.

${ }^{14}$ Source: Canada Revenue Agency; retrieved from http://www.cra-arc.gc.ca/E/pub/tg/rc4472/rc4472-e.html
} 
panel report cites the SR\&ED programme, the single largest, for its failure to assess if that money is making Canadian companies any more innovative. ${ }^{15}$ The report points out that a large number of federal tax breaks and grants (at least 60 programs, run by 17 different departments and agencies) exist but they are not guided by a unified strategy. The SR\&ED loses some of its focus and impact because it is an indirect form of innovation support administered by the Canada Revenue Agency whose competency lies not in innovation but in taxation. It is expected that the government may overhaul some innovation support programmes in the next 12-18 months.

\section{Human Resources and Skills Development Canada (HRSDC)}

HRSDC is the lead department in the Government of Canada for policies that affect the development and utilization of skills in the economy. According to the HRSDC website ${ }^{16}$, their mandate includes, among other things:

- developing policies that make Canada a society in which all can use their talents, skills and resources to participate in learning, work and their community;

- creating programmes and support initiatives that help Canadians move through life's transitions-from families with children to seniors, from school to work, from one job to another, from unemployment to employment, from the workforce to retirement.

HRSDC runs a number of programmes aimed at skills development in general, with some specialized programmes aimed at targeted population segments, such as youth, aboriginal persons, immigrants, persons with disabilities and older workers. The overall objective is to create an educated, skilled and flexible workforce by investing in programmes that help individuals and businesses succeed in today's economy and prepare for the jobs of the future. For example, some of these programmes include: Aboriginal Labour Market Programmes; Learning and Post-Secondary Education; Literacy and Essential Skills; Foreign Credential Recognition; Workplace Skills; Trades and Apprenticeship; Apprenticeship Grants; and, CanLearn.

In addition, HRSDC's Working in Canada website is the Government of Canada's leading source for labour market information, for all job seekers, employers and policy makers. It offers users free occupational and career information such as job opportunities, educational requirements, main duties, wage rates and salaries, current employment trends and outlooks.

A major change in HRSDC's mandate took place in the 1980s when the federal government began to transfer responsibility for delivery of many training programmes to provinces and territories. The Government of Canada provides $\$ 2.5$ billion annually to provinces and territories for skills and employment programmes in two categories.

Labour Market Development Agreements (LMDAs) that support the design and delivery of labour market programming by provinces and territories for unemployed individuals, particularly for EI clients who are active EI claimants, or who have had an active claim in the past 3 years. These labour market programs are designed and delivered by provinces and territories and must be similar to federal Employment Benefits and Support Measures that are laid out in Part II of the Employment Insurance Act (EI Act). Employment Benefits, which generally involve longer term interventions that can last from several weeks to a year or more, comprise Skills Development-Regular, Skills Development-Apprentices,

\footnotetext{
${ }^{15}$ See McKenna cited in Note 12 above.

${ }^{16}$ http://hrsdc.gc.ca
} 
Targeted Wage Subsidies, Self-Employment, Job Creation Partnerships (JCPs) and Targeted Earnings Supplements. The Support Measures authorized by Part II of the EI Act comprise Employment Assistance Services, Labour Market Partnerships, and Research and Innovation.

Labour Market Agreements (LMAs) are designed to provide flexibility to provinces and territories to address their labour market needs and are aimed at increasing access to training for unemployed individuals who are under-represented in the labour market and who currently do not qualify for EI and low-skilled workers.

Another significant initiative in skill development is the Sector Council Programme (SCP), a national program in existence since 1993, which is an industry-driven labour market program that seeks to address human resource and skills development needs of businesses, workers and job seekers. SCs serve as a platform where businesses, labour and educational stakeholders can come together to foster the development of a "training culture and to increase private sector investment in training by matching employer’s training investments."

Sector Councils (SCs) are guided by the following four objectives:

- Increased industry investment in skills development to promote a quality workforce;

- A learning system that is informed of, and more responsive to, the needs of industry;

- $\quad$ Reduced barriers to labour mobility, leading to a more efficient labour market; and

- Enhanced ability of industry to recruit and retain workers and to address human resource issues.

SC's, while receiving funding from the federal government, are independent, non-governmental organisations that allow stakeholders to determine unique sector-specific challenges and work to find solutions to these challenges. In 2011, 33 sector councils were listed as being operational although the level of activity varies a lot across the councils. The councils collectively cover approximately $50 \%$ of the Canadian labour market.

Sector councils undertake a number of activities to respond to skills and labour market issues affecting their sectors, including:

- Developing labour market information products to allow businesses to plan human resources and project investments;

- Developing national occupational standards to facilitate labour mobility (including apprenticeship), influence college curricula and promote health and safety in the workplace;

- Targeted recruitment and skills development initiatives to increase labour force participation and integration of under-represented groups such as aboriginals and immigrants;

- Efforts to ensure that curriculum meets industry needs;

- Skills development tools, including e-learning;

- Essential skills initiatives; and

- $\quad$ Tools and approaches to integrate foreign-trained workers. 
Sector Councils exist in all the three industry sectors profiled in this report (see sections 179-241 on pp 61-81).

In 2012/13, the Sector Council Program is being refocused to align with core federal roles, specifically the development and provision of labour market intelligence. The refocused program will respond to emerging labour market skills issues and Government of Canada priorities by supporting industry partnerships in the development of sectoral labour market intelligence including, national occupational standards, as well as accreditation and certification regimes in economic sectors of strategic importance. HRSDC will continue to help individuals access the information required to participate in the labour market, to ensure a better match between skills and job market demands, creating growth that benefits the economy, communities and most importantly, Canadians.

There are also federal programs that are aimed at giving the youth the skills they need to be more employable in the labour market.

The Youth Employment Strategy ${ }^{17}$ helps young people, particularly those facing barriers to employment, get the information and gain the skills, work experience and abilities they need to make a successful transition into the labour market. It is a horizontal initiative that involves eleven federal departments and agencies. The Youth Employment Strategy is comprised of three program streams: Skills Link, Career Focus, and Summer Work Experience.

- $\quad$ Skills Link provides funding for employers and organisations to help youth facing barriers to employment obtain the knowledge and develop the broad range of skills and work experience they need to participate in the labour market.

- $\quad$ Career Focus provides funding for employers and organisations to create career-related work experiences for post-secondary graduates.

- Canada Summer Jobs (an initiative under Summer Work Experience) provides funding to help employers create summer job opportunities for students.

The Federal Government also runs a website (http://www.youth.gc.ca) to direct young people to the collective resources and programs run by various government departments. The website also provides links to resources available outside the government.

\section{Provincial Government Policies and Programmes}

\section{Ministry of Economic Development and Trade (MEDT)}

MEDT is the lead department of the Government of Ontario that helps Ontario businesses become innovative and more competitive, attract new growth and investment into Ontario, and support the industry expand their export. It offers a range of investing and exporting services. Its primary focus is on helping small and medium sized businesses.

MEDT has two primary strategies when it comes to funding. The first one, Advanced Manufacturing Investment Strategy, is a repayable loan programme that can assist manufacturers make investments in new

${ }^{17}$ See http://www.servicecanada.gc.ca/eng/epb/yi/yep/newprog/yesprograms.shtml 
technologies, products, and processes. The second one, Ontario Automotive Investment Strategy, is a \$500 million programme that makes investments in the auto industry in areas such as skills training and innovation.

\section{The Advanced Manufacturing Investment Strategy (AMIS)}

The Ontario Advanced Manufacturing Investment Strategy (AMIS) is a \$500 million programme encourages organisations to make investments in leading-edge technologies and processes. AMIS provides repayable loans up to $30 \%$ of the total eligible costs of a project - up to a maximum of $\$ 10$ million. The loans are interest free and principal free for five years as long as the company meets the agreed upon job and investment targets. After that, the rate is the province's cost of borrowing plus $1 \%$.

\section{The Ontario Automotive Investment Strategy (AIS)}

Introduced in 2004, the Ontario Automotive Investment Strategy (AIS) is a \$500 million programme that invests in skills training and innovation in the auto industry. The fund is used in partnership with industry for advanced-skills training of workers, improved environmental and energy technologies, public infrastructure and investments in research and innovation.

\section{The Next Generation of Jobs Fund}

The Next Generation of Jobs Fund (NGJOF - see Box 2 below) is a $\$ 1.15$ billion five-year programme with the goal of promoting the creation and retention of jobs. The focus of this goal is for strategic areas that have great potential for Ontario. Essentially, the programme serves to: create and sustain jobs for Ontarians, level private sector investment in Ontario, improve the level of competitiveness of business in Ontario, promote innovation, and support Ontario's Go Green Plan. In terms of NGJOF's funding criteria is that $15 \%$ or more is available to support companies making new investments that:

- assist Ontario in becoming a global leader in an emerging market

- projects over $\$ 25$ million or that secure at least 100 good jobs for Ontarians

- $\quad$ reduce greenhouse gas emissions in certain sectors

- build on existing expertise in areas in which Ontario has a strong research and commercialization base or create new expertise, and

- create synergies among researchers, industry and entrepreneurs. 
Box 2. New Ideas, New Jobs: a NGOJF project in the field of medical imaging in Ontario

Ontario is helping create 100 new jobs and supporting 276 existing jobs through a \$29.6-million grant to Agfa HealthCare. The funding comes from Ontario's Next Generation of Jobs Fund (NGOJF). Agfa HealthCare is developing new software that allows radiologists to share digital images across a regional network, reducing the need to develop X-rays and physically transport them between facilities and healthcare professionals. The total project investment is nearly $\$ 200$ million. In discussing the scheme, Premier Dalton McGuinty said "we're proud to support Agfa HealthCare's investment in their Ontario operations and helping create quality jobs for Ontario families. We are committed to continuing to build on Ontario's strengths: a skilled and educated workforce, a culture of innovation, and a competitive business environment".

Source: http://www.newswire.ca/fr/story/473027/new-ideas-new-jobs

\section{Ministry of Training, Colleges, and Universities (MTCU)}

MTCU is the lead department in the Government of Ontario for policies and programmes relating to education and skills training. Its policies and programmes focus on increasing the supply of skills by enabling Ontarians to acquire the skills demanded by employers. Thus, they are aimed at workers and not at employers with a few exceptions. For example, the MTCU supports initiatives sponsored by other Ministries that could attract employers of higher skills such as: MEDT's Ontario Economic Framework, Ministry of Northern Development, Mines, and Forestry's Northern Growth Plan and Ministry of Research \& Innovation's Innovation Agenda. Further, under the current Employment Service, MTCU offers a placement incentive to encourage employers to provide on the job training, which could be considered as an incentive for employers to hire unemployed workers and provide training.

MTCU funds education and skills training needed for productivity-enhancing new technology, which indirectly helps employers with their investment. For example, the Ontario Apprenticeship Employer Bonus Programme awards Employers $\$ 1,000$ for each apprentice they employ who earns a Certificate of Qualification or Certificate of Apprenticeship in an apprenticeable trade. There is no stipulation for employers as to how they can spend the Bonus. They may choose to invest the Bonus in new technology.

For some projects/programmes the MTCU targets a specific segment of the population such as: Northern Ontarians, Aboriginal People, and laid-off workers based on an assessment of need. The focus of Employment Ontario is unemployed individuals (both EI and non-EI eligible). The Employment Ontario promise includes supporting individuals to meet career or hiring goals and providing opportunities to improve their skills through education and training. The Northern Training Partnership Fund and the Emerging Sector Aboriginal Projects both target new and emerging sectors, including the "green" sector.

Other MTCU programmes target certain industry sectors or regions or some combination of sector or region with certain demographic groups. For example, on a pilot basis, a Solar Photovoltaic Installation programme for journeyperson and apprentices in four different electrical trades was offered in 2011. The 42-hour programme offered by qualified Training Delivery Agents provides instruction in the safe and efficient installation of solar panels. This training initiative also supports the government's green energy policies. 


\section{Box 3. The Case of HealthForce Ontario - Ontario's Health Human Resource (HHR) Strategy}

In 2005, the Health Human Resources Strategies Division (HHRSD) was created within the Ministry of Health and Long-Term Care (MoHLTC). The ADM of HHRSD reports to the Deputy Ministers of both MoHLTC and the Ministry of Training, Colleges and Universities (MCTU) in recognition of the responsibilities of both ministries in educating, training and supporting health care providers. The objective of the strategy is to ensure Ontario has the right number and mix of providers educated, trained and supported to meet the population health needs of the province.

\section{Forecasting Demand for Policy Priorities}

At the provincial level, MTCU develops detailed occupational demand projections for the coming five-year period. These are based on projections developed by the federal government using its Canadian Occupational Projection System (COPS), which estimates expansion (employment growth) based on industry output and employment forecasts, and replacement (retirements and death) based on demographic characteristics.

These federal government COPS-based projections provide a framework within which regional demand can be assessed, but do not provide regionally specific projections for demand. MTCU staff derive region-level demand projections in selected regulated occupations, such as Early Childhood Educators, and apprenticeable trades. These assessments combine administrative data, demographic profiles, and COPS based demand projections to assess potential imbalances at the provincial and regional level.

However, the regional assessment is limited to broad administrative regions, which are not consistent across Ontario ministries. For instance, the Employment and Training Division within the ministry divides Ontario into four broad regions whereas the Ministry of Finance divides the province into six regions. Other ministries develop projections of supply and demand for specific regulated occupations relevant to their mandate, including the Ministry of Health and Long-term Care (doctors, nurses) and the Ministry of Education (teachers).

Apprenticeship in Ontario.

Apprenticeship is a learning model applied to more than 150 skilled occupations in Ontario. Ontario assesses and estimates demand for apprenticeship programmes within the regions for seat purchase planning by reviewing previous year's seat purchases, using current data (such as current seat purchasing plans), registration data, wait lists, and historical participation rates. In-year adjustments are made to regional plans to respond to any shifts in demand identified through regular monitoring of wait lists. Tools used in forecasting include data and reports generated from the Employment Ontario Information System Apprenticeship (EOIS -APPR) and Region specific Seat Purchasing Monitoring Tool Adjustable Spreadsheets.

The Apprenticeship Training Tax Credit (ATTC) is a refundable tax credit for corporations and unincorporated businesses employing apprentices in over 120 skilled trades during the first 48 months of an apprenticeship programme. Employers can claim up to $\$ 10,000$ per year. At a total maximum tax credit of up to $\$ 40,000$ per apprentice, this is the most generous apprentice tax credit in Canada.

\section{Role of Employers in Training Policy: local training boards and sector councils}

At a project level, employers are a required member of the training partnership. In this way, the employers' skill needs are the primary focus of the training plan development. For example, under the 
apprenticeship system, employers (along with labour and industry associations) may sit on Provincial Advisory Committees (PAC) or Industry Committees (IC) that make recommendations to the ministry about their apprenticeship training needs for their particular trades.

The MTCU also supports a Network of Local Training Boards in 25 areas of the province. The role of these Not-For-Profit organisations led by business and labour includes:

- Engaging communities in a locally-driven process to identify and respond to key workforce development challenges that prevail in their area;

- Compiling and updating local labour market profiles annually based on 10 key Labour Market Information indicators;

- Researching the "Demand" side of their local labour market to provide a clearer picture of sectorspecific occupational needs and skills requirements.

Local Training Boards often conduct labour market research to assess current or future occupational demand and skills needs of employers/sectors within their local economies. The results of this research are posted on individual Local Training Board websites. A few examples of reports based on employer surveys:

- Monthly Labour Force Survey Results - published by the Workforce planning Board of Waterloo-Wellington-Dufferin;

- Workforce Focus - Small and Medium Size Enterprises - published by the 1000 Islands region Workforce Development Board.

A number of Sector Councils advocate on behalf of similar MTCU stakeholders. As a member of the Sectoral Skills Council, the Canadian Apprenticeship Forum (CAF) provides research and educational support for the pan Canadian apprenticeship system. The Ontario Director of Apprenticeship is a member of CAF.

MTCU provided financial support to the Canadian Steel Trades and Employment Congress (CSTEC) to run a sector outreach initiative to support apprenticeship capacity building in the steel industry during the recent recession. CSTEC is a federally-funded Sector Council.

The Ministry worked with staff at the Alliance of Sector Councils (TASC) to obtain input from Ontario representatives within the various sector councils when it developed the occupational profiles for the most recent update to Ontario Job Futures. The occupational profiles were published by the Ministry in December 2009.

Sector councils periodically approach the Ministry with requests to support their human resource development strategies. Most recently, the Ministry has met with representatives from the aerospace, culture and tourism, and financial service sectors.

\section{Second Career Programme}

Second Career is a programme for those recently laid-off unemployed workers for whom long-term skills training is the most appropriate intervention to help them transition into high-skill, demand 
occupations in the local labour market. ${ }^{18}$ Workers are expected to bear some of the costs depending on their ability to pay. If they qualify they can receive up to $\$ 28,000$ to train for an occupation deemed to be in demand at the time in Ontario's labour market.

\section{Post-secondary Education}

The Ministry targets funding for enrolment growth and supports a broad range of postsecondary education and training programmes. The Ministry budgets for education and training programmes including Apprenticeships and Second Career. Many of these supports have the potential to indirectly affect other Ministry initiatives that promote innovative forms of work organisation. However, it is the institutions themselves that work with industry to ensure that the training meets their innovation needs.

Also, as part of the capital planning process, the placement of publicly-funded postsecondary institutions in particular geographical regions (i.e. University of Waterloo) could be viewed as an incentive to attract various employers to that region. The specialized fields of study and research of these institutions have the potential to attract higher skills employers to invest in those regions.

MTCU supports publicly-funded postsecondary education institutions that target local and provincial needs. These needs and gaps are identified by the Ministry's PSE partners based on their involvement with their respective communities and sector expertise (i.e. business advisory committees, sector advisory bodies, professional and industry associations, etc). The Ministry supports initiatives to address these needs and gaps.

\section{Specific programmes}

\section{MITACS Accelerate - Ontario’s Graduate Internship Programme}

In support of the government's Reaching Higher Plan, and the goal of improving quality in Ontario's postsecondary education and training systems, in 2008 the Ontario Government provided a \$16.89 million grant to MITACS, an independent non-profit collaboration among Canada's universities, research labs and governments, to establish the Accelerate programme in Ontario over four years.

MITACS Accelerate works with universities to identify graduate students and connect them with research opportunities in private businesses and public sector employers. The internship programme provides excellent training opportunities for Ontario's graduate students and young researchers in all graduate disciplines. Since its inception in Ontario, the MITACS Accelerate programme has awarded 635 internships to graduate students.

The MITACS Accelerate internships awarded in Ontario directly support the Government's priority areas in research and innovation: clean and sustainable technologies, health sciences and advanced health technologies, digital media, information and communication technologies, and advanced manufacturing.

The Ministry's Labour Market Information and Research Unit produces Monthly reports that look at labour market conditions by presenting data from Statistics Canada, such as unemployment rate, participation rate, and employment. The Unit also produces annual regional reports that describe labour market conditions in four regions of Ontario.

\footnotetext{
${ }^{18}$ For more detailed information please see http://www.tcu.gov.on.ca/eng/secondcareer/
} 


\section{Medical Education Expansion}

The Ontario government regulates enrolment in medical education. When necessary, it can adjust enrolment levels to ensure that the supply of qualified doctors can assist with meeting the demand. The government's targeted investments are creating a total of 260 new first-year medical school spaces in Ontario.

Medical schools are partners on expansion initiatives, and MTCU continues to work with the Ministry of Health and Long-Term Care to address issues related to the training of health care professionals and the government's Health Human Resources Strategy.

In 1993, first-year enrolment was decreased by $12 \%$ and stayed stagnant until 1999. In 2000, the government decided to increase medical enrolment by $30 \%$ in an effort to address the current and future need for doctors. Again in 2005, the government expanded medical education by $15 \%$ at existing medical schools, and at the same time, created the Northern Ontario School of Medicine.

In 2009-10, the Government introduced an additional \$20 million investment in undergraduate medical education at the 5 southern medical schools to further support medical schools in providing high quality and innovative medical programming. Each medical school's allocation of the new funding is based on creating a consistent per student funding rate of just over $\$ 39,000$ per student in 2010-11. Box 4 includes two specific cases of investment in medical care skills in North and North West Ontario.

\section{Box 4. Examples of investment in medical care skills}

\section{Northern Ontario School of Medicine (NOSM)}

The new Northern Ontario School of Medicine (NOSM), the first new medical school in Ontario in over 30 years, was created to improve the quality and accessibility of the health care system. This medical school makes use of the latest "e-learning" technologies to help physicians to learn and live in northern Ontario over the long-term.

- Between 2003-04 and 2005-06, NOSM received \$95.3M for capital development and operating start-up costs.

- NOSM began operations in September 2005, accepting 56 undergraduate students, and at maturity in 200809 , it had 224 undergraduate medical students.

- $\quad$ NOSM has full campuses at Laurentian University in Sudbury and Lakehead University in Thunder Bay.

- The school received about 1,800 applications for its 56 places for the 2009-10 academic year.

- $\quad$ NOSM received \$19.5M in operating grants in 2009-10.

- In 2010-11, NOSM's first-year class was increased by 8 students as part of the government's plan to increase the total number of first-year medical spaces in Ontario by 100. At maturity, NOSM will have 256 students.

\section{Community-Based Nursing Programme in North-western Ontario}

The 2005 Budget provided $\$ 2.4 \mathrm{M}$ over four years to support an innovative, community-based nursing programme, offered by Confederation College and Lakehead University in Dryden, Kenora, Sioux Lookout and Fort Frances (small towns in north-western Ontario). After the successful conclusion of a four-year pilot programme, which began in 2005, Confederation College began to admit students on a regular basis in Fall 2010. The programme was granted a first-stage accreditation by the Canadian Association of Schools of Nursing (CASN). 


\section{Role of Other Ministries}

In addition to the MEDT and the MTCU, there are other ministries with a regional or industry focus whose programmes would overlap with those of MEDT and the MTCU. Two such examples would be the Ministry of Agriculture, Food and Rural Affairs (OMAFRA) and the Ministry of Northern Development, Mines and Forestry. Another significant player is the Ministry of Research and Innovation (MRI) in regard to fostering competitiveness and innovation. There would be some overlap with almost all other departments although their role in regard to increasing supply and demand for higher skills may be small and/or indirect.

\section{Regional Government Bodies}

In many areas of Ontario, regional governments play an important integrative role across several towns and cities. For example, the county government of Niagara Region is active in working with employers, other levels of government and community organisations in charting some of its economic and social policies. More details on their role in some projects are discussed in the next section on the Niagara regional development strategy.

The Niagara Economic Development Corporation (NEDC) is a non-profit corporation whose aim is to, "advance the economic prosperity of the Niagara community. The corporation provides innovative services to promote investment and to provide businesses with support services to attract, sustain, and increase their economic activities in Niagara.” It is run by a Board of Directors that includes individuals from the Regional Municipality of Niagara, Brock University, Niagara College, Westbrook Floral Ltd., DTZ Barnicke Niagara, and Handling Specialty Mfg. Ltd. Among other activities, it develops analyses, background papers, and positions in regards to economic development and Economic Growth Strategy priorities. ${ }^{19}$ More details on the roles and activities of regional bodies can be found in the sections on regional level collaboration.

\section{Industry Associations}

Industry associations as non-profit organisations are involved in promoting the welfare of its member firms. They play several significant roles in terms of the move to a high-skill equilibrium. First, they play both a direct and an indirect role in skill development by sponsoring training and promoting the need for skill upgrading. Second, they foster connections at the local level with other stakeholders such as governments at various levels, educational institutions and community groups. Third, they promote business development by promoting efficiency and productivity. Some associations have specific skill related initiatives but almost all of them have programmes aimed at improving the competitiveness and value-added of its members. Those initiatives result directly in increasing the demand for higher skills. A few examples are given below. More specific examples are cited in the context of our regional and industry case studies.

\section{Alliance of Ontario Food Processors (AOFP):}

AOFP is a non-profit organisation that promotes and represents Ontario's food processing sector. The AOFP membership consists of Association of Ontario Chicken Processors, Baking Association of Canada, Ontario Dairy Council, Ontario Fruit and Vegetable Processors Association, Ontario Independent Meat Processors, and Wine Council of Ontario. It provides training and other services to their members. Performance Management and Diversity Management are two areas where they have offered training in addition to an Occupational Health \& Safety Programme which aims, "to provide cost effective value-

\footnotetext{
${ }^{19}$ http://www.niagaracanada.com/
} 
added training, audit, inspection and consulting services in the area of occupational health and safety for the food processing sector." Services offered include inspection (overview of the organisation and the status of the compliance practices), system audits (for compliance purposes), consulting services (issues such as health, safety, and regulatory compliance and training (customized or multi-company training safety and productivity). In addition to training, the AOFP collaborates with government on developing strategic directions for the industry in a variety of capacities. It played a lead role in developing the concept for the Institute for Food Processing Technology (described in more detail in the section of Educational Institutions). It also promotes careers in the industry with the help of educational institutions.

\section{Canadian Manufacturers \& Exporters (CME):}

CME is Canada's leading trade and industry association and the voice of manufacturing and global business in Canada. The association directly represents more than 10,000 leading companies nationwide. More than 85\% of CME's members are small and medium-sized enterprises. As Canada's leading business network, CME, through various initiatives including the establishment of the Canadian Manufacturing Coalition, touches more than 100,000 companies from coast to coast, engaged in manufacturing, global business and service-related industries. CME's membership network accounts for an estimated $82 \%$ of total manufacturing production and $90 \%$ of Canada's exports. Box 5 below provides more information about the CME SMART Programme, which promotes productivity improvement especially among small and medium-sized manufacturers. This program contains elements of all three roles identified above: skill development, fostering local connections and encouraging business development.

\section{Box 5. Canadian Manufacturers \& Exporters (CME) - the SMART Programme}

Thanks to funding provided by the Government of Ontario and the Southern Ontario Development Programme (FedDev Ontario), CME has created the SMART Programme to help small and medium-sized manufacturers in Ontario improve their productivity so they can compete more effectively in the global economy.

SMART funded productivity improvement projects such as lean design and lean manufacturing, quality improvement, energy efficiency, IT best practices, and environmental impact reduction. SMART supported the best projects with $50 \%$ funding up to $\$ 50,000$.

\section{SMART I - Programme (Ontario)}

The \$25-million dollar investment provided by the Ontario government has now been committed and over 425 applications were approved.

\section{SMART II - Programme (FedDev)}

The funding announcement in November 2009 includes a \$15.75-million investment under the Southern Ontario Development Programme for the Canadian Manufacturers \& Exporters (CME) SMART programme to fund approximately 300 projects. This funding has now been committed and 344 applications were approved.

\section{Grape Growers of Ontario (GGO):}

GGO represents over 600 grape growers in eastern, southern and southwestern Ontario, Canada who produce grapes for processing. It negotiates prices for all grapes sold to processors. The grape and wine sector generates approximately 6,900 jobs and more than \$100 million in direct wages and salaries. As a tourism destination, Niagara attracts nearly 20 million visitors annually and over one million people visit the province's wineries each year. Grapes are the highest-ranked Ontario agricultural commodity, and represent 35\% of the farm value of Ontario commercial fruit. GGO services provided include: negotiating prices for grapes grown commercially for sale, negotiating sugar standards for grapes and updating them 
annually, collecting and supplying data regarding crop size, sugar levels, acreage and trends for and to the industry and government, crop insurance, crop subsidies, promoting the industry generally and the VQA as a mark of quality. The GGO is more focused on pushing for business development rather than on skill development. But they do play an active role in local level organisations like the Niagara Workforce Planning Board and thus help foster connections among various stakeholders.

\section{Community-level non-profit organisations}

Another significant input in increasing the demand for and supply of high skills comes from community organisations that are akin to self-help groups: clusters of organisations and institutions banding together to create resources for innovation, competitiveness and acquisition of high skills. Some of these organisations tend to be region specific, e.g., Canada's Technology Triangle and Communitech in the Waterloo region (described in greater detail later), while others like Excellence in Manufacturing Canada have a wider reach across Ontario and maritime provinces. But, in each of these cases, their activities are focused on helping organisations become more competitive and on the other hand encourage greater investment in skills by government, organisations and individuals. Their input can play a significant role in moving a region to a higher-skill equilibrium in two ways. First, these organisations mobilize social capital within a region by promoting social connections through their programmes. Second, they provide an integrative role across various stakeholders in policy formulation and implementation. An example is the Excellence in Manufacturing Consortium:

\section{Excellence in Manufacturing Consortium (EMC):}

EMC founded in the mid-1980s, provides "primary expertise to manufacturers”. EMC's unique consortium infrastructure provides need-driven (and real-time) solutions to manufacturing organisations. Services help EMC members "become more globally competitive and produce a variety of high precision products \& services marketed throughout the world.” EMC partners with other organisations based on project need. In recent years partners included: Waterloo Manufacturing Innovation Network, Government of Ontario and Industrial Safety Trainers among others.

EMC's basic model is to use the collective knowledge and other resources of its member companies to educate, increase awareness of best practices and find solutions. This is achieved by creating clusters of knowledge around specific sectors or problem areas. Some illustrative examples include the food \& beverage group which provides manufacturing training, Web 2.0 networks, and labour-pool building initiatives for food sector manufacturers. Other groups form around issues such as safety (including health and safety prevention into regular duties), energy (expertise to find better energy supply, achieve better energy conservation, cost savings, and environmental safety), purchasing (find suppliers at reduced costs, buy larger volumes, and share container purchases), and learning (sourcing of training, provide training and certification programmes in lean manufacturing, human capital, health and safety, etc.).

EMC provides a forum for members to collaborate and share information to learn about each other's experiences and find better solutions for policies. These procedures can be accessed online and the questions are anonymously grouped together by subject. Peer-to-Peer networking includes field services where members have opportunities to network between members, government, and other organisations. The Strategic Interest Groups meet in monthly/bi-monthly networking sessions where members have a chance to discuss their problems, solutions and new developments in manufacturing at large. EMC members have access to an advertising programme, a bookstore, and classified ads. EMC began in Ontario but has since expanded to three other maritime provinces: New Brunswick, Nova Scotia and Prince Edward Island. 


\section{Role of Educational Institutions}

Almost all of Ontario's colleges and universities are funded in part or in whole by the Government of Ontario. In addition to offering general and professional education programmes leading to bachelor's, master's and doctoral degrees that have national and international appeal, colleges and universities connect with the local (and regional) labour markets in a variety of innovative ways. Encouraged by the MTCU, a number of college and university programmes have been established programmes that have a specific connection to a local or regional industry. The programmes listed below provide a good illustration of institutional links that foster mobility of knowledge across industry, educational institutions and public policymakers. The basic activity in educational institutions is to help young people acquire knowledge and skills but when the education takes place in a context guided by developments in science, technology, industry and the labour market it contains the necessary conditions to spur increased demand for and supply of high skills.

\section{The Institute of Food Processing Technology (IFPT) at Conestoga College:}

The IFPT was created in 2009 in partnership with the Alliance of Ontario Food Processors (AOFP). Situated at Conestoga College's new Cambridge campus, IFPT opened its doors in September 2011 with small classrooms, mechanical shops and laboratory settings. Construction continues on a pilot plant with different processing lines that will help maximize the learning experience for its students.

The creation of IFPT was the direct outcome of a recent labour study conducted by the AOFP in partnership with the Ontario Ministry of Agriculture, Food and Rural Affairs (OMAFRA) and Human Resources \& Skills Development Canada. The study highlighted the need to have an up-to-date training facility, such as the IFPT for providing unique skills to workers that employers of the food processing industry are continuously seeking and for attracting students to the industry. With the current skilled group of workers retiring at a rate of $10 \%$ per year, it is imperative that there are an adequate number of highly skilled workers available for the implementation and maintenance of latest technology and to keep the industry as a major economic force in the upcoming years. The IFPT has introduced a Food Safety course with the goal of encouraging potential employers to recruit and register apprentices in the food-processing sector. Employers who are able to recruit and register apprentices may be eligible to receive up to

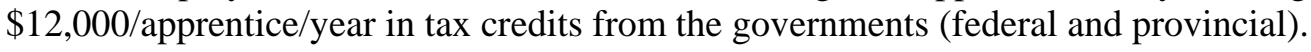

\section{University of Guelph Food Science Programme:}

The Bachelors of Food and Agriculture Business programme has full accreditation by the Agricultural Institute of Canada. The programme has co-op opportunities available and it essentially provides management skills in the agri-business industry. The government (mostly through OMAFRA) and private organisations provide the University of Guelph with more than \$100 million in research funding on various projects.

The Bachelors of Food, Agriculture and Resource Economics programme aims to prepare for careers as Economic Analysts in the agri-food sector and public agencies. It is ideal for students that come from rural areas and want to work in the agri-food sector or in farming since the programme provides strong training in farm management. The Bachelors of Food Science programme applies courses like chemistry, microbiology, and physics to examine how food products and processes are developed and processed. The multi-disciplinary approach covers areas of law, health, nutrition, and security as they relate to food safety and quality. Essentially, it provides hands-on experience in the industrial processes such as pasteurization, sterilization, and fermentation. 
The Bachelors of Organic Agriculture programme focuses on food production, food security, processing and marketing, environment health, and rural community sustainability. As well, it examines the design and operation of crop and livestock production systems which are socially responsible, ecologically sound, agronomically viable, and economically sustainable.

\section{Brock University Cool Climate Oenology and Viticulture Institute (CCOVI):}

The CCOVI offers a number of programmes directly relevant to Niagara's grape and wine industry: Honours Bachelor of Science in Oenology and Viticulture; Certificate in Grape and Wine Technology; and, Masters in Plant Sciences and Oenology and Viticulture. All programmes combine comprehensive scientific education with exposure to practical skills in business (marketing, tourism, etc.) and consumer tastes (wine flavour and appreciation, sensory evaluation of wines, etc.). Several programmes offer a co-op component in which students must complete three school terms working for an employer in the region. The combination of scientific knowledge with on-the-job skills is feasible primarily because of the support and involvement of local employers and industry associations.

\section{Niagara College:}

Niagara College, situated in the Niagara peninsula in Ontario, has in recent years developed multiple connections with the region's labour market. There are at least three initiatives aimed at developing the local labour force and thus contributing to regional economic development.

1. Training of skilled labour by developing and delivering appropriate programming to match existing and future demand in the regional labour market.

2. Providing and supporting access to specialized expertise, resources and equipment to facilitate business development, innovation and technology transfer in industries specific to the Niagara region.

3. Enhancing the region's capacity to attract new employers and investment. There are several examples of programmes, services and processes that the College has created that connect to the regional labour force, businesses and industries, and community:

- Links between the College and the labour force:

- Applied education and training of future and current labour force through post-secondary programmes, continuing education, apprenticeship and skills development

- Assistance to new business start-up

- Employment and employment transitions‘ support

- Links to regional businesses and industries:

- Programme Advisory Committees

- Co-op placements, internships, clinical placements, simulated work environments

- Industry-focused applied research leading to commercialization, technology/ knowledge transfer, and/ or improved products/ processes

- Applied labour market and social research, workplace instructional design, facilitative services, programme evaluation, and information sharing 
- Industry access to advanced technologies, equipment and expertise

- Business acceleration services and programming, including trade and innovation

- Customized training and consulting

- Partnership development and resource access

- Links to communities:

- Service/participation on the Boards of several economic and/or social development agencies in the Niagara region. For example, the Niagara Workforce Development Board, the Niagara Economic Development Corporation, etc.

- Co-locations with community organisations

- Work placements in community organisations

Given the importance of tourism to the Niagara region, Niagara College offers programmes in food and culinary trades through the Niagara College Canadian Food and Wine Institute (CFWI). Some example of courses offered include: Culinary Innovation and Food Technology, Culinary Management, Chef Training, Baker - Apprenticeship, Cook - Apprenticeship. Many of these programmes are offered on a coop basis, which require students to spend part of their time working with an employer to acquire on-the-job skills.

CFWI provides services to industry in four areas: training, specialization ${ }^{20}$, education and research. It provides assessment and analysis of the workforce, designs curriculum for the workforce, and provides training on-site or at the college campus. When we contacted the CFWI in 2011, there were 64 applied research projects in progress with more than 50 industry partners. These projects employ 20-40 students each semester and provide course-based research projects for more than 600 students. The Student Applied Research Opportunity Fund provides resources to encourage students to engage in learning, innovation and entrepreneurial initiatives. Grants are awarded in the amounts of $\$ 500-\$ 1500$ for supplies, materials and travel.

\section{The Guelph Food Technology Centre:}

GFTC, an independent, non-profit research and development centre on the campus of the University of Guelph, provides another example of the infrastructure for a higher-skill equilibrium in Ontario. Although technically it is not part of the university, its location and ties to university and industry make it a key player in upgrading technology and skills in the food and food-processing sectors of the economy. It is a global leader in food safety, training, quality and technical solutions. They offer the most up-to-date knowledge to leading companies in the food and beverage industry. Each year, GFTC experts audit and consult with over 1500 businesses in the food and beverage industry and train more than 3000 professionals. GFTC services reach across the globe to 26 countries in 8 languages.

It is governed by a Board of Directors appointed by the Government of Ontario but drawn from key stakeholders such as industry, government, educational and scientific communities. The initial funding came from the government but many of its operating expenses are recovered from client fees and sponsored research contracts.

${ }^{20}$ For a list of specializations offered by the CWFI see www.niagaracollege.ca/programmes/programmes_academic_culinary.htm 
GFTC expertise ranges from developing new products to meeting global food safety standards to incorporating sustainable practices. Some examples of their services:

- Help food processing facilities implement or improve food safety and quality management plans

- Offer auditing and consulting in global standards for food safety and microbiology such as HACCP, SQF, BRC, GMA-Safe and ISO

- $\quad$ Provide rapid-response training in new food regulations

- Develop new products according to upcoming trends and for specific needs

- Test and improve products for shelf life, quality, safety and packaging requirements

- $\quad$ Provide nutritional labelling, from individual foods to entire product lines

- Create sustainability programmes that improve profitability while minimizing environmental footprint

- Develop and deliver customized training solutions for a company's workforce

George Brown College Centre for Hospitality and Culinary Arts (GBC):

GBC located in the Toronto area offers several programmes of interest to hospitality and culinary industries. Among them: the Hospitality Services Programme, Chef Programmes, Culinary Arts - Italian (a post-graduate hands-on exposure to Italian culinary arts and culture), and Culinary Arts - French (postgraduate). 


\section{PARTNERSHIPS \& COLLABORATION: THE REGIONAL APPROACH}

This study investigated two sub-regions in Ontario for a better understanding of how policies and programmes come together at the "local" level. The two geographical entities selected for the study are: the Niagara region and the Kitchener-Waterloo-Cambridge-Guelph region. Neither of these two regions is strictly demarcated for the purpose of this study. Each of these two regions encompasses multiple towns, cities and counties. Our interest is in a geography within which the labour market is unified and the services infrastructure is shared by all employers. In other words, within the region people can look for jobs without having to move their residence and businesses can take advantage of services available locally. ${ }^{21}$

\section{The Niagara Region: Moving to a Higher Value-added Economy}

The Niagara Region is home to over 435,126 people (according to the 2006 Canadian Census) and host to many millions of tourists a year ${ }^{22}$, covers 715 square miles $(1,852$ square $\mathrm{km}$.) and includes 26 cities, towns, townships. The Niagara peninsula has been known historically as the home of the Niagara Falls and in more recent decades, as the seat of the wine industry in Ontario. Thus, tourism and agriculturebased industries have been the primary drivers of the regional economy in the past. A less well-known fact is that since the 1980s the regional economy has grown significantly in services and to a lesser extent in knowledge-based economic activity such as information technology and other technology-driven services for industry. The principal employers in the region are manufacturing and retail industries. In recent years, manufacturing has registered a decline while employment growth has been the highest in accommodation and food services (NWPB 2010).

The region is geographically well-defined on three sides: US to the east, Lake Ontario to the north and Lake Erie to the south. Its boundaries are relatively open to the west but many consider the urban area of Hamilton to be its western boundary. The enclave-like geography gives the people of Niagara a sense of community similar to what is found among people living on an island.

A variety of groups from various levels of government, industry, educational institutions and community organisations, focus on development at the "local" level. The fieldwork for this study identified a strong sense of a shared purpose ${ }^{23}$ and destiny irrespective of which organisation an individual

21 Methodology. A roundtable of discussions was organised in each region. Representatives from business, government, academia, the non-profit sector and other relevant industry and community organisations were invited. In addition, site visits were made to selected businesses, academic institutions, research centres, etc.

${ }^{22}$ Niagara Falls on both sides of the border attract a total of nearly 20 million tourists a year. It is hard to ascertain the precise number of those tourists who come over to the Canadian side. According to Government of Ontario statistics, Ontario received nearly 17 million visitors from the US, other countries and other parts of Canada. Again, the number of these tourists who went to the Niagara region is not readily available. But these two numbers are revealing about the large number of tourists that visit the Niagara region. Neither of these two numbers include visits by Ontarians which would further swell the estimated number of tourist visits to the region.

${ }^{23}$ A roundtable discussion was held on February 1, 2011, at the premises of Niagara College. A list of participants, attached here at the end of this section, very well describes the "local" infrastructure for policy development and coordination. At the table we had representatives from academia (Niagara College, Brock University, and University of Guelph which is not technically within the region but specializes in agriculture-related research and teaching); the Government of Ontario (OMAFRA, MTCU and MEDT); the Government of Canada (HRSDC); regional level government and government-appointed bodies (Niagara Workforce Planning Board, Niagara Economic Development Corporation, Niagara Region county 
represented. While government programmes at the federal and provincial levels were aimed at broader constituencies, it was the regional institutions that brought focus on "local" needs and policy responses.

\section{Box 6. The Niagara Region: A Profile}

Population: 435,126 (2006 Census)

Area: $1852 \mathrm{Sq} \mathrm{Km}$

Municipalities: 26

Principal Industries:

- $\quad$ Tourism adds over $\$ 57$ Billion to the economy. As the number one tourist destination in Ontario, the Niagara region receives $50 \%$ of all travelers entering the province and accounts for $40 \%$ of the Ontario tourism industry.

- Manufacturing has been the backbone of Niagara's economy. Although employment levels have declined in recent years, it employs approximately 30,000 people (2004). It remains the largest wealth-producing sector and contributor to the region's \$14.13 Billion Gross Domestic Product (2000).

- $\quad$ An emerging advanced technology manufacturing sector is gaining momentum in Niagara led by small to medium sized Canadian manufacturers with niche market products.

- $\quad$ Agriculture has grown $117.7 \%$ growth in employment over 1989 -1999, with 260 greenhouses and over 18.2 million square feet under cultivation.

- Commercial services sector is now the largest employer (29.6\%) and the second largest contributor to total output (15.9\%).

Income: The 2010 Average Household Income in Niagara is $\$ 71,893$ (which is $\$ 15,907$ less than Ontario's average), while Per Capita Income is $\$ 29,150$. Niagara's income is $10 \%$ below the national average, and Niagara's average earnings for full-time workers is $\$ 51,260$ per year, making Niagara a competitive place to do business.

Employment: With a workforce of 339,400 of persons 15 or older, Niagara had a labour force participation rate of $63.6 \%$ and an employment rate of $58.7 \%$ in April 2012. The unemployment rate of $7.7 \%$ was close to the average for Ontario (7.8\%) but higher than the national average (Sources: Statistics Canada, CANSIM, table 282-0087 and Catalogue no. 71-001-XIE).

From: www.niagaracanada.com and other sites linked to this page.

Among the academic institutions, both Niagara College and Brock University offer programmes that serve the specific needs of the region. Niagara College offers education programmes in culinary skills such as cooking and and wine-making through its Canadian Food and Wine Institute. It also offers programmes in locally relevant skills such as horticulture, hospitality and agri-business. In addition to these programmes the College is locally well-known for making their activities relevant to the local labour market. Among many initiatives it offers students internships and co-op education (work-and-study) opportunities. It conducts local workforce surveys and provides skills and consulting services to employers in emerging areas of technology.

government, City of St. Catharines); industry groups (St. Catharines-Thorold Chamber of Commerce, Grape Growers’ Association of Ontario); and a private sector employer, Handling Specialty Inc. 
Similarly, Brock University offers programmes in oenology and viticulture through its Cool Climate Oenology and Viticulture Institute (CCOVI). Its newly-built Cairns Family Health and Bioscience Research Centre includes alongside scientific and technical research, a business incubator to spin off research and development into innovations that can be taken to market. The University of Guelph offers a host of programmes with a focus around agriculture such as food science, agri-business and resource economics. It also runs a $\$ 50$ million research programme in these areas that is funded by OMAFRA.

The federal government through the department of Human Resources and Skills Development Canada (HRSDC) has local level presence through Service Canada offices. Individuals can obtain information on federal programs and services related to skills development at these in-person locations. In addition, the region would have some participants in the Sector Councils formed at the national level by industry sectors. The Government of Ontario was represented by the Ministry of Economic Development, the Ministry of Training, Colleges and Universities (MTCU) and the Ministry of Agriculture, Food and Rural Affairs (OMAFRA). Both the MTCU and MEDT ha ve regional offices to serve "local" needs. OMAFRA did not have a regional office in the Niagara region and was represented by a senior policy advisor from its head offices in Guelph.

An integrative focus at the "local” level appears to be the primary goal of agencies like the Niagara Workforce Planning Board, the Niagara Economic Development Corporation and the county level government of the Niagara Region. A word about each is helpful in understanding how local processes shape policy.

The Niagara Workforce Planning Board (NWPB) is a creation of the Government of Ontario as part of a network of workforce planning boards across the province. These agencies function at arms-length from the government with the participation of constituents like business, labour, community groups and the government itself. The NWPB's mandate is to research and develop priorities for developing the workforce of the Niagara region. In late 2010 it issued an authoritative report, Niagara 3D, that identified key workforce development needs of the region based on a body of research undertaken specifically for this purpose. It made seven recommendations aimed at increasing the skills of the workforce and aligning it with skill needs of potential employers. A report such as this brings a "local" focus around which all interested parties can align their own programmes and policies. But the work of NWPB is strictly advisory. It plays no executive role in implementing (or even coordinating) action by various actors.

The Niagara Economic Development Corporation (NEDC) is also a government-created entity that focuses on the economic prosperity of the region by encouraging investment and supporting businesses with services that would make them more competitive. The NEDC promotes technology- and innovationdriven quality and productivity improvement for Niagara businesses. It produced a brochure to get this message out to employers. It organizes seminars where leading-edge employers share their experiences with others.

The Niagara Regional Council is comprised of a Chair, and 30 Councillors representing five cities, five towns and two townships. The work of this level of government also provides a "local" focus for policy development.

Another "local" level focus comes from region-specific industry associations. The St. CatherinesThorold Chamber of Commerce is the leading voice of employers in the region. The Grape Growers of Ontario (GGO) discussed earlier, lobbies on behalf of its members and provides information to the general public, media, and other businesses engaged in viticulture-related activity. In this role, it acts as a champion for the region contributing to the excellence, quality and value of Niagara's products. For example, by promoting and supporting the VQA, Ontario's appellation for wines, it helps attract tourists as well as new investments. 
There is an effort underway to bring more value-added tourism to Niagara by promoting "culinary" tourism, i.e., attracting tourists who would come to sample the region's culinary offerings. Evidence suggests that "culinary" tourists would pay more but expect greater value than the average "sightseeing" tourists who come to view the falls. The Ontario Culinary Tourism Alliance (OCTA) was formed to build capacity for the culinary tourism by connecting growers, producers, processors, tourism operators and other participants in the culinary tourism supply chain. ${ }^{24}$ To build this capacity, regional identities need to be developed and promoted. Agricultural resources and food supplies need to be secured and opportunities have to be created for tourists to sample products and experiences. All of this requires creating uniqueness in products and services, educating tourists and promoting the local culture through festivals and other participative events.

Our discussion would not be complete without mentioning the Vineland Research and Innovation Centre (VRIC) located in the region and funded largely by the Government of Ontario as a centre of excellence dedicated to research and innovation relevant to the region's development. VRIC is dedicated to research and innovation to support the horticulture industry in Ontario. Aside from research it also aims to catalyze partnerships that would allow businesses to use the latest horticulture technology and bring innovative new products to the market. A recent example of their research:

The 'Made in Canada' Pear. The AC ${ }^{\mathrm{TM}}$ Harovin Sundown pear stands as an example of many years of research culminating in successful launch of a new product, and made in Canada no less. Dr. David Hunter and his Agriculture and Agri-Food Canada colleagues developed a top class performing pear with impressive production and storage traits. Vineland's Business Development Office quickly saw an opportunity to facilitate an agreement with Vineland Growers' Cooperative for marketing of the Sundown pear. In 2011, over 5,000 trees were sold to growers in Ontario, Quebec and the Maritime provinces for commercial production.

This and other examples can be found on their website (www.vinelandresearch.com) and in Annual Reports and Newsletters posted there.

\section{Local-level partnerships}

The web of institutions and programmes described above becomes effective only when different organisations come together to address regional problems and opportunities. Our discussions revealed several illustrative types of collaborations at the "local" level. In one case, under a federal government initiative, Niagara College has received \$750,000 in funding from the Federal Economic Development Agency for Southern Ontario - FedDev Ontario. This initiative will enable Niagara College, a leader in applied research, to increase its capacity to support the innovation goals of regional SMEs. Niagara College, through its applied research division Niagara Research, works with small and medium-sized companies in areas that include product and process applied research; engineering design; technology development; product testing; proof of concept; piloting and problem solving. Under this programme that runs for a year from March 2011, Niagara College is partnering with 165 SMEs to develop basic business tools from the following sectors: information and communication technology, advanced manufacturing, greenhouse/viticulture/horticulture, renewable energy and environmental technologies.

Another illustrative example is the creation of $\mathbf{n G e n ,}$ a multi-lateral effort to create jobs in interactive digital media and related business development in the Niagara region. Initially funded through the Ontario Media Development Corporation (OMDC), nGen's founding partners include Brock University, Niagara

${ }^{24}$ Among OCTA's members are over thirty organisations representing more than 10,000 businesses across the province: Ontario Restaurant, Hotel \& Motel Association (ORHMA), Greater Toronto Area Agricultural Action Committee, Ontario’s Finest Inns, Wine Country Ontario, Ontario Farm Fresh Marketing Association, The Ontario Hostelry Institute, Farmers’ Markets of Ontario, Ontario Craft Brewers. 
College, Interactive Ontario, City of St. Catharines, the Niagara Enterprise Agency, and the Niagara Economic Development Corporation. In addition, nGen is supported by a dozen private employers including large computer firms like Microsoft, Dell and Autodesk.

By bringing together key partners in industry, economic development and post-secondary education, nGen works to create an innovative business incubation and generation model to help jump-start and grow interactive digital media enterprise in the Niagara region. nGen is unique in that it fosters synergies between interactive digital media companies, local arts and culture industries in Niagara, as well as the educational and research infrastructure at Brock University and Niagara College. nGen's programmes are designed to help Niagara retain fresh talent from its two post-secondary institutions, and to attract and assist new business in a context where creators and entrepreneurs can thrive. nGen's core programmes include tenancy, mentorship, seminars, networking, interactive digital media projects and providing access to technology. It opened its new state of the art facility recently, the Generator at One. This expansion includes more office and learning space, as well as cutting edge technologies and equipment all housed within one facility.

nGen in conjunction with its partners provides employment and internships to students with skills in game design using Flash, Director and other prototyping tools; 2D and 3D character and scene building; animation; game design; web design; web development; game development; writing for interactive media; sound design and music creation and editing and related areas. In addition, students enrolled in business and marketing courses are recruited to provide assistance in business development. These opportunities provide students with hands-on industry experience, which significantly improves their chances of securing a job in their field once they have graduated.

nGen recruits recent graduates who have interactive media skills and are eager to pursue an interactive media or game project of their own. Graduate/entrepreneurs are provided with a modest income support for between 6 months and a year. During this period, they are provided with space, equipment and software to enable them to develop their own project. In exchange, they are asked to contribute $50 \%$ of their time to an nGen project that gives them related hands-on experience.

For its business development mandate, nGen presents seminars and workshops for project innovators and business start-ups on topics such as project teams, project management, marketing, interactive media deal flow, financing, and managing intellectual property, etc. It brings start-ups together with accountants, lawyers, and other professionals who can provide much needed advice for new/young entrepreneurs. As well, nGen serves as a learning house for regional, provincial and federal services and programmes aimed to assist emerging enterprises and projects in interactive media.

While it is too early to tell if this initiative has had a significant impact on the local economy, it is worth our while asking if this could serve as a model for local level partnerships in moving to a higher value-added economy. Initiatives like nGen can mobilize resources around need with a local focus. In the absence of similar such programmes local priorities do not always register with organisations, public or private, that have broader mandates at the provincial or national levels.

\section{Discussions with local firms}

Our review of the region also included two individual businesses. The CEO of Handling Specialty, Thomas Beach, participated in our roundtable while we visited the winery of Henry of Pelham where the CEO, Paul Speck, provided a tour of the facilities and sat down for a face-to-face discussion. Each of these businesses are illustrative micro-level examples of the processes that are transforming the Ontario economy at the margin and moving towards a higher-skill equilibrium. 


\section{Box 7. Handling Specialty Inc}

Handling Specialty is a small firm (45 employees) located in Grimsby, ON, exclusively dedicated to the custom design and manufacturing of material handling systems for demanding applications. They manufacture engineered-toorder lifting, tilting, rotating and traversing equipment for Fortune500 clients seeking innovative customized solutions. Over the past 40 years, they have built a reputation for providing innovative solutions to a wide range of original equipment manufacturers in industries such as automotive, aerospace and defense, entertainment, rail, and factory automation. Clients include firms such as GE, Boeing, and Northrup Grumman among others such well-known organisations.

Handling Specialty has carved out a niche for itself as a small but specialized producer of technology-driven solutions to high-end clients. Their success can be attributed to factors such as establishing a reputation for being reliable, working closely with the client and their ability to keep up with state-of-the-art technological capability. The latter is rooted in a "training culture" within the organisation. They used the federal tax credit programme, SR\&ED, to introduce new technology and to train people in its use. They also participated in CME's SMART Manfacturing programme to improve productivity by introducing technology and training people to use them. Under a dollar-matching programme (costs are shared by the firm and public funds) they trained every engineer in the organisation.

As a result of these training inputs engineers at Handling Specialty have state-of-the-art knowledge in 3D rendering. Every technical employee uses an iPad. Largely due to such capability the firm has recently won and completed four projects through competition at the international level.

To achieve such results on being able to attract and retain highly-skilled staff the firm works closely with other organisations in the region. A third of its engineers have been hired through co-op education programmes from nearby Ontario colleges and universities. It has worked closely not only with educational institutions and the NWPB on the supply side but also on the demand side with organisations such as the CME, the NEDC and the Chambers of Commerce.

Post-script: In August 2011, Handling Specialty was sold to another Niagara region firm, Whiting Equipment of Welland, ON. In its press release the firm said that the sale "merges complementary strengths and could boost international sales". The transaction turns Handling Specialty into a sister company of Whiting Equipment and under the terms of the sale it would be able to pursue its lines of business without any interruption. 


\section{Box 8. Henry of Pelham Estate Winery}

Henry of Pelham is a family-owned, family-run grape grower and winemaker of recent vintage. Located in St. Catharines, ON, it was started in 1988 by a trio of brothers who inherited farmland from their father. At the time the family was not into winemaking but the brothers saw an opportunity in growing grapes better suited to the terroir (geography, geology, topography and climate) of their land and turning those grapes into higher value-added wines. It took time, hard work, and visionary leadership to develop new vines, make excellent wines and persuade consumers of the value of a distinctive product.

Ontario's wine and grape industry, of which the Niagara region is the largest part, is small compared to other major wine-producing areas of the world. In 2009, Ontario wineries produced 56 million litres of wine to chalk up annual sales of $\$ 575$ million. But, most wineries are niche producers resulting in a large number of small wineries. There were roughly 140 licensed wineries including grape and fruit wineries in 2009 of which 103 were members of the appellation, VQA (Vinters Quality Assurance). It is not easy any more for a new entrant to distinguish itself from the pack as did Henry of Pelham through specialization, excellence and creative marketing. Roughly half of their production is shipped outside Ontario.

They began in the 1980s by tearing out the Concord and Niagara grapes at the farm and replacing it with Riesling and Chardonnay under newly contoured hills and under proper drainage. After studying the heat scans over the land and consulting with other more progressive growers, they were convinced that their vineyard was not only suitable for these special varieties but was also located on the prime grape growing lands of the area. Their conviction led them to take this risk and create the vision for a unique estate winery.

According to Paul Speck, the CEO, there are three founding principles behind the success of Henry of Pelham. First, it is the belief that good wines must be grown and then made. In other words, unless high quality distinctive grapes are grown and the winemaking techniques matched to the characteristics of the grape, one cannot expect to be successful in a market crowded with cheaper, more generic wines. Beginning with planting of appropriate varieties of grapes, they followed up with being a founding member of the VQA which is an "Appellation of Origin" system by which consumers can identify the wines of Ontario based on the origin of the grapes.

Second, they believe in the use of technology and leading edge techniques in the vineyard and winery as a way to maintain competitiveness and quality. To this end, they have participated in hiring young people through co-op programmes as well as in incentive programmes to introduce new technology and related training.

Third, they believe in using natural methods in growing grapes and wine-making. For example, they hoe the vines as much as possible instead of spraying for weeds. Or, use egg white fine instead of pad filtering to minimize handling the wine as much as possible. These techniques make winemaking more difficult and more expensive but if followed they enable the winery to produce a more distinctive product. In addition to a line of distinctive wines they also produce icewine and other late harvest wines, which are sweet dessert wines made from grapes harvested a few weeks after the onset of winter frost.

The winery concentrates on selected wines such as Chardonnay, Riesling, Sauvignon blanc, Pinot Noir, Baco Noir, and Riesling Icewine. It has won numerous domestic and international awards, including those at Vinltaly and the London Wine Trade Fair. In a September 2011 review, David Lawrason writing in the Wine Align e-magazine had this to say:

It's fitting to whet your appetite for next week's special Ontario release with a pair of 90-point Ontario reds from Henry of Pelham. About ten years ago a very accomplished palate and Niagara industry leader told me that no 90point Niagara reds had been made to that point. Well all that has changed, with top reds routinely hitting that mark as new high end, quality focused wineries explode onto the Ontario landscape. What is even more significant about the pair of 90s from Henry of Pelham is that they are $\$ 20$ and $\$ 25$ wines, not $\$ 50$ wines. And it is also significant that they come from an original family winery that has been toiling for almost 25 years, consistently maintaining very good quality and commanding respect from consumers and pundits alike. One of the chief reasons is the red winemaking prowess of Ron Giesbrecht, who long ago turned the fortunes of baco noir around by taming this ribald hybrid with the patience of a father - lowering yield to make it work harder and ageing in good wood for many months as a reward. The HENRY OF PELHAM 2009 RESERVE BACO NOIR (\$24.95) is a delicious, robust autumn red, and very likely to age as well as the lush 2007 and several earlier vintages still showing well. The other 90 pointer is HENRY OF PELHAM 2007 RESERVE CABERNET/MERLOT, a great buy at \$24.95. Patience is once again a virtue, with this 2007 (an excellent vintage) now rounding into fine shape with a real sense of class and balance. And I suspect it will live another five years with the greatest of ease. 
There are a number of lessons one can draw from the experience of Handling Specialty and Henry of Pelham. First, they have succeeded in a highly competitive environment by creating unique products of excellent quality. These strengths overcome their disadvantage in terms of scale - both are small businesses in markets dominated by very large firms. Second, they have sustained an advantage in the market by employing people with high and specialized skills. Employees at Handling Specialty have been encouraged to acquire new skills on a continual basis. At Henry of Pelham, there is some upgrading of knowledge but given that the technology used is very standard, there is not so much new technology but rather employee engagement to use the current knowledge more effectively to solve problems. These investments in their employees have allowed both firms to convince their customers of the uniqueness of their products.

Lastly, both examples demonstrate the value that these firms obtain from the networks around them. As a part of the government-education-industry nexus, they both contribute to regional resources while at the same time they benefit by drawing on these resources. Although it is hard to prove it in a scientific way, all the first-hand evidence we could get suggests that these networks have created significant resources within the local economy for the individual firm to add value, be competitive and access specialized talent.

\section{Analysis}

As mentioned in the section on the conceptual framework for this study, formulating a local level strategy for a high-skill equilibrium can be challenging specially given the blurring of local boundaries taking place in a globalizing economy. Yet, there are local imperatives that will likely not disappear for some time to come. In the Niagara experience we see some of these factors at play. Specifically, the advantages of a local approach to policy development in the Niagara region are apparent in the following.

1. The well-delineated geography (boundaries and topography) has helped create local level institutions with clearer mandates and scope of policy formulation.

2. Social and knowledge networks within the region appear to be dense and close. Most key individuals across various stakeholders and institutions are known to each other which makes it relatively easy to form coalitions, exchange knowledge and pool resources to undertake projects that would not be possible if each party had to reply on their own resources.

3. Niagara College is a key resource to the region in fostering collaboration with other stakeholders at the local level. It contributes directly to increasing the supply of specialized, region-specific high skills. It also makes important inputs in spurring demand for higher skills by working with employers and regional bodies dedicated to economic development.

4. A local focus in Niagara has led to initiatives to add value in traditional industries of the region as opposed to an exclusive focus on high technology industries.

Despite many strengths apparent in the region several gaps in policy and infrastructure pose challenges for the future according to various stakeholders contacted during this study.

1. Government policy and policymaking was seen as the great limitation because policies were often made without considering their impact (or lack of impact) on local outcomes.

2. More centres of excellence are needed like the Vineland Research and Innovation Centre or others like it on campuses, in areas such as manufacturing and clean energy. 
3. More creative counselling needs to be provided to young people making career choices. It was felt that many new careers are coming on stream in the wake of globalization and new technologies and many young people including their parents, are unaware of these choices. Also, many traditional occupations, such as welding as an example, are becoming more high-tech offering better salaries in return for higher skills. Yet, many young people shy away from such choices because of traditional notions about such work.

4. Lack of coordination among various government agencies and other organisations was also mentioned as limiting effectiveness of policies and programmes designed to move jobs and output higher up the skill scale.

5. It was felt that in many industries important to the Niagara region such as tourism, hospitality, food processing, farming and light manufacturing, adding more value to their products involved incremental innovation in processes rather than giant leaps in new product introduction driven by high technology. This reality, it was felt, is not fully reflected in policymaking.

\section{The Waterloo Region: Moving to a Higher Value-added Economy}

The Waterloo Region with an estimated population of 534,900 (in 2009) includes the adjoining cities of Cambridge, Kitchener, and Waterloo as well as the townships of North Dumfries, Wellesley, Wilmot and Woolwich, and is located approximately $100 \mathrm{~km}$ west of Toronto. The economy is diversified with significant clusters in several industries: arts and culture, clean technology, information technology, education and knowledge creation, and life sciences in addition to its traditional strength in light and medium secondary manufacturing. In recent years, the region has also attracted smaller financial services firms apart from large firms such as Manulife Financial (3,800 employees) and Sun Life Financial (3,300 employees). 


\section{Box 9. The Kitchener-Waterloo-Cambridge Region: A Profile}

Population: 498,500; growth over 2006-2011: 5.7\% (Source: CANSIM Table 051-0046).

Municipalities: Cambridge, Kitchener and Waterloo, and the townships of North Dumfries, Wellesley, Wilmot and Woolwich.

- $\quad$ Employment: With a workforce of 412,100 of persons 15 or older, Kitchener-Waterloo had a labour force participation rate of $73.8 \%$ and an employment rate of $68.9 \%$ in April 2012 . The unemployment rate of $6.6 \%$ was below the average for Ontario (7.8\%) and for Canada (7.3\%). (Sources: Statistics Canada, CANSIM, table 282-0087 and Catalogue no. $\underline{71-001-X I E)}$.

- $\quad \$ 19.5$ billion GDP, with a 5.8\% increase from 2009 to 2010 (2010)

- Major economic sectors: IT, Automotive, Advanced Manufacturing, Business and Financial Services, Hightech

- $\quad$ Emerging economic sectors: Health Sciences, Environmental, Nanotechnology, Pharmaceutical, Renewable Energy, Food and Beverage

- 150 research institutes and more than triple the provincial and national number of patents per million (2006)

- $\quad$ Canada's 10th and Ontario's 4th largest urban population (2010)

- One of Canada's fastest growing communities, with a population of 543,700 people that is expected to reach 729,000 people by 2031

- $\quad 74,000$ full-time post-secondary students, including 15,000 co-operative education students

- $\quad$ The University of Waterloo, Wilfrid Laurier University and Conestoga College are all located within this region

- Home to leading global think tanks: Perimeter Institute for Theoretical Physics, Centre for International Governance Innovation, Academic Council on the United Nations System and the University of Waterloo's Institute for Nanotechnology and Institute for Quantum Computing

Taken from: http://www.techtriangle.com

The Waterloo Region is home to the University of Waterloo, Wilfrid Laurier University, and Conestoga College, which houses the Institute of Food Processing Technology. The University of Guelph although not technically part of the region is located less than $30 \mathrm{~km}$ to the east. Its focus on food and agriculture-related industries serves the region's food processing cluster.

Research In Motion, maker of the Blackberry smart phones with 8,000 employees is the region's largest employer while large manufacturers like Toyota Motor (4,300 employees) and ATS Automation Tooling Systems (1,800 employees) are surrounded by many small and medium size firms making parts for original equipment manufacturers. In the public education sector, the largest employer is the Waterloo Region District School Board (5,000 employees) along with the University of Waterloo (3,500 employees). Grand River Hospital (2,200 employees) and the City of Kitchener (1,700 employees) are other large public employers.

Some institutions are similar between this region and the Niagara region in terms of the policy infrastructure. The presence of most government departments, federal and provincial, is similar. The Waterloo-Wellington-Dufferin Workforce Planning Board serves this region as well as two other adjacent counties. On the economic development side, this region is served by Canada's Technology Triangle Inc. (CTT), a not-for-profit, private-public partnership organisation (see Box 10 below). The CTT promotes the region as a leading location in the world for investment. Its mandate is to attract the most innovative businesses, entrepreneurs and talent to the region. 


\section{Box 10. Canada's Technology Triangle (CTT)}

CTT is a not-for-profit, public-private regional economic development partnership whose goal is to, "Market the competitive advantages of the Waterloo Region to the world, and work to attract new businesses, investment and talent to the Region." CTT partners with municipalities (Regions of Waterloo, City of Waterloo, Corporation of the City of Cambridge, Kitchener, Township of North Dumfries, Corporation of the Township of Wellesley, Township of Wilmot, and Woolwich Township), the University of Waterloo and Logikor Corporation. It provides a variety of services to industry and community: for individuals visiting the region as a place to invest and work, it provides orientation about the geography, economy, and demographics of the region. Other services include: arrangements of appointments, help with business arrangements, inventory of available commercial and industrial sites, assistance contacting property owners for business people, statistics with Regional Research, and help with immigration requirements.

Source: www.techtriangle.com

Another not-for-profit, organisation, Communitech has been set up with the goal of supporting technology companies in the Waterloo Region and promote the area as a technology cluster (see Box 11 below).

\section{Box 11. Communitech}

Communitech's goal is to, "Support technology companies in Waterloo Region and promote the area as a technology cluster" with a large variety of programmes which include a job website (WaterlooTechJobs.com) to help local companies attract talent, the Canadian Digital Media Network (CDMN), which connects commercialization organisations and nodes around the county, a retrofitted space $(30,000 \mathrm{sq} \mathrm{ft})$ dedicated to digital media startups and other tech companies, and numerous other meetings, symposia, and conferences for members to connect with each other and to learn from experts. The Venture Services Programme provides an organisation with an advisor who can help with: making connections, receiving funding, workforce development, and accessing market research.

A number of programmes foster links between business and schools. The Business Education Partnership allows students in grades 7-12 to identify their career goals and explore various career options. The Speakers Bureau programme arranges for business leaders to address students in the classroom. The Business Visitation programme provides corporate tours for students., Approximately 2000 students participated in business tours in 2009-10. The Science Superheroes programme aims to encourage students' greater exploration and participation in STEM (Science, Technology, Engineering and Mathematics) career opportunities and entrepreneurship. The ZOOM Career Days programme is a one-day 'sector-specific' career exploration day. It is targeted at Specialist High Skills Major students and other interested senior high school students in the Waterloo Region (grade 11 and 12).

Source: www.communitech.org

As discussed earlier, another institution prominent in this region is the non-profit, Excellence in Manufacturing Consortium (EMC) dedicated to helping manufacturers grow and become more competitive, at home and around the world. It has offices and affiliates all across Ontario and Atlantic provinces.

One theme prominent in our interviews and discussions with key informants centres around the development of new industries and the ability of policies and institutions to respond quickly enough to shifting market needs. For example, recent growth in solar and clean energy have created a strong demand for specialized skills in that sector but the supply of trained labour in those occupations is restricted in the near term. Also, it was pointed out that given the global nature of these technologies and industries the 
labour market has become more aggregated than the local labour market. So, even if a local employer like Canadian Solar ${ }^{25}$ is hiring 300 employees, it does not translate fully into local hires.

A more successful example of quick response was given in the case of food processing industry where educational and apprenticeship programmes at Conestoga College with funding from the MTCU were able to supply the industry with needed skills. Conestoga College's close connections with the industry allowed it to better anticipate employer demand for skills and match it with supply of skills with appropriate training.

In the case of manufacturing, EMC with the help of funds from MTCU was able to mount training programmes for its affiliates. The EMC also collaborates with the Yves Landry Foundation, a private foundation that funds upgrading of skills for current employees. Other training provided by the EMC has been funded by the federal government agency, FedDev. CME's SMART Manufacturing programme is funded by both federal and provincial governments. Many of these programmes result directly in more value-added production because firms applying for public funds are required to show that they are adding value in some specific way.

Many of the people contacted during the study mentioned a host of programmes funded by federal and provincial governments for training in specific skills: the provincially-funded Second Career programme, the school-to-work programmes for young people entering the workforce, the federally-funded Apprenticeship Incentive Grant (AIG) and the MTCU-funded programme for apprenticeship training for truck drivers in Ontario.

\section{Discussions with firms}

Our review of the region again included discussions with an individual business - CGL Limited which has implemented a system of lean manufacturing as part of its bid to improve productivity and job quality.

${ }^{25}$ Canadian Solar (NASDAQ: CSIQ), one of the world's largest solar panel producers, was founded in Ontario, Canada in 2001. They operate seven wholly-owned manufacturing subsidiaries across 9 countries (Canada, China, Germany, Italy, Japan, Korea, Spain, Australia, and the United States), serving customers in over 30 countries. Its revenue in 2010 was $\$ 1.5$ billion. 


\section{Box 12. CGL Limited}

CGL Manufacturing, founded in 1977 in Guelph, Ontario, is a mid-size manufacturer of precision parts for original equipment manufacturers (OEM) such as John Deere, Volvo, Caterpiller, Toyota and Tohmatsu among others. CGL provide machining, welding, fabrication and assembly solutions to OEMs of off-road and construction equipment used in industries such as construction, locomotives, material handling and forestry.

Although small in size (about 200 employees in 2011) CGL strives to be a global leader in its class in terms of quality, productivity, innovation and customer service. To achieve the current level of success, CGL positions itself as a learning organisation that embraces innovation, continuous improvement and change. They practice principles of lean manufacturing to eliminate waste, cut inventory costs and to encourage all employees to brainstorm creative ideas to improve processes and quality.

The road to building such an organisation has been gradual and long. CGL began with offering conventional machining services to non-automotive OEM's, gradually adding more value-added services as they built up their competencies in newer areas. These services evolved into CNC machining, manual and robotic welding, fabrication, paint and complete sub-assemblies. In 2005 CGL entered into a joint venture to provide cutting and forming of metal profiles for its machining and fabrication requirements. More recently, a joint venture was established in mainland China to supply castings and rough machined parts to be processed further in the Guelph facility. From the 2000 sq./ft. rental unit where CGL first started to the current 107,000 sq./ft. modern facility, constant change and improvement has always been an important factor for success and growth.

The culture of lean manufacturing translates into a number of initiatives on the shop floor: e.g., Kaizen, Cellular manufacturing, Kanbans, SMED (single minute exchange of die), TPM (total preventative maintenance), Poka yoke (mistake proofing), shadow boards for tools and Cl (Continuous Improvement). CGL's success with these systems can be traced to their investment in three important inputs: technology, training and trust. The latest technology is used along with measurement of performance at every stage of its operations. Training is provided for leadership and soft skills as well as in areas of skills shortages. Lastly, the concept of Lean is based on trust and mutual respect among management and workers. CGL strives to effectively communicate with its employees to get everyone "on board".

At the individual level, all employees are encouraged to submit suggestions to reduce cost or eliminate waste, participate in $5 \mathrm{~S}$ activities, volunteer in Kaizen activities, use Kanban systems and also return tools to their proper place for the next time to eliminate time wasted in searching. Under another programme, any workers can call a "focus" around a problem which activates a multi-disciplinary group to gather around the issue and develop possible solutions. Among the roughly 50 people at work on the shop floor at any time there often are two such incidents a day.

In keeping with its goal to be world-class, CGL has obtained a number of certifications in quality, technical performance, etc. Some of them are: the ISO 9001:2000 certification in "quality management"; the ISO 14001:2004 certification in "environmental management"; and, the Canadian Welding Bureau (CWB) accreditation. The CWB is accredited by the Standards Council of Canada (SCC), the national Certification Body. In 2006, CGL won the Level II Achievement Award for outstanding workplace health and safety performance from the IAPA (Industrial Accident Prevention Association).

In line with its goals of excellence, CGL is a member of the Association for Manufacturing Excellence (AME), a US-based non-profit organisation founded by manufacturing firms dedicated to promoting excellence in manufacturing. Besides organizing conferences and seminars the AME organizes tours of exemplary plants as opportunities to learn from each other. CGL is also a founding member of the Ontario-based Excellence in Manufacturing Canada (EMC) whose activities are similar to the AME.

Accessing training funds from public sources has not been a priority for CGL because most government-funded programmes are aimed at helping displaced and disadvantaged workers. Firms like CGL could benefit from public funding if funds were available for training workers to develop skills in lean manufacturing.

CGL Manufacturing Ltd is an illustrative example of small and medium-sized firms that have succeeded in surviving and prospering in a globalising economy by constantly migrating to more value-added manufacturing. A key element of their success has been investment in skills of their workforce. Other elements include adoption of new technology and developing an organisational culture of trust and excellence. 


\section{Analysis}

There are several strengths apparent at the local level in terms of institutional and policy-related infrastructure.

1. This region has achieved a relatively high concentration of high-skill jobs compared to other regions in Canada. This is evident when we compare this region to other Canadian regions (see Figures 5, 6) and also to other regions in Ontario (see Figures 12, 13).

2. Although the region is open to expansion in all directions, there is a cluster of institutions around the high-technology and light manufacturing sectors that creates local level synergies among the stakeholders.

3. The University of Waterloo with its programmes in high technology and Conestoga College in food processing and other region-relevant areas of study provide the educational anchor but there is scope for expansion by adding more specialized programmes.

Some of the gaps and issues that emerged from our discussions with key stakeholders include:

1. What is the best way to determine which skills are in high demand? It appears that policy formulation relies more on advocacy and representation by constituent groups rather than based on some objective criteria. Workforce Planning Boards can add value to this process by gathering relevant data on supply and demand.

2. When training is provided using public funds there is no requirement of employers to provide a minimum level of wages or promise of a career. Should there be such a requirement?

3. Almost all of the publicly-funded programmes for training are aimed at getting people who are unemployed (or underemployed) into appropriate jobs. Very few funds can be used for upgrading the skills of current employees.

4. Many people displaced from jobs are not able to qualify to train for the high-skill jobs in the new technology-driven industries. So, this type of structural unemployment (and underemployment) is not readily addressed by many of the existing training programmes. The MTCU-funded Second Career programme remains outside the reach of such people.

5. Government-funded programs do not often value process innovation the same way they do introduction of new hardware (technology) and product innovation. This poses a problem for funding incremental innovations which are relatively more important for service industries. 


\section{PARTNERSHIPS \& COLLABORATION: THE SECTOR APPROACH}

As explained earlier, another plank in the methodological strategy was to take a closer look at selected industry sectors. While the food processing sector was the main study focus, additional research has been carried out in the hospitality sector and the food retail sector in Ontario. There were a number of considerations that make these sectors an interesting lens on changes occurring in the larger Ontario economy. First, all the three sectors are important for the Ontario economy because they provide significant and growing employment. Since the 1990s these sectors have grown in employment as manufacturing's share of employment continued its long-term decline. Second, these sectors are traditionally viewed as being low in skill and low in value-added. Yet, if Ontario is to grow and prosper these industries and others like them, have to gradually move to value-added services and products.

Each of the three sectors is prominent within the two regions we discussed earlier. Thus, they complement the regional perspective. Food processing is very central to the Niagara economy given its rural base. Similarly, the Kitchener-Waterloo region houses university, college and research programs with a focus on food and agriculture. Food retail is equally common to these regions as well as to Ontario and Canada at large. Hospitality is also widely distributed sector across the entire province. So, these industries have a presence right across Ontario and Canada.

\section{Case Study 1: The Ontario Food Processing Sector ${ }^{26}$}

The Ontario food processing industry is the largest of manufacturing sub-sectors in the province with $\$ 33$ billion in sales. It employs over 110,000 people directly and at least another 100,000 people indirectly in related industries (Figure 14.). In terms of size, it is the third largest food cluster in North America. This industry sector is the largest customer for Ontario farmers, responsible for buying the vast majority of Ontario's produce. Within a one-day driving distance, the industry has access to a market of over 140 million consumers. There are more than 3,000 food-processing businesses in the province, of which 700 are located in rural communities. In terms of sub-sectors the largest five account for $72 \%$ of its output: meats (23\%), tobacco and beverage (14\%), dairy (13\%), grains $(11 \%)$ and bakeries (11\%) (see figure 15.$)$

We selected this sector for closer study because innovation and quality are key themes for sustainability and growth in the industry. It strives to develop new, high quality products that are likely to meet consumer demand for convenience and well-being. The industry is considered a leader in safe, high quality food products for Ontarians, Canadians and other consumers worldwide.

\footnotetext{
${ }^{26}$ This case was written by Gary Szczerbaniwicz, a doctoral student at the University of Guelph under the direction of Dr, Sara Mann, Professor, School of Business, University of Guelph and Anil Verma, University of Toronto.
} 
Figure 14. Ontario's Food \& Beverage Processing Industry

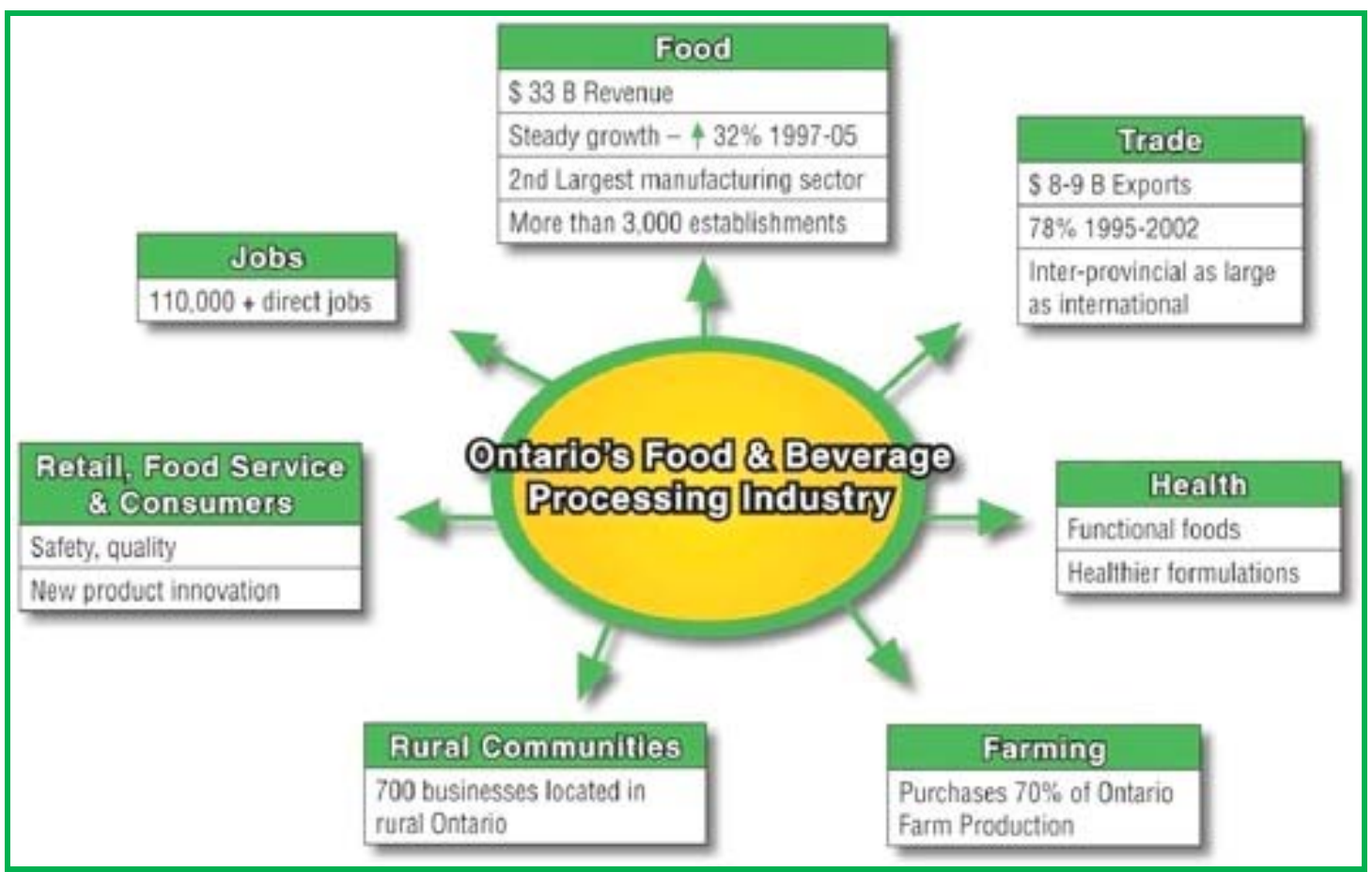

Source: Courtesy of 'The Alliance of Ontario Food Processors'

Figure 15. Food processing value of shipments, Ontario, 2007

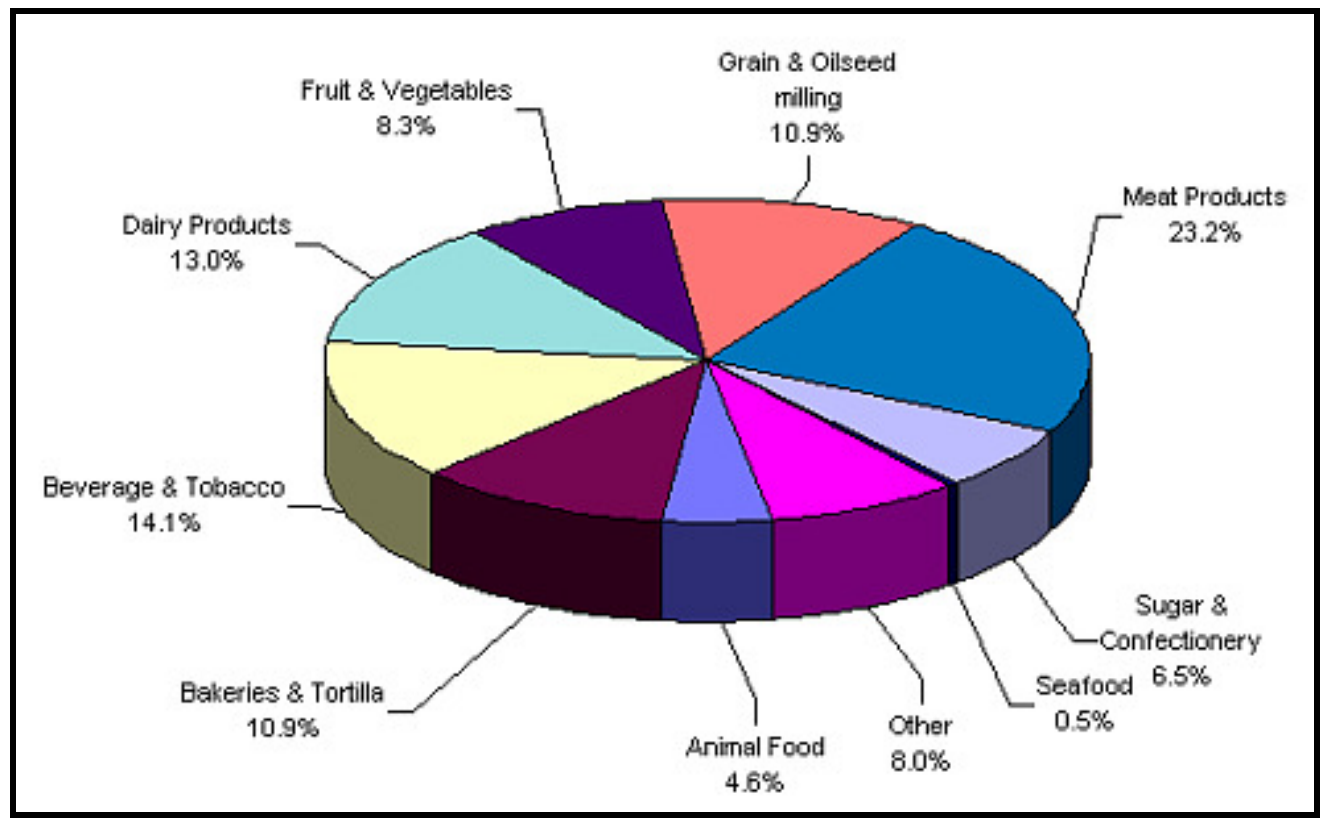

Source: Courtesy of Ontario Ministry of Agriculture, Food and Rural Affairs (OMAFRA)

The food processing industry in Ontario has been given a significant level of support in terms of public policies and programmes. It is recognized as a significant producer that employs a large number of 
Ontarians. A number of Government programmes from several ministries such as Ministry of Agriculture and Rural Affairs (OMAFRA), Ministry of Economic Development (MEDT) and the Ministry of Training, Colleges and Universities (MTCU) benefit the industry directly. Apart from direct funding of skills and new investment projects, the government has also funded colleges and universities to offer programmes that directly benefit this industry. Specifically, the following universities, colleges and research institutes offer programmes relevant to this industry:

- University of Guelph offers courses and conducts research in a number of areas of direct interest to this industry.

- Conestoga College offers programmes through its Institute of Food Processing Technology.

- George Brown College, located in the Toronto area with multiple campuses, offers programmes in food preparation

- Niagara College, located in the Niagara peninsula, offers many programmes in hospitality and horticulture.

- Brock University, also located in the Niagara peninsula, offers programmes in oenology and viticulture.

- Guelph Food Technology Centre is a research institution that provides industry-relevant research in areas such as food safety, nutritional labelling and

- The Vineland Research and Innovation Centre, located in the Niagara peninsula, conducts research facility that focuses on horticulture.

In addition, industry associations such as the Alliance of Ontario Food Processors, the Grape Growers of Ontario and the federally-funded Food Processing Council, provide the industry with forums in which the industry can articulate its priorities and communicate its needs to policymakers.

\section{Methodology.}

Our research was conducted by interviewing six medium-sized businesses in Southern Ontario. ${ }^{27}$ All interviews were conducted using the same questions with high-ranking officials from each company. The questions sought to determine how these businesses were moving to more value-added production in order to remain competitive in their areas and what the implications of such a shift was for worker skills in terms of external hires as well as the skill set of current employees. This summary presents the highlights of these interviews by considering the following areas of particular interest:

1. Methods or practices used to gain/maintain a value-added product line;

2. Employee skills requirements associated with the value-added production;

3. Human resources issues related to finding, developing, and/or maintaining the requisite skills;

\footnotetext{
${ }^{27}$ Interviews were conducted in May 2011 at: Sweet \& Sticky Syrup, Niagara Falls, ON, The Meat Factory (TMF), Stoney Creek, ON, Gunn’s Hill Cheese, Woodstock, ON, Picard Foods, Waterford, ON, Conestoga Meats, Breslau, ON, and Organic Meadow, Guelph, ON. There were five (5) face-to-face interviews and one telephone interview (Organic Meadow).
} 
4. Connections to educational/governmental institutions that exist, or are planned for development of the skilled labour force required to support the particular value-added production process; and

5. Future plans for continued sustained competitive advantage for these Canadian companies.

\section{Methods and Practices for Value-added Processes}

Food processing, in general, is not considered a high technology industry. Improvements in products and processes are likely to be observed incrementally rather than in large quantum leaps. The nature of innovation in the industry is typically characterized by incremental improvement in products, processes and niche marketing which can all add value. In our investigations all of the following ways of adding value were cited by employers during the interviews: unique product, $100 \%$ Canadian, going local, consistently high quality, value over price, going green, hand-made, direct retail, responsive, green/organic, enhanced quality, customer loyalty, etc.

There were four key approaches to adding value to products that emerged from the interviews: being local, maintaining consistently high quality, having a unique product, and being small enough to be responsive to changes in consumer habits/tastes. Each of these is discussed in turn.

\section{Being Local.}

Five of the six companies interviewed cited 'being local ' was an important aspect of their business. They were striving to develop and maintain that image for a number of reasons, not the least of which was profitability. Being local means using local products, local personnel, and selling locally (as a primary market). For example, Picard Foods grow their own Ontario peanuts, use other products from local farms and industries to process and package their products, and sell their products through direct retail outlets that employ local personnel who have connections in the immediate area. This enables them to develop connections with their customers, speak to them and respond directly, and to advertise as a local company. This generates the customer loyalty that has enabled the company to grow and sustain its competitive advantage despite having higher prices for similar products available from `non-local providers. Similarly, Gunn`s Hill Cheese will produce a unique, local cheese that will be hand-made by local people, using local milk products, on a local farm. This 'close to home` approach has generated considerable interest and support in the community and the company aims to build on this loyalty to generate income and sustained profit despite paying higher wages than competitive cheese processors. 'Being local` is a central tenet of these Canadian companies as they have recognized that the Canadian consumer values this attribute for environmental and 'patriotic` reasons. Consequently, they have built this value-added component into their processes and approach and are looking to capitalize on a Canadian consumer who is aware and concerned about where their food comes from and how it is produced.

Maintaining consistently high quality.

The second theme that arose from the interviews was the insistence on high quality product and production processes. Four of the six companies interviewed had a strong focus on maintaining the highest quality that met or exceeded industry standards. Through the maintenance of high quality products, the companies were/are seeking to generate customer loyalty as a means of sustaining profitability. Through trial and error, some of the companies (e.g. TMF, Picard) found that cutting corners reduced profitability and have consequently insisted upon maintaining high quality throughout their production processes. Although this is more costly, they have discovered that the consumer is willing to pay a little extra to get consistent taste and reliable quality. Those companies that have not learned through trial and error have put quality at the forefront of their processes based on their personal values (e.g. Sweet \& Sticky, Gunn's Hill Cheese). The insistence on quality at these firms is the foundational aspect of how they produce their 
products - from raw materials through the entire production to final product. This high quality approach provides them with a unique product upon which consumers can depend. This, in turn, generates customer loyalty and long-term profitability for the company.

\section{Unique Product(s).}

Four of the six companies produce unique products that enable them to capture a particular segment of the market due to lack of direct competition. Sweet \& Sticky and Gunn's Hill Cheese are entering the market with new products that are not made anywhere else. The production processes combined with personal knowledge of the owner/operator provide the company with a competitive advantage through rarity, imperfect immitigability and non-substitutability. Because of their small size and the unique processes they use to produce their products, these firms can offer products that cannot be compared to other products in the marketplace. This provides them with an uncontested share of the annual estimated $\$ 560$ billion global food industry. According to Steve Murdza, President of Sweet \& Sticky "\$1 out of every $\$ 7$ in the food industry is spent on exotic foods", making a share of $\$ 80$ billion available for unique products like ice wine syrup available each year. The Meat Factory and Picard Foods take a somewhat different approach to uniqueness in that their production processes generate unique products that have captured a market share already. Being small enough to produce unique products and respond to customer demands quickly, enables these firms to "corner" the market for particular products. TMF, for example produces meats that are naturally smoked (unlike its competitors who use liquid smoke flavouring) providing a taste that is unique. Picard Foods, again because of their relatively small size can produce single products that are not found anywhere else on the market. Having generated a loyal customer base through insistence on high quality, they can introduce unique products and generate sales from that base. Organic Meadow, although they do not produce any unique products, the processes they use do set them apart. They are part of a very small subset of "organic companies" not "companies that do organics" - a distinction that the educated and aware consumer appreciates and is willing to support with his/her wallet. Each of the unique products of these companies requires specialized production processes that, although costly, generate profit by providing something that cannot be found elsewhere.

\section{Responsiveness/Flexibility.}

As mentioned, the ability to respond quickly to consumer demands enables the company to provide a value-added product. Three of the six companies interviewed cited their ability to speak directly to the consumer and adapt their products or production line to meet the customer requirements/requests as providing a competitive advantage - especially over the larger corporations who could not adapt as readily. Organic Meadow, Picard Foods, and Conestoga Meats all offered examples of how and when they were able to adapt their processes and products in response to customer feedback. The payoff was immediate as consumers appreciated the new products and recognized the efforts of the company to respond to their demands. This generates a connection between the two parties and increases brand loyalty which is ultimately reflected in profits. For these smaller firms, adapting the production line or changing an aspect of their products involved changes that could be implemented quite readily as they have one shift of workers, direct communication lines, and hands-on owners who can train and oversee the new process directly. 
Figure 16. Factors considered important to adding value in the food processing industry

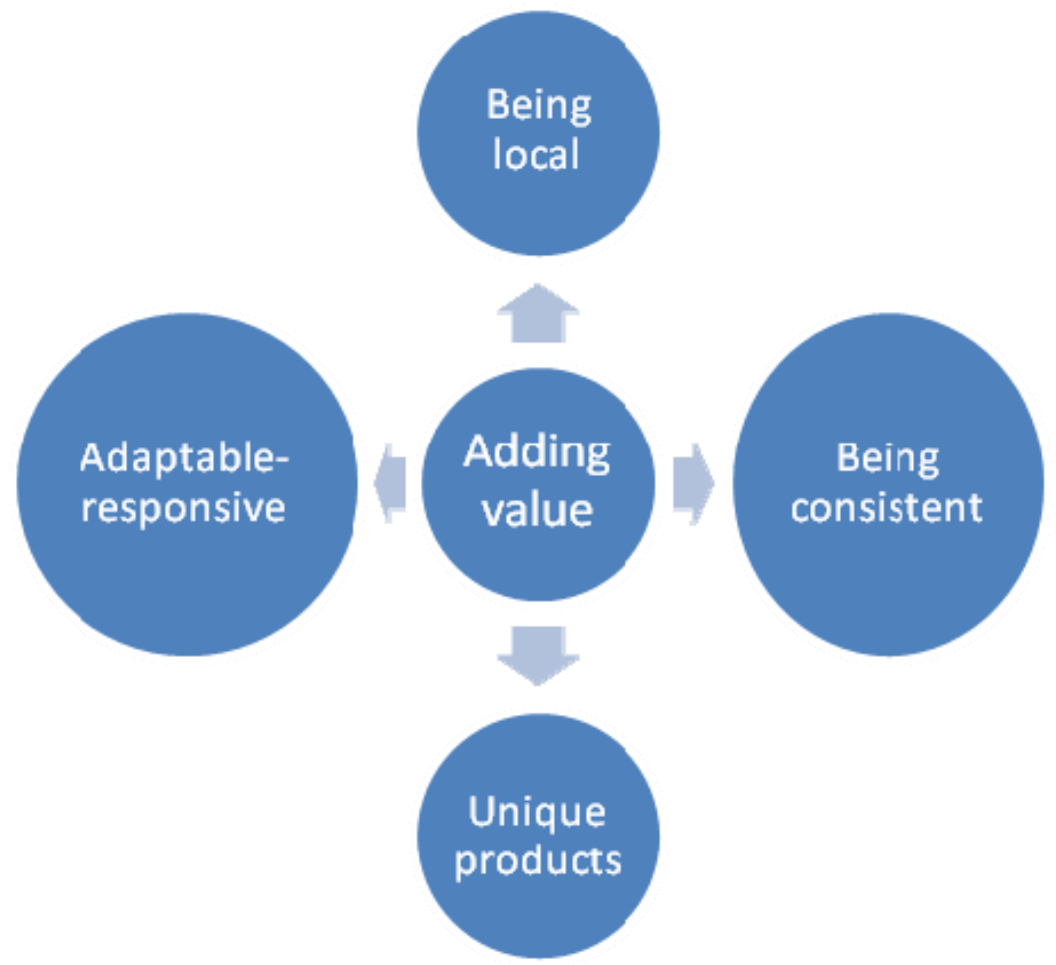

\section{Impact of Value-added processes on Employee Skills}

The four value-added processes described above have varying impact on the workforce of these companies. The focus on being local affects the workforce in a positive manner by generating employment opportunities for local workers. Once hired, attention is placed on understanding the importance of maintaining the local focus, from raw materials through to final product. However, this is more of a mindset that a skill set. The Organic Meadow example illustrates this well as they encourage a "familial" atmosphere by hiring people committed to the values of organics and co-operatives. In this way, they are able to retain their workforce without paying a high wage premium.

The attention paid to maintaining consistently high quality products impacts the workforce much differently. This does require specific training and education that costs the companies and, in some cases, requires them to seek a different type of worker. For example, Sweet \& Sticky require their employees to understand their products and be aware of potentially creative uses for it. For these reasons, they seek employees with food science background or education. TMF provides another example of how insistence on quality impacts their labour force. Due to the nature of their processes and their products, they require more specialized, skilled and knowledgeable employees who are comfortable working under environmentally challenging conditions. TMF uses incentive programmes and effective leadership focused on relational aspects in order to attract and retain the type of employee they need.

The companies who have unique products require very specific skills and education for their employees. Gunn's Hill Cheese for example will use an apprentice approach to developing their skilled labour force as there are no educational institutions that provide the requisite courses specific to their product. Sweet \& Sticky intend to hire university graduates with majors in the food sciences while Picard 
Foods use premium wages to retain personnel once they have been trained in the unique processes involved in producing their products. Similarly, having an adaptable workforce is a key to those organisations that want to remain responsive to the customer. This requires that the employees remain open to learning about the products and the processes. Again, this is more of a mindset than a skill set.

\section{Finding / Developing / Retaining Skilled Employees}

As alluded to earlier, the companies take different approaches to hiring, developing and retaining their workforce. With the exception of Conestoga Meats and Organic Meadow, the companies all see value in or are already connected with local colleges as a way of finding and/or training potential employees. The type of work at Conestoga Meats and Organic Meadow does not lend itself to development through a college environment. They both employ in-house, hands-on training systems.

Sweet \& Sticky use Niagara College as a source for finding employees and because of the established ties between the college and the local wine industry, Sweet \& Sticky intend to pursue other possibilities with the college as their company grows. TMF's major training (other than in-house) requirements are in the areas of food safety and food handling. Through co-op programmes with the local colleges (Niagara and Mohawk) they are able to generate a sufficient pool of potential employees. Gunn's Hill Cheese and Picard Foods would both welcome opportunities to work with local colleges to develop programmes or courses that would be relevant to their businesses. They have both approached the respective colleges but those discussions are in the preliminary stages only.

The companies all discussed the potential opportunities for employment for local residents. TMF and Conestoga Meats both discussed the difficulty in finding good quality employees from the local population. Not that there is not sufficient numbers, the problem arises in getting the local population to work in the conditions associated with meat-packing. TMF uses incentives other than wages, such as biweekly barbeques, awards and allowances to retain the employees in whom they have invested training time and resources. Organic Meadow has no shortage of applicants but is very selective in their hiring process to ensure the proper "fit" between the employee and the organisation. This reduces their attrition in the long-term. Picard Foods hire unskilled labour, for the most part, and then train them in-house. They use premium wages and a friendly work environment as methods of retaining their trained workforce.

\section{Government/Educational Connections}

The aforementioned connections to the local colleges (Niagara, Mohawk, Sheridan, etc.) are seen by the companies as valuable ties that not only produce potential employees, but strengthen the links between the business and the local communities. When asked, all of the organisations were willing to explore possible opportunities with the colleges to either develop a labour force or conduct research (e.g. University of Guelph) that could enhance their products in the future while increasing the "Canadian" content of their image and brand.

Four of the six companies had government assistance at the time of the interviews (May 2011) or in the recent past, in developing their products, facilities or processes. Picard Foods and Sweet \& Sticky are the two exceptions. Both are privately owned and both indicated that they had not thought of government grants as potential ways of helping their respective company. The other four have all received grants for facility development, product development and marketing or technology upgrades to streamline their processes. They intend to continue to explore and seek government funding as the need arises for larger facilities, streamlined processes or product development. None of the companies who have used government money have pursued that source for money to develop or institute training programmes. 


\section{Future Outlook}

Without exception, all the companies anticipated a profitable future. Sweet \& Sticky is in the development stage but anticipates continued growth based on previous sales. As their market grows, they intend to expand their product line, install a new processor, export in bulk and package overseas and conduct research \& development. TMF recently invested in expanded facilities and introduced new technology that has increased the training and skills required of their workers. They are looking to continue to expand in order to satisfy consumer demand - not through new product lines rather by augmenting existing ones. Picard Foods has a two-year plan for product line expansion - and possible establishment of a micro-brewery to complement its peanut-based product lines. Like Gunn's Hill Cheese, they see agrotourism as a potentially lucrative aspect of their business in the future. Organic Meadow and Conestoga Meats see continued steady growth fuelled by customer demand for their high quality, locally made products.

\section{Summary}

With the exception of Sweet \& Sticky and Gunn's Hill Cheese, which are at the early stages of development, these firms have firmly established themselves as upwardly mobile on the value-added spectrum. By emphasizing uniqueness and high quality, they have been able to offer products that are responsive to the consumer's taste and demands. The higher costs of following this approach is well recouped by the value gained from providing consistently high quality and generating customer loyalty. A consumer that seems to be more aware - more concerned about what they eat, where it comes from, how it was made - is providing a solid base for these Canadian companies to add value to their products and services. While employers in this industry do not always use uniquely skilled labour as a key to their success, they produce unique products or common products in a unique way. This sets them apart from the normal fare offered to the consumer, and the consumer is buying into that. That said, there is potential for future collaboration between local colleges and these types of organisations as processes develop, technology is introduced, and product lines expand. This bodes well for employment in these rural areas of Southern Ontario.

\section{Industry Case-study 2: Hotel Industry in Ontario ${ }^{28}$}

To draw comparisons with the food processing sector, some brief analysis has also been carried out in the tourism and hospitality and the retail sectors in Ontario. The hotel industry was chosen for the second case study in this report because a large number of hotel jobs, similar to the jobs in the broader hospitality industry are low-wage service jobs (see Box below). Workers holding such jobs are less well educated; they earn less, have fewer benefits and are more likely to be employed in part-time and temporary jobs. Their unionization rates are lower and they have fewer opportunities for advancement because they receive little or no training on the job to learn new skills.

\footnotetext{
${ }^{28}$ This case draws on a previous study, Verma (2009).
} 


\section{Box 13. Tourism in Canada - Facts and Overview}

Tourism, one of the world's largest and fastest-growing industries, includes accommodation, food and beverage services, recreation and entertainment, transportation and travel services. With $10.4 \%$ of all employment in Canada, the tourism sector is one of Canada's largest providers of jobs. In 2009 , tourism activities contributed approximately $2.02 \%$ to Canada's GDP, equivalent to that of the fisheries, forestry and agricultural sectors combined.

Total tourism sector employment by province, 2006 (employed labour Force)

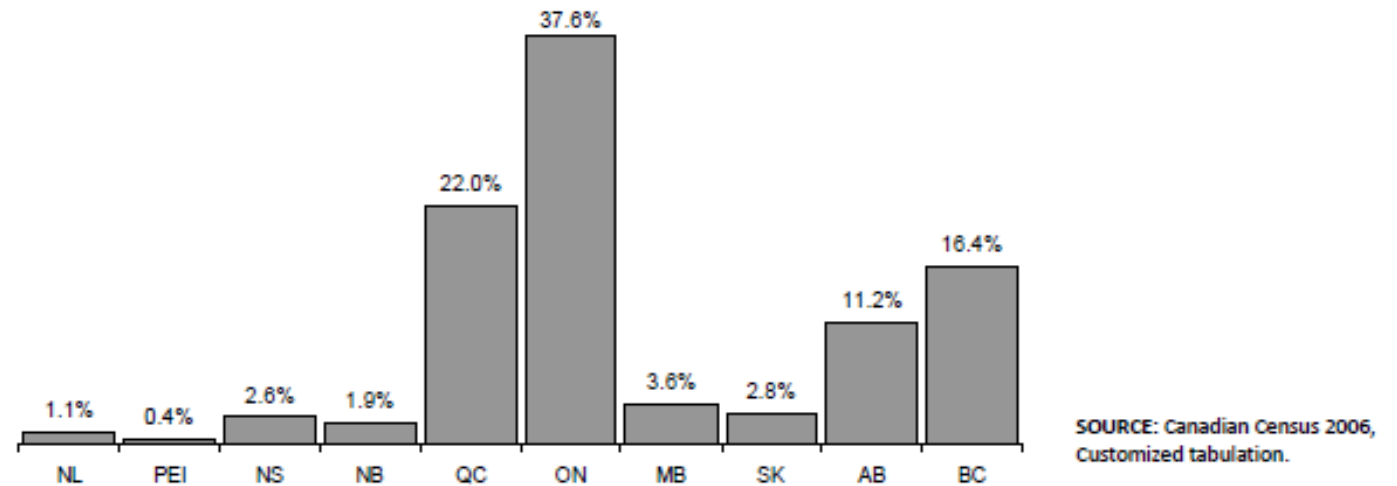

Employment in the tourism sector is characterized by a large number of small businesses. Of all tourism business establishments, $97.9 \%$ employ fewer than 100 people and $86.8 \%$ employ 20 or fewer people. Additionally, $13.8 \%$ of the tourism labour force is self-employed. Education levels are low in this sector in Canada. Most workers of the tourism sector (87.7\%) have not completed post-secondary education. Nearly a third of all tourism workers tend to be very young (15-24 years) which suggests that for many young people this sector provides their first jobs and the opportunities to combine work with study. In comparison to other industry sectors, the tourism sector also employs a greater proportion of youth, women, new immigrants and aboriginals.

It is anticipated that Canada's tourism sector could face a cumulative shortage of people to fill over 64,000 fullyear jobs by 2015 . To adequately support growth projections, the industry must add to its labour pool and implement effective recruitment strategies for further engagement and recruitment from these groups into tourism jobs.

Since this study is focused on moving the economy towards a higher-skill, higher-wage equilibrium it is important to ask if hotels that employ a large number of relatively low-skill service workers, can add more value to their services by giving their workers better skills? What follows is first an overview of the industry followed by a case study of two leading-edge hotels in Ontario that train their employees to deliver better value to their customers.

\section{Research and policy development relating to the tourism sector in Ontario}

The Ontario Tourism Strategy, a long-term, innovative plan for the sustainability and growth of Ontario's tourism industry, points to the need for the following to ensure that the industry has access to an adequate labour force: staff training, promoting tourism in secondary schools, improving post-secondary tourism education and training, partnering with industry associations to develop career paths, and exploring the immigrant labour pool as a source of employees.

The Government of Ontario commissioned the Ontario Tourism Competitiveness Study released in Spring 2008 referring to partnerships with Ontario Tourism Education Corporation and identifies key considerations for an action plan going forward on developing a well-trained workforce (Source: Ontario Budget, 2009: 30). It identifies the following key challenges facing the industry is currently: 
- Labour shortages: Projected labour shortages continue to be the most serious labour market issue facing the tourism sector in Canada. There is competition from other sectors to attract people currently working in Tourism. The sector will face an acute labour shortage in the future as the number of young people entering the labour force continues to decline.

- Poor Career Image: This is due to the high proportion of entry-level, frontline, part-time and seasonal positions, lacking knowledge on the part of businesses of competitive wage and compensation rates, and insufficient awareness of career opportunities in some 400,000 professional, supervisory and management occupations.

- High Turnover Rates: Resultant of poor recruitment and retention strategies on the part of employers, this is also reflective of a younger student workforce that moves on to other career opportunities upon completion of their education.

- Poor Training Culture: The sector has a poor training culture with minimal uptake of workplace training programmes and resources by employers/ employees.

- Low Skill Levels: The literacy, language, and essential skills levels across the sector are low. Industry skill levels must improve to increase workplace efficiency and productivity.

\section{Firm-level analysis}

Methodology.

It is against this backdrop that our case study is situated. Key informants were interviewed at two large hotels in the Greater Toronto Area. In addition, we contacted two unions that organise workers in this industry in Canada and in Ontario. As stated before, the hotel sector is widely distributed across many regions of Ontario. So, although our cases are from the Toronto area, the kind of services they provide can be found in both the Niagara and the Kitchener-Waterloo regions. Many of the same tourists who arrive in Toronto also visit Niagara Falls and the Stratford Shakespeare Festival in Stratford, ON, in the K-W region.

The two hotels that were chosen were the Four Seasons Hotel and the Fairmont Royal York Hotel, both located in the heart of Toronto. These two are discussed together because they follow a similar strategy to create value for the customer by focusing on the employee to deliver a better customer experience. Yet, there are significant differences between the two hotels because they occupy somewhat different niches in the large hotel chain market.

\section{Company ethos}

Since in the 1960s, when architect Isadore Sharp designed and built the first Four Seasons property, this chain of international luxury hotels has grown to managing 83 hotels in 34 countries with more than 31 properties under development. Four Seasons employs more than 35,000 employees worldwide (of this 5,000 are in managerial positions) and conducts business in 30 different languages. Right from the beginning their strategy focused on developing a worldwide chain of mid-sized luxury hotels and resorts with the finest comforts and distinctive service.

The Four Seasons approach to building a growth-oriented, high quality, business depends on delivering a distinctive experience to the customer. For this they rely heavily on their employees since a guest's experience is entirely personal and it depends on how they are treated by the numerous staff they come in contact with during their stay. This basic idea refined over the years is now articulated in terms of 
four pillars: quality, service, culture and brand (see Box 14). The management believes that high service quality standards in a traditional industry can be achieved and maintained by investing in the skills of their employees and engaging them in an organisational culture of customer satisfaction. Another dimension of this philosophy is to introduce innovative new services for the business and leisure traveler to build up the brand. Their assumption is that a segment of the market is willing to pay higher prices for a superior service in an otherwise commoditized industry. The Four Seasons chain adopts "The Golden Rule", which states that one should treat others as one would wish to be treated. This guiding principle is, in the words of the founder, “.... deeply felt ethical belief”, regardless of diverse national cultures from which its workforce is drawn. People around the world want to be treated with dignity and respect irrespective of other cultural differences.

\section{Box 14. A brief overview of "The Four Pillars" at Four Seasons Hotels}

The Four Seasons business philosophy rests on four pillars identified over many years: Quality, Service, Culture and Brand.

Quality - 1972: Over its history, Four Seasons would make four strategic decisions that formed the pillars of its business platform. The first was about quality. Rather than being all things to all people, Four Seasons would focus on one thing: being the best in each location, with medium-sized hotels of exceptional quality.

Service - 1976: The second key strategic decision that formed the business platform was about service. True luxury is defined not by architecture or décor, but by service. So Four Seasons must make the quality of their service their distinguishing feature and a competitive advantage.

Culture - 1982: The third of the four strategic decisions that formed the business platform was about culture. Four Seasons had always had an implicit operating philosophy. As the company expanded, Issy Sharp decided to make it explicit. He knew that shared values were essential to the service culture he wanted to create. Therefore, he and his team developed a formal credo, founded on the Golden Rule: We treat others - all others: customers, employees, partners, suppliers - as one would wish to be treated. This has become the cornerstone of the Four Seasons culture.

Brand - 1986: The final strategic decision that formed the pillars of the company's business platform was about the brand itself. In 1986, a decade after winning its first hotel management contract, Four Seasons made its fourth strategic decision - to grow as a management company and build a brand name synonymous with quality.

Based on material from: www.fourseasons.com/aboutus/four seasons history

The Royal York Hotel is an "architectural splendour” built in 1929 by the Canadian Pacific Railroad Company as one of a series of distinctive hotels across Canada. Its architectural form can be described as "modern classicism" from the art deco era. ${ }^{29}$ In 1999, Canadian Pacific Hotels \& Resorts acquired Fairmont Hotels of San Francisco bringing together two old hotel chains with over a century of building and acquiring distinctive properties. Fairmont Hotels \& Resorts has one of the largest collections of unique properties with a storied past in the world. Well-known addresses in the Fairmont portfolio include The Fairmont Banff Springs, The Savoy, A Fairmont Hotel, in London, Quebec City's Fairmont Le Château Frontenac and New York's The Plaza.

Thus, both hotel chains have a long history of trying to provide a distinctive experience to their guests through unique physical properties, i.e., location and architecture, and through a highly personalized guest

\footnotetext{
${ }^{29}$ A detailed description of the hotel as a tourist destination can be found at: http://www.travelandtransitions.com/stories_photos/toronto_royal_york.htm
} 
experience. Their approach to employees is derived directly from this business model. The value chain that both hotels have built successfully posits that a better trained and acculturated employee would deliver a high quality and unique experience to the guest leading to high guest satisfaction and repeat stays. This would increase hotel reputation and earnings and thereby create greater shareholder value.

\section{Attracting, Motivating and Retaining Talent.}

The Four Seasons approach to finding new employees is to "hire based on attitudes and to train for skill”. Four Seasons recognizes that sustaining service excellence (their key competitive edge), depends on their ability to carefully select employees who exhibit Golden Rule attitudes of courtesy and helpfulness. Each candidate is assessed on six core competencies known by its acronym, ASPECT: Adaptability/ Flexibility; Service Passion; Professionalism; Ethic for Work/Integrity; Communication; and Team Player. The assessment is done using a Behaviour Based Interview, in which candidates are asked how they behaved in certain historical job or personal life situations. Candidates who score high on these attributes are then interviewed a minimum of four times, sometimes five, by different levels of management. The Royal York follows a similar pattern in interviewing and hiring new candidates. Given the reputation of both hotels when they seek new hires they get a large number of applications. This allows them to screen carefully and hire the very best from the pool of qualified applicants.

In both hotels, most employees start at relatively junior levels of employment and move up in the company through the process of acquiring new skills and moving to other better-paid jobs as openings become available. Workers at all levels are encouraged to learn new skills and to bid for new positions. Both hotels offer training programmes in-house as well as encourage their employees to pursue learning interests outside. As described later, the Royal York has begun to participate with its union, UNITEHERE, in a joint training centre. At both hotels the policy is to promote from within. By some estimates a little more than half the supervisors and junior managers are promoted to their jobs from within. This gives qualified and high performing employees an opportunity to develop a career within the organisation. Each employee and manager undergoes an annual development. For employees this is a review of performance in six competency areas known by its acronym, ASPECT, described earlier. Managers are assessed on a set of behaviour statements (called Behaviour Based Assessment) applicable to the level at which they are expected to perform. Managers can also see the list of expected behaviours at levels above them in order to plan for promotion.

Pay at both hotels is competitive within the industry. It is not the highest but certainly within the top $25 \%$ of all hotels. Benefits are generally among the best in the industry as they are negotiated through collective bargaining and industry patterns exert a strong influence. Both hotels offer a pension plan to which both the employer and the employee contribute. Both hotels also supplement the basic medical coverage provided by the Province of Ontario to all Ontarians.

\section{Training and development for staff}

Training and development initiatives are at the core of the Four Seasons' business strategy. Training that provides career development opportunities, helps mobilize talent that in turn fuels the growth of the company. Each Four Seasons Hotel has a full time dedicated Learning Manager who has access to over 400 hours of instructor-led and Four-Seasons-specific electronic learning. Hotels are measured by their approach to learning and must attempt to provide a minimum of 10 hours for each employee and average of 40 hours for each manager of customer service and leadership learning per year, in addition to any job specific training.

Training programmes communicate both 'hard' information regarding standards of performance and 'soft' cultural messages. Training programmes are designed to be fun and engaging, yet challenging and 
results-based. Orientation materials are translated into 20 languages to accommodate non-English speaking employees. A hybrid approach combining classroom lecture and on-the-job training is used. Employees spend time learning techniques inside the classroom and then practice their skills under the guidance of a peer mentor. All managers are expected to deliver learning to other employees, and this continues up the organisation to the CEO.

The Royal York also provides training to its employees along similar lines. In addition to in-house training organised and paid-for by the Royal York, a partnership with its union runs a joint training centre that delivers basic training modules such as literacy, use of computers, safety on the job, etc.

\section{Summary}

A major consequence of the employment system described above is that turnover (i.e., voluntary quits) among employees is well below industry average. Both hotels report a turnover rate of $8-12 \%$ in recent years, a figure lower than the industry average.

Both hotel chains are organised by unions in Toronto. The United Food \& Commercial Workers (UFCW) represents workers at the Four Seasons while UNITE-HERE represents workers at the Fairmont Royal York. Both hotels have above-average relations with their unions. While union and management have their usual differences in many areas, the parties have collaborated at both locations in joint projects and problem-solving.

The two hotels discussed here have shown that a relatively low-skill, low-wage workforce in a traditional industry where the product (or service) is often viewed like a commodity by many producers and consumers, can be trained to create value for the customer. More value can be created for the customer if workers are better trained and engaged in their work. A higher level of skill and involvement helps the worker deliver a superior service for which the customer would be willing pay more. Thus, the low-wage worker in this organisation is an integral part of the value chain that connects the organisation with the customer.

This approach leads to better outcomes for the employer as well as for the employees. The employer builds a large customer base of people who keep returning to the hotel for future stays and talk-up the high quality standards to others. The employee, in turn, performs a job that requires higher levels of skill. Such jobs come with opportunities to move up which in turn, encourages workers to be fully engaged with their work. These jobs give employees a higher level of pride in their work and greater identification with the goals of the organisation.

Both hotels have created a competitive advantage in the marketplace by leveraging the skill and involvement of their lowest-paid workers. Is this lesson relevant to other hotels or other service-oriented organisations? Can organisations that do not operate in the luxury-end of the market be able to benefit from this lesson? These are pertinent questions that can be answered at two levels. In these two cases wages for workers are not much higher than wages at other large hotels in Toronto. So, it is not wages per se but the investment these hotels make in their workers that make the difference.

\section{Broader training and skills development in relation to tourism and hospitality}

In a broader sense, the Ontario Hotel and Motel Association (ORHMA), the largest provincial hospitality association in Canada, addresses the issue of skill shortages in the industry through its own education and training programmes. It has more than 4000 members and represents over 11000 establishments in the province. It provides members with current and value added training programmes and access to educational resources. 
Through its association with e-Cornell University, members have access to training in CHRP Exam Prep, Hospitality and Foodservice Management, Leadership and Strategic Management, Human Resources Management, Financial Management, Management Essentials. The university offers over 70 different courses and 21 different certificates in all areas of hospitality management.

In 2007, a Taskforce on the Hotel Industry addressed the issue of skill development needs of lowwage workers in the hotel industry in Toronto, in particular. In its report, the Taskforce emphasised the need for a skill development strategy aimed at building "an economy based on skills, innovation, opportunity, sustainability and equitably shared prosperity rather than on low-road practices that lower living and working standards and weaken communities." The report cited the achievements of the Culinary Training Academy, a non-profit organisation supported by the largest union local in the U.S. (UNITE-HERE Local 226) and nearly all the major hotels and casinos in Las Vegas (see Box 15 below, which describes a recent project to establish a training centre for hospitality workers in the city).

Training and skill development needs of the Toronto hotel industry have been met historically through a variety of sources. Employers do some of their own training while others enter the industry after completing educational programmes at colleges. The Ontario Tourism Education Corporation (OTEC) develops curricula and training programmes for many occupations in the tourism industry. However, none of these existing avenues for skill development adequately fill certain gaps in training needs for a high value-added hotel industry. This gap is best illustrated by comparing Toronto with the industry infrastructure that exists in the Las Vegas hotel industry where a dedicated training academy trains entrants to the industry in a large variety of skills and occupations.

\section{Box 15. Hospitality Workers Training Centre in Toronto}

The Toronto arm of the union, UNITE-HERE, Local 75, which represents over 7,000 hotel, food service and gaming workers in the Greater Toronto Area, began to push for a dedicated training academy for the sector with a number of parties as early as 2006. Apart from proposing to work with hotel employers, the union approached community groups, city councilors, representatives of the provincial government, federal government and others. Beginning in 2009, some large hotels such as the Fairmont Royal York, began to contribute 2-cents-an-hour into a training fund (The Equal Opportunities Training Fund) to comply with a negotiated provision in their respective collective agreements. This fund is a potential source for funding training activities at the training academy.

An opportunity for finding a physical location for a training academy came up when a city-owned building was demolished at 60 Richmond Street. Councillor Pam McConnell worked hard to prevent the city from selling the land and was instrumental in leasing the property to the Toronto Community Housing Corporation (TCHC) for a nominal sum $(\$ 1 / y r)$ on the condition that the TCHC build affordable housing for hotel workers at the site. Providing affordable housing to people who work in the city is an identified priority of the city government. This project came to fruition because of the support and cooperation of three principal stakeholders: the city government, TCHC, and UNITE-HERE Local 75. Construction on the building began in July 2011 and is expected to be complete by the end of the year.

The Hospitality Workers Training Centre (HWTC) already operational, offers on-site training in many Local 75 hotels across the city, including classes in English as a Second Language, literacy, computer skills and housekeeping skills. The HWTC would move into the ground floor of this building (roughly $3000 \mathrm{sq} f \mathrm{ft}$ ) by the end of 2011. A teaching kitchen will be built (2000 sq ft) while the rest of the space would consist of classrooms (1000 sq $\mathrm{ft}$ ). In addition, the training centre would rent one of the apartments in the building to set up a teaching hotel suite for housekeeper training. In addition to classroom space, the Training Centre will also house a training restaurant where students can get hands-on instruction in the basics of cooking, serving and bartending, preparing them for entry-level jobs in the hotels' food and beverage operations.

The HTWC is a partnership between the union and the major hotels. When the union, UNITE-HERE approached major employers in the industry with the idea, among the first to support the initiative was the Fairmont Royal York Hotel. The initial motive for supporting the HWTC may have been different for different employers but it is instructive to take the case of The Fairmont Royal York. The Royal York extended significant cooperation early on even at the planning stages. The Head Chef at the hotel helped in the design of the teaching kitchen by using his influence to get a design firm to donate pro bono services. Anna Chartres, the Director of Human Resources signed on to serve as an 
employer representative on the Board of the HWTC. The Centre is governed by a Board comprising of an equal number of members (4 each) from the union and the employers.

At The Fairmont Royal York, employer cooperation with the union on the training academy is seen as a "smart" move. According to Anna Chartres: "We are already involved [by agreeing to the 2-cents-an-hour training contribution]. So, it is smart for us to be involved in the joint operation of the training academy and in joining forces to lobby the government for training funds. The upside potential for us is significant."

In an interview, she expanded on the 'upside potential' within the larger context of the hotel organisation and their relationship with the union. Within the Fairmont 'culture', there is a strong belief that quality service can be delivered only through well-trained and committed employees. So, any effort to develop skills for the hotel is well-aligned with their strategic goals. Moreover, the hotel chain has developed a policy of dialogue and engagement with the union. Another concrete example of cooperation given is that of union-run but employer-paid dental care centres for hotel employees. In bargaining, management and union have been generally successful at achieving a high level of involvement and participation from both sides. Their common vision for training has led the parties to join forces in developing proposals for funding by the government and in lobbying the government more generally to support the industry. The HWTC will also receive $\$ 500,000$ from a developer under Section 37 provisions of city by-laws that require developers of urban sites to invest a small portion of their profits in community infrastructure. This grant is being used to equip the kitchen and buy other necessary hardware such as computers, furniture, etc.

The training centre has two goals. The first is to provide existing Local 75 members with the opportunity to upgrade their skills and move up in the industry. The second is to create opportunities for newcomers to enter the growing hospitality industry by providing the training they need to begin entry-level jobs in Toronto's hotels.

This experience in creating an infrastructure for skill development in a traditionally low-wage, low-skill service industry is instructive in several ways. First, it demonstrates that the existing skill development infrastructure in the province does not serve the hotel industry very well. Hitherto, Toronto had no industry-specific training facility for industry-specific skills. Second, most hotel workers but especially those working as housekeepers and in food services, are seen as being low-skilled and hence attract few investments in their skills. Third, building a training academy for the industry is very difficult because it requires funds as well as a common vision among various parties such as labour, management, various levels of government and other training and educational institutions. Fourth, labour and management, if they share a common vision, can begin the process but they will need the engagement of the government and the community to make it successful and sustainable. Although the HWTC is a reality it would struggle to find the funds to provide adequate training to all its members. Lastly, labour and management need to go beyond their traditional attitudes and engagement in collective bargaining, to collaborate in the area of skill development of workers.

\section{Industry Case Study 3: The Food Retail Industry in Ontario}

The food retail industry lies at the intersection of retail and food industries. GDP in the total retail trade sector, which includes all types of merchandise, increased from $\$ 55.2$ billion in 2001 to $\$ 76.3$ billion in 2010. The increase in GDP reported between 2001 and 2010 represented a compound annual rate of 3.7\%. Between 2009 and 2010, the total value-added of the Retail Trade sector increased by $3.8 \%{ }^{30}$ The food retail industry grew slightly slower than the total retail sector between 2002 and 2008. See Box 16 below for further facts in relation to the food retail industry in Canada.

\footnotetext{
${ }^{30}$ State of Retail: The Canadian Report 2010”, a joint report by the Retail Council of Canada (RCC) and Industry Canada. Accessed from http://www.ic.gc.ca/eic/site/retra-comde.nsf/eng/qn00282.html
} 


\section{Box 16. Food retail in Canada - Facts and Overview}

In 2008, there were 45,251 business establishments in the food sector in Canada. A large proportion of food retail employee's work in enterprises with 500 or more employees (Jacobson, P. M., 2006: 42). This reflects the importance of five corporate chains in the food sector (i.e. Loblaws, Métro, Sobeys, Canada Safeway, Overwaitea Food Group, which employ $67 \%$ of the Canadian food retail workforce). SMEs, such as Co-Ops and independent grocers/ specialty foods stores, try to remain competitive but the market is largely dominated by the five corporate chains mentioned above.

Roughly $18 \%$ of the sector is located in rural areas. This represents the reality of the food retail and wholesale sector, which is a truly national industry that is present in communities all across Canada (Source: Census 2006).

The sector's employed labour force age distribution differs from the national average in some key ways. The 1524 age cohort dominates the demographic pyramid with $38.10 \%$ (more than double the national average of $17.33 \%$ ), and there are actually slightly more men than women in this age cohort. It is also noted that $28.60 \%$ of the sector's workers are over the age of 45 compared to $13.89 \%$ nationally (Source: Census 2006).

Roughly $28 \%$ of the sector has no post secondary education compared to $14.01 \%$ nationally. Many of the front line occupations do not require a post-secondary diploma or degree for entry into the occupation. The high proportion of young workers (15-24), who might still attend school, also needs to be taken into consideration.

Tables 1-4 below summarise data on three types of food retail stores: beer, wine and liquor stores, convenience and specialty food stores and supermarkets. The data emphasises that although supermarkets dominate food retail they do not include everything. It is often the innovations and efficiency in the smaller stores that drives the big supermarkets to push for further innovations. Table 1 shows that while chain businesses, defined as businesses with 4 or more stores, dominate both supermarkets and liquor stores, most convenience and specialty stores are non-chain businesses.

Supermarket chains registered the fastest growth over 2002-08 of all the categories: $6.3 \%$ cumulative aggregate growth rate (CAGR). In terms of profitability as measured by return on sales, liquor stores did better (46\%, see Table 2) than anyone else and supermarkets were at the bottom ( $24 \%$ for both chain and non-chain stores). In terms of growth in profitability, all chains declined in their return on sales over 200208. This shows the tremendous downward pressure on margins due to competition. Non-chains improved their return on sales in every category. It can be inferred here that chains have been under great pressure to improve efficiency through innovation and technology. Some of this pressure comes from cheaper sourcing overseas but a lot of it comes from non-chain competition from across the street.

Inventory costs are very salient for profitability in the retail business. On this metric ${ }^{31}$, as Table 3 shows, supermarket chains (14.3 turns per annum) and non-chain supermarkets (15.4) did much better than other groups such as liquor stores (7 turns per annum) and the total retail sector (7.2). However, efficiency in inventory management did not grow during 2002-08. It shrank by $2 \%$ for chain supermarkets. The only groups to improve inventory efficiency were chain convenience and specialty food stores that grew their inventory turnover by 6.6\% CAGR over these years. Data on gross margin return on inventory (GMROI), shown in Table 4, suggest that chain supermarkets lagged behind in GMROI while non-chain supermarkets led all other retail sectors in GMROI. Again, this provides a good illustration of the competitive pressure on big chain supermarkets for innovation. The same pattern of competitive pressure on chain supermarkets

${ }^{31}$ Inventory turnover $=$ Cost of goods sold /Average inventory, where Average inventory $=$ (Starting inventory + Closing inventory) / 2. (For example, 1 inventory turn is equal to a retailer having 365 days of inventory, 12 is 1 month of inventory, and 365 is 1 day of inventory.) So, the larger the number the higher the inventory efficiency. 
is suggested by the growth rates in GMROI. Interestingly, non-chain liquor stores grew their GMROI while it shrank for chain liquor stores with the pattern being the reverse for convenience stores.

Table 1. Operating revenue (2008) and revenue growth (2002-2008) All Retail and Food Retail

\begin{tabular}{|c|c|c|c|c|}
\hline & \multicolumn{2}{|c|}{$\begin{array}{l}\text { Operating Revenue by } \\
\text { trade group (2008) in } \\
\$ \text { billions }\end{array}$} & \multicolumn{2}{|c|}{$\begin{array}{l}\text { Operating Revenue CAGR*, by } \\
\text { trade group (2002-2008) }\end{array}$} \\
\hline & Chain & Non-Chain & Chain & Non-Chain \\
\hline Total, all trade groups & 213.8 & 240.9 & $7.3 \%$ & $3.2 \%$ \\
\hline Beer, wine and liquor stores & 15.1 & 1.6 & $5.2 \%$ & $3.0 \%$ \\
\hline Convenience and specialty food stores & 3 & 10.9 & $4.8 \%$ & $0.5 \%$ \\
\hline Supermarkets & 44.1 & 28 & $6.3 \%$ & $2.9 \%$ \\
\hline
\end{tabular}

Note: CAGR: Cumulative Aggregate Growth Rate

Sources: Based on Annual Retail Trade Survey, 2010, Statistics Canada; taken from State of Retail 2010, report by Retail Council of Canada and Industry Canada

Table 2. Return on sales (2008) and change in return on sales (2002-2008) All Retail and Food Retail

\begin{tabular}{|l|l|l|l|l|}
\cline { 2 - 5 } \multicolumn{1}{c|}{} & \multicolumn{2}{l|}{$\begin{array}{l}\text { Return on sales, by } \\
\text { trade group (2008) }\end{array}$} & \multicolumn{2}{l|}{$\begin{array}{l}\text { Return on sales CAGR, by } \\
\text { trade group (2002-2008) }\end{array}$} \\
\cline { 2 - 5 } \multicolumn{1}{c|}{} & Chain & Non-Chain & Chain & Non-Chain \\
\hline Total, all trade groups & $\mathbf{3 0 \%}$ & $\mathbf{2 5 \%}$ & $\mathbf{- 1 . 5 \%}$ & $\mathbf{2 . 1 \%}$ \\
\hline Beer, wine and liquor stores & $46 \%$ & $25 \%$ & $-1.7 \%$ & $3.2 \%$ \\
\hline Convenience and specialty food stores & $32 \%$ & $27 \%$ & $-0.4 \%$ & $1.3 \%$ \\
\hline Supermarkets & $24 \%$ & $24 \%$ & $-1.8 \%$ & $1.9 \%$ \\
\hline
\end{tabular}

Sources: Based on Annual Retail Trade Survey, 2010, Statistics Canada; taken from State of Retail 2010, report by Retail Council of Canada and Industry Canada.

Table 3. Inventory turnover (2008) \& change in inventory turnover (2002-2008) All Retail and Food Retail

\begin{tabular}{|l|l|l|l|l|}
\cline { 2 - 5 } \multicolumn{1}{c|}{} & \multicolumn{3}{l|}{$\begin{array}{l}\text { Inventory turnover, by } \\
\text { trade group (2008) }\end{array}$} & \multicolumn{2}{l|}{$\begin{array}{l}\text { Inventory turnover CAGR, by } \\
\text { trade group (2002-2008) }\end{array}$} \\
\cline { 2 - 5 } \multicolumn{1}{c|}{} & Chain & Non-Chain & Chain & Non-Chain \\
\hline Total, all trade groups & $\mathbf{7 . 2}$ & $\mathbf{4 . 6}$ & $\mathbf{2 . 6 \%}$ & $\mathbf{- 2 . 0 \%}$ \\
\hline Beer, wine and liquor stores & 7 & 6.6 & $-0.9 \%$ & $0.9 \%$ \\
\hline Convenience and specialty food stores & 11.2 & 11.5 & $6.6 \%$ & $-0.8 \%$ \\
\hline Supermarkets & 14.3 & 15.4 & $-2.0 \%$ & $-0.1 \%$ \\
\hline
\end{tabular}

Sources: Based on Annual Retail Trade Survey, 2010, Statistics Canada; taken from State of Retail 2010, report by Retail Council of Canada and Industry Canada. 
Table 4. Gross margin return on inventory (GMROI) (2008) \& change in GMROI (2002-2008)

\begin{tabular}{|l|l|l|l|l|}
\cline { 2 - 5 } \multicolumn{1}{c|}{} & \multicolumn{2}{l|}{$\begin{array}{l}\text { GMROI, by trade } \\
\text { group (2008) }\end{array}$} & \multicolumn{2}{l|}{$\begin{array}{l}\text { GMROI CAGR, by trade group } \\
\text { (2002-2008) }\end{array}$} \\
\cline { 2 - 5 } \multicolumn{1}{c|}{} & Chain & Non-Chain & Chain & Non-Chain \\
\hline Total, all trade groups & $\mathbf{3 . 1}$ & $\mathbf{1 . 5}$ & $\mathbf{0 . 4 \%}$ & $\mathbf{0 . 7 \%}$ \\
\hline Beer, wine and liquor stores & 5.9 & 2.2 & $-4.2 \%$ & $5.1 \%$ \\
\hline Convenience and specialty food stores & 5.2 & 4.2 & $5.9 \%$ & $0.9 \%$ \\
\hline Supermarkets & 4.5 & 4.9 & $-4.3 \%$ & $2.3 \%$ \\
\hline
\end{tabular}

Sources: Based on Annual Retail Trade Survey, 2010, Statistics Canada; taken from State of Retail 2010, report by Retail Council of Canada and Industry Canada.

\section{Pressure for Innovation and Response}

As documented in the Retail Council of Canada study and further corroborated by information gathered in this study, there is plenty of scope for increasing efficiency through technology and innovation in this sector. This view belies the notion that retail is a low-skill, low-value-added industry. There are a number of areas where targeted investment can improve efficiency and profitability. Some examples given by leading firms are: reducing lead times for product delivery, increasing inventory turns, reducing distribution and transportation cost and reducing the probability of out-of-stock occurrences. Management can improve in each of these areas by using new technology and training its workforce to manage more creatively.

The industry is confronted with significant deficiencies and problems in the areas of: skills development, labour market intelligence, employee attraction and retention. ${ }^{32}$ The following human resources issues were identified in the Sector Study Update (July 2004):

- Industry image - One of the areas of greatest concern is the perceived poor image of the industry, particularly among potential employees, which impacts attraction and retention.

- Career opportunities - Many young employees abandon the sector due to a perceived lack of a career path into management opportunities.

- Demographics - Changing demographics cause changing consumer tastes and buying patterns, and stores/workers need to respond to these new patterns and have product knowledge to help consumers.

- $\quad$ Skills - As the industry changes, new positions requiring new skills and training are opening up (e.g. radio frequency identification devices (RFID) technology, pharmacies, floral sales, etc).

- Strategic Human Resource Planning- HR planning/development has not kept pace with changing consumer preferences and food safety related knowledge requirements.

- Training Delivery Systems -not sufficiently coordinated with each other and to meet industry needs

\footnotetext{
${ }^{32}$ Source: Canadian Food Industry Council 2007-2008 Annual Report : 4
} 
In addition to the HR issues and challenges listed above, the following specific challenges are also considered:

- Low skills: given education levels within the sector, skills upgrading is a critical area for investment. However high turnover and poor retention rates can be a deterrent to employer investments in skills development.

- Employee attraction and retention: are challenging especially given lower average wages and the significance of part-time employment. The nature of the work also has an impact on the perception of the sector as a career destination.

- Labour market intelligence: the sector needs better intelligence to demonstrate the important impact of HR issues on the sector's business performance, and to understand particular dynamics within this sector comprising large food chains in order to strategically focus HR solutions.

\section{The Canadian Grocery Human Resource Council}

The mandate of the Canadian Grocery Human Resource Council (CGHRC) is to identify gaps and opportunities in developing talent for the industry that would allow it to be competitive by national and international standards. For example, the CGHRC has developed several toolkits for employers such as: HR Toolkit for Independent Grocers, Employee Turnover Cost Calculator and an employee Retention Toolkit.

The CGHRC interviewed 12 large industry employers in late 2010 and early 2011. ${ }^{33}$ Among other questions they were asked whether their expenditure on training would increase, or decrease or remain the same compared to the previous year? It was found that of the twelve employers, six indicated an increase in spending on training, four indicated that there would be no change and only two employers saw a decrease in such spending. Although the sample is small these results are revealing of the extent of training going on in the industry.

The intelligence gathered and the subsequent analysis carried out by the industry association (the RCC) and the CGHRC suggests that the Canadian food retail industry needs to make significant investments in upskilling its workforce if it is to stay competitive which implies improvements in efficiency, productivity and profitability. This task facing the industry is daunting when it is considered that the industry traditionally does not attract high-performing individuals seeking a career rather than just a job. The industry has both an image problem and a real problem in that it has not attracted people with high education in the past.

This situation is even more acute in Ontario where more businesses than in any other province compete for the consumer. In the last ten years Ontario has seen major changes in the industry through mergers and acquisitions. Some regional chains like Metro have expanded aggressively into Ontario. Walmart has not only opened several hundred stores in Canada, a large number of them are in Ontario. Many of these stores have lately opened a supermarket wing to sell groceries. Loblaws, one of the largest of home-grown Canadian supermarket chains, has undergone significant restructuring to stay competitive. A new management team under the leadership of Galen Weston has initiated significant changes in the last five years. Many senior managers have left and new ones hired. Operations have been restructured with a focus on new systems that can get products to market promptly. It has shifted increasingly to discount retailing, with two-thirds - or \$20-billion - of Loblaw's revenues now in the low-price arena. But sales growth has been difficult to achieve.

\footnotetext{
${ }^{33}$ CGHRC Quarterly HR Trends Analysis Report - January 2011; accessed from www.cghrc.ca
} 
The system overhaul at Loblaws was still not complete at the time of this writing in September 2011, which means that more changes are on the way. It is felt at the company that many members of the team are still new in their jobs and their response to the customer and competition is not as aggressive and prompt as it could be. All of this suggests that people skills and innovation are key to Loblaws making any gains in its market share.

Sales of store brands, or private label products, began to spike since the beginning of the economic downturn in 2008. At first, sales of private labels sales were driven by higher commodity prices, but volume growth began to catch up with dollar growth in mid-2008. ${ }^{34}$ As the economy continues to struggle, the stakes are even higher for retailers operating in Canada, compared with the US, because the food market is dominated by a handful of large national retail chains.

Few chains are more dominant than Loblaws, and its latest marketing strategy has dramatically upped the ante for its national brand suppliers. Long known for its more premium private label brand, President's Choice, Loblaws has shifted its gear to highlight its more basic No Name products. Recast in its original black-on-yellow packaging, the line is more prominently featured on store shelves. Meanwhile, its rival supermarket operator, Metro, is bringing more of its Quebec-based brands into its newly acquired Ontario stores.

The increase in consumption among consumers and the introduction of high quality store brand products has changed consumer perceptions of private label grocery brands. Consumer attitudes about many store brands have actually shifted. Private label brands are now considered unique and as having quality commensurate with that of traditional brands. The number of store brands is projected to continue to grow as the economy recovers from the recent downturn. While private label pricing is a strong motivator for consumers, the quality and flavor of private label organic products drive the most positive sentiment.

\section{Union-run Training}

The United Food and Commercial Workers (UFCW) is the largest union in Canada representing workers in the food retail industry. Its president during the 1980s and the 1990s, Clifford Evans negotiated a training fund contribution from the employers initially of 2-cents-per-hour. The fund has been used since it was first negotiated in Cambridge, Ontario, in the early 1980s. At the time it was the first-ever employer contribution to a UFCW Training Trust Fund. Over the years, tens of thousands of workers who are union members have improved their skills and advanced their careers through the free training they received at their Local Union's centre.

\footnotetext{
${ }^{34}$ Mergent Industry Reports: Retail-North America, Report Number 1009, January 2011.
} 


\section{Box 17. Walmart - the food retailer}

Walmart, the world's largest private-sector employer, which operates 329 stores in Canada and thousands more in 28 countries, feels the scarcity of talent in many areas of its operations. If one takes the example of merchandising as a case, it is an area crucial for Walmart to maintain its competitive edge. Yet, it is hard for this giant firm to attract the best because it must compete with others for the scarce talent. Given that Walmart sells a very large variety of products it merchandising operations are complex. They need to integrate their inventory with both the suppliers and with the stores at the local level. Even slight imbalances can cost the firm large sums of money if stockouts occur too frequently resulting in loss of customers on the one hand and on the other hand carrying a much larger inventory that results in more waste in perishable goods or higher cost of working capital.

Executives at Walmart believe that the level of complexity in their merchandising operations makes it difficult to source talent from the outside. Hence, they are embarking on ever increasing investment in developing talent internally. Susan Chambers the head of Human Resources was recently quoted in The Economist as saying:

"You can't hire enough talent that can deal with the merchandising complexity. So it is incredibly important to develop talent internally."

Employees at all levels are having to handle growing complexity. Senior managers, professionals and supervisors always had to deal with change but now the lowest levels employee, the person who stocks the shelves at Walmart, has to interface with the supply chain software that connects each shelf in the store to some supplier and possible manufacturer somewhere. Customers are demanding more flexibility everyday with new channels of shopping such as internet and mobile technology. These changes have implications across the entire organisation that implies a general increase in technical skills across the board. In India, Walmart has established some free academies to train future store workers in its joint venture with Bharti, a local conglomerate. In many emerging markets, an investment in training really pays off, both because these markets are growing faster and also because the education systems do not produce "work-ready" talent.

Despite its reputation as a tough, anti-union employer, Walmart is currently trying to shift its human resource approach across the world from authoritarian to one driven by a strong organisational culture. The aim is to ensure employees "feel empowered and [that they] have the right values so they can make the right decision", according to Susan Chambers. This implies significant investments in training. Key informants at Walmart Canada have shared that Walmart's strategy in Canada going forward is to invest in its people through training. Skills acquired through training are seen as the key to growth and profitability in a competitive market. Without such investment in training Walmart cannot offer value-added services to the consumer and hence cannot expect to grow. Thus, investing in employee skills is seen as an integral part of a successful business strategy, not as just as socially-progressive human resource policy.

\section{Summary}

Food retailing has been viewed traditionally as a low-skill, low value-added industry. Yet, the growing competition and sophistication in sourcing and merchandizing driven by technology is pushing retailers to build up the skills of its workforce. In Ontario, the bigger chain stores have begun to deploy ever more sophisticated supply chains and in-store merchandise management that they need a more skilled workforce to run these systems optimally and at full capacity. The largest union in this sector, the UFCW, has pushed for better training opportunities since the 1980s. The federally-funded CGHRC provides a multi-partite forum for discussing sector-wide problems and solutions. The growing concentration within the industry structure, i.e., more larger employers, is likely to help speed up the move to more value-added retailing if the competitive pressures remain in place. 


\section{SUMMARY AND CONCLUSIONS}

This study conducted an investigation of how regions can move to a higher-skill, higher value-added equilibrium in Canada, drawing on Ontario as a case study example. Given the complexities of measuring such a shift this investigation examined the issue from different perspectives. It examined aggregate labour market data in order to map skills supply and demand at the level of employment insurance (EI) regions. This analysis is supplemented with an overview of institutions and policies that facilitate the shift to higher skills and higher value-added production in Ontario. Two geographical regions (Niagara and the Kitchener-Waterloo regions) and three industries within Ontario (food processing, hotels, food retailing) were examined in greater detail.

In mapping Ontario's infrastructure for creating high-skill jobs and producing high-skill talent, we have followed the widely-accepted notion that policy interventions can facilitate this process without impeding market forces that are at work in a relatively small and open economy like Canada's. Our investigations have yielded the following insights:

1. higher skill jobs are created when firms try to compete through innovation, world-class benchmarking, value addition, cost reduction, quality improvement, and higher productivity;

2. any kind of improvement, whether in cost, quality, productivity or value addition in general, requires using cutting-edge knowledge and learning new skills;

3. effective policy interventions need to be coordinated across multiple stakeholders;

4. effective policy interventions need timely responses to market shifts (short-term) as well as an infrastructure that encourages and facilitates investment in skills (long-term);

5. the effectiveness of policy interventions is contingent on the "local” community's social capital.

The institutional framework in Ontario for a shift towards a high value-added economy includes the federally-funded Sector Councils. In the Government of Ontario the following play a key role in increasing supply and demand for high skills: Ministry of Training, Colleges and Universities, Ministry of Economic Development and other region-specific and industry-specific (e.g., Ministry of Northern Development, Mines and Forestry; Ministry of Agriculture, Food and Rural Affairs) ministries including the Ministry of Research and Innovation.

Federal programmes generally apply to all provinces and provincial programmes apply to the entire province. The push for a "local" dimension to policy interventions comes from quasi-government bodies, industry (or employer) associations, non-profit community organisations, labour unions, etc. The local dimension of the policy intervention infrastructure is important if one subscribes to the theory that multistakeholder involvement is the key to effective intervention. In this regard, Ontario has set up local level workforce planning boards with membership from various constituencies (e.g., employers, labour, community groups, etc.) to identify training priorities. These agencies develop broad directions for policy guidance but do not make policy or decisions. Other local level institutions of note are regional governments (e.g., the Niagara Regional Council, the Niagara Economic Development Corporation, etc.), regional industry associations (e.g., the St. Catharines-Thorold Chamber of Commerce, the Grape Growers 
of Ontario, etc.) and non-profit organisations (e.g., Excellence in Manufacturing Canada, Communitech, Canada’s Technology Triangle, etc.). help keep the local perspective alive in policy deliberations.

Most of the Provincial spending on training is for "downside” adjustment, i.e., to rehabilitate workers displaced by merger, closure, tech change or other disruptions. Monies spent on upgrading skills of the workforce, is much more limited in scope and in quantity. Some programmes to fund "upside" training involve the Ministry of Economic Development and are often related to incentives to bring new investments to Ontario. Bulk of the funds spent on "upside" training in Ontario, comes from employers. Although recent data on expenditure on work-related training are not easily available, previously collected data suggest that Canada lags behind other leading nations in its support for training. ${ }^{35}$ In terms of employer-paid training, according to the 2003 Workplace and Employee Survey, Ontario lagged behind the national average in terms of dollars spent (\$277 per employee vs. national average of \$315 per employee) as well as a percentage of payroll $(0.71 \%$ vs. national average of $0.89 \%) .{ }^{36}$

Overall, it can be concluded that Ontario has an elaborate infrastructure for policy intervention. It consists of a variety of institutions representing different constituencies. However, the coordination at the local level is not as focused as some situations demand. Many firms are benefitting from the policies and programmes available to encourage and support firms to move to a high-skill equilibrium. However, it is not possible to ascertain based on existing information, the share of Ontario's economy that is fully participating in this change. Institutions that help build social capital at the local level are the key to innovation and change in the direction of a high-skill equilibrium and while Ontario has some of this institutional infrastructure, more can be done to foster stronger institutions and processes.

This study raises a number of emerging policy issues for consideration by federal and provincial/local stakeholders in Canada. All levels of government should consider the following:

\section{Joined up approach to skills and local partnerships}

By bringing together key partners in employment and training, economic development, and postsecondary education with industry, better outcomes and efficiencies can be achieved. This report highlighted the efforts of Niagara College, where synergies are being fostered between local companies and the educational and research infrastructure. The web of institutions and programmes described in this report will become more effective when different organizations come together to achieve collaborative outcomes. These types of local level partnership are a critical mechanism for moving areas toward a higher-skills equilibrium.

Local workforce planning boards have a critical role to play in assessing local strengths, weaknesses, threats and opportunities as well as linking supply and demand approaches to skills and employment, particularly in areas in a low skilled equilibrium. In the United States, the Workforce Investment Boards (WIB) have played a strong role in creating more integrated strategies to address employment and skills

${ }^{35}$ According to the International Adult Literacy and Skills Survey administered in 2003 as part of an international project, the overall rate of participation in training and learning in Canada (49 percent) was somewhat lower than in Norway (53 percent), the United States (55 percent) and Switzerland (57 percent). Close to one in five Norwegians with low literacy skills get support from the government as compared to just over one in ten in Canada. Government support for those with low literacy skills (Levels 1 and 2) is less frequent in Canada than in the United States. Source: Kjell Rubenson, Richard Desjardins and Ee-Seul Yoon (2007). “Adult Learning in Canada: A Comparative Perspective Results from the Adult Literacy and Life Skills Survey”. Catalogue no. 89-552-MIE — No.17 Ottawa: Statistics Canada.

${ }^{36}$ Ontario Monthly Labour Market Report, Vol. 7, No. 6, June 2007. Available from http://www.tcu.gov.on.ca/eng/labourmarket/currenttrends/2007monthly.html 
within boarder economic development strategies at the local level. Local workforce planning boards can work with economic development stakeholders to ensure that actions to attract and retain talent are developed in tandem with actions to build a responsive education and training system, while integrating disadvantaged groups, and up-skilling those individuals who are already employed.

The study has highlighted the value of coordinated approaches at the local level to raising both the supply and demand for skills. The Niagara regional economy, anchored by tourism, hospitality, winemaking and light manufacturing, is diversifying to fill the loss of jobs in manufacturing by attracting both higher-tech manufacturing as well as start-ups in digital media. There are also efforts to add value to the traditional tourist trade by promoting "culinary” tourism. Local level networks are anchored by bodies such as the Niagara Workforce Planning Board, the Niagara Economic Development Corporation, educational institutions (Niagara College, Brock University) and industry associations (Grape Growers Ontario, local Chambers of Commerce, etc.). The Niagara region benefits from a well-defined geographical and industrial profile both of which have contributed to investments in social capital.

Regional coordination in the Kitchener-Waterloo-Cambridge area is anchored by community nonprofit organisations (e.g., Excellence in Manufacturing Canada, Communitech, and Canada's Technology Triangle), educational institutions (University of Waterloo, Wilfrid Laurier University, Conestoga College, University of Guelph) and industry associations (e.g., Association of Ontario Food Processers). The boundaries of this region are less clearly delineated (both an advantage and a disadvantage at the same time) and the regional economy is more diversified relative to the Niagara region. For social capital formation the geographical and industrial diversity translates into multiple networks rather a single large network.

However, although a significant variety of institutions exist in Ontario the likelihood of a wellcoordinated response at the local level is not always likely to happen. Any coordinated local level policy intervention has been episodic at best. Ontario could improve its response to local needs by creating processes that require periodic consultations at the local level. Organisations like the Niagara Economic Development Corporation can help to foster a strong sense of a shared purpose in bringing together local organisations to set common targets and implement common strategies. Provincial governments in conjunction with federal programs should consider establishing broader platforms at the local level to bringing together institutions from the skills, employment and economic development side together so that they can reduce fragmentation and pool resources around common concerns and priorities.

Cross-referencing other policy areas in target setting can also be useful in reducing fragmentation. For example when training or public programmes (such as guidance on productivity improvements) are provided to employers using public funds, policy makers could consider requiring employers to provide an improved wage and/or career prospects compared to pre-training wages and employment conditions. There is a risk that such a policy could discourage more employers from taking up support from public sources of funding. But this risk has to be balanced against the use of public funds that allegedly occurs under the current system to perpetuate a low-skill equilibrium which may be unsustainable in the long-run.

\section{Supporting incremental innovation and evolving product market strategies}

In the past there has been an emphasis in many OECD countries on improving innovation through investment in research and innovation. This study has shown however that in a number of sectors, particularly those that show a high concentration of low skilled work, innovation happens more incrementally, from the shop floor up. In many industries and workplaces, moving towards a high-skill equilibrium does not always have to mean investment in sophisticated technology, research and development. The problem lies in boosting value addition in the traditionally low skills sectors. For rural 
areas it means a singular focus on the comparative advantages of the local area which takes away from developing the human resources in the area.

There is therefore an important benefit to be gained from both training staff and giving the opportunities to influence the nature of the work that they carry out. For example, the hotels examined in Toronto had recognised that value can be created for the customer if workers are better trained and engaged in their work. A higher level of skill and involvement helps the worker deliver a superior service for which the customer would be willing pay more. Thus, the low-wage worker in this organisation is an integral part of the value chain that connects the organisation with the customer. In this sense, low-skill equilibrium regions appear to be a blindspot for Canadian policy development. They attract less attention because they are not seen as glamorous in terms of attracting new investments and the latest technologies. But lack of priority for their development is worrying in terms of the long term sustainability of these jobs and communities.

This study has highlighted that there are a number of routes to adding value and creating high quality employment. This may mean diversifying and establishing centres of excellence in higher skilled sectors and incubating high-tech firms to build and attract higher skilled jobs (as is the case of nGen in Niagara), or alternately, evolving product market strategies in existing sectors. For example, research in the food processing sector highlighted that companies were adding value through an emphasis on the importance of being local; offering consistently high quality products, being unique and being responsive and flexible to emerging market needs. By emphasizing uniqueness and high quality, local firms have been able to offer products that are responsive to the consumer's taste and demands. The higher costs of following this approach is well recouped by the value gained from providing consistently high quality and generating customer loyalty. There is potential for future collaboration between local colleges and these types of organisations as processes develop, technology is introduced, and product lines expand. This bodes well for employment in these rural areas of Southern Ontario.

\section{Valuing the contribution of non-profit groups in this policy area}

Non-profit groups (e.g., Excellence in Manufacturing Canada, Communitech, Canada's Technology Triangle) also provide key inputs by providing training and other services to employers, individuals and local governments. Even more important than delivery of training and other services, these organisations play a key role in diffusing innovations. They legitimize innovations, assist with training and provide an on-going consultative role that is necessary for sustaining innovations. These organisations also serve an integrative role at the local level by creating a forum for public-private regional economic development partnership and by pooling community resources to address common concerns. They also serve as a major platform for building the local community's social capital. Because they are relatively less constrained than other institutions discussed above, these organisations can be as expansive in defining their scope as their resources and constituents permit. They can help individuals and organisations as well as market the competitive advantages of their region to the world to attract new businesses, investment and talent to the region. As information providers and network facilitators, they complement partner municipalities' focus on local business retention and expansion in addition to serving as a contact point for enterprises outside the region interested in new ventures, expansion, or relocation to the region. While many such organisations exist in Ontario, most of them have limited resources which limits their reach and effectiveness. Strengthening their role should be a part of any comprehensive strategy aimed at moving to a high skill equilibrium. 


\section{Federal Considerations}

The following are emerging policy issues for consideration by the federal government in Canada:

\section{Developing a local differentiated approach to skills}

The data findings for this study help to support previous research by the LEED Programme (Froy et al, 2009) on the importance of local skills strategies, through highlighting sub-regional variation in skills contexts and clear differences in the trends experienced by local labour markets over time. National, regional and local policy makers also welcomed the tool in increasing their understanding of the variability in local skills contexts and highlighting the relative changes in position of different regions over time.

Gathering up-to-date, local-level labour market information for this project has been challenging. In order to gain comparability internationally, this study needed to use relatively crude measures but there is an opportunity for Canada to adapt and enhance the model using more disaggregated Canadian data. The statistical diagnostic tool has been found useful by several staffers in the Canadian government both within the HRSDC and other policy areas. As one analyst put it, "It lets us think about the labour market in new ways”.

\section{Provincial Considerations}

The following are emerging policy issues for consideration by the Ontario government in Canada:

\section{Incentivising employers to invest more in the skills of their workforce}

This study has highlighted examples of employers who have adopted a policy of investing in the skills of their employees and better utilising these skills to increase productivity and market-share. These employers used their investments in training to create unique, value-added products for which customers are willing to pay. Although not every employer could follow this strategy given the market structure, even if $10 \%$ more employers could be persuaded to take this "high road", the Ontario economy would move to a significantly higher skill equilibrium. The point to emphasize is that employers and their internal policies must play an important role in the dynamic of moving to a high-skill equilibrium. Employers have a critical role to play to working in partnership with government and community stakeholders to ensure quality employment and up-skilling opportunities. Such partnerships should take place both at the sector level, and at the level of local travel to work areas.

Based on existing information, it is not possible to ascertain the share of Ontario employers that comes in contact with organisations and programmes described here. It is likely that many companies undertake training and business improvement on their own without any contact with government or nonprofit programmes. Although difficult to determine, it will be important in the future to better assess the extent to which Ontario industry accesses the external resources supplied by public, private and not-for profit programmes and organisations to boost the supply and utilisation of skills.

The study highlighted that work with employers should not only focus on generating efficiency but also on encouraging the creativity and innovation which will lead to the development of new product market strategies. Provincial policy makers in Ontario agreed that the ability to change and innovate the design of products would be intrinsic to the ability of their region to keep up with market developments and produce better quality and more sustainable jobs. 


\section{Boosting the role of training institutions in balanced local skills strategies}

Educational institutions can play an important role in the above policy agenda. Educational institutions were identified by the study as a key player in stimulating greater skills utilisation by firms in Ontario. Many region- or industry-specific university and college programmes in Ontario were established after being proposed by an educational institution with the support from relevant industry. Some colleges and universities have adopted region- or industry-specific priorities but it is not a defining characteristic of educational programmes in general which tend to be focused around academic disciplines or occupations that cut across regions and industry. Colleges and universities with a regional focus are more likely to offer industry-specific and region-focused programmes as we saw in the case of Niagara College, Conestoga College, Brock University and the University of Guelph. In particular, Niagara College provided a good illustration of ways in which education, industry and government can engage in dialogue and coordinating their own policies for intervention.

Economic development strategies frequently focus on high-skilled sectors such as new technology, media and advanced manufacturing. However there is also a need for incremental innovation in Ontario in sectors which have not traditionally focused on these types of strategies, such as retail, food processing, care and tourism). These sectors are of strategic importance to the Ontario economy. Community colleges in particular could play an important role to play in efforts to support incremental innovation at the local level in such sectors, and this should be recognised and supported by government policies.

\section{Targeting some areas and some firms rather than others}

The analysis in this report gives us an idea of where the regions in Ontario stand in relation to the concept of a high-skill equilibrium. The evidence presented shows that urban areas generally do better than rural ones. This would suggest that some consideration should be given to policies specifically targeted at rural areas, while considering the linkages that would be necessary into successful local urban economies. Critical for any targeted place based initiative is carrying out an impartial local needs assessment. Furthermore, in the context of limited public resources, it may also be difficult for the government to gain political and social support for programmes which target narrowly specific communities and are not seen to offer support more generally.

\section{Final Word}

Moving to a high skill equilibrium is a complex process that involves many actors and many multilayered processes. It is nearly impossible for any single player to adopt a policy or practice that will drive an economy like Ontario's towards a high skill equilibrium. But those parts of this complex system that are better understood provide significant clues to policy areas where public and private policymakers can focus their efforts. The text box below makes some suggestions for policy initiatives that deserve consideration. 


\section{Box 18. Summary of Issues for consideration}

Based on the discussion above the following initiatives can be considered for implementation.

\section{All levels of government in Canada:}

- $\quad$ Promote joined-up local level partnerships as a mechanism for moving areas toward a higher-skills equilibrium

- Broaden the definition and scope of innovation in policies and programmes to include product improvement, process improvement, higher-value product introduction, higher-value process introduction; and, target relatively low value-added sectors with high employment for funding innovations.

- Foster community- and industry-level organisations that provide information, training and support for adoption of value-addition practices within small and medium-sized enterprises.

\section{Federal Government}

- Improve labour market information to better track the shift towards a higher value-added, higher-skill economy:

- Implement a workplace (establishment) survey like the former WES but in a modified form that would track both demand- and supply-side practices for higher value-added products and processes and higher skills.

- Augment the reporting of monthly (or quarterly) employment statistics from the Labour Force Survey, with employment and unemployment broken down by occupational skill categories (e.g., creative, service, working) and by income categories.

\section{Provincial Government}

- $\quad$ Create a process (or forum) that would bring together local level bodies from both demand- and supply-side of the high-skill equilibrium on a regular basis. Currently, the two sides work in parallel and consult when deemed necessary.

- $\quad$ Work closer with employers to understand what skills are in high demand and to bring about a better skills supply and demand match

- $\quad$ More focus could be placed on "upside" adjustment, where employment and training programmes are targeted to upgrade the skills of current employees. 


\section{REFERENCES}

Boxwell Jr, Robert J. 1994. Benchmarking for Competitive Advantage. New York: McGraw-Hill, pp. 225.

Breyfogle, Forrest W. III. 1999. Implementing Six Sigma: Smarter Solutions Using Statistical Methods. New York, NY: John Wiley \& Sons. ISBN 0471265721.

Camp, R. 1989. The search for industry best practices that lead to superior performance. Productivity Press.

CME (Canadian Manufacturers \& Exporters). March 2010. Roadmap to Recovery. Charting A Course for Economic Renewal. Ottawa, ON.

Cole, Robert E. 1979. Work, Mobility, and Participation : A Comparative Study of American and Japanese Industry. Berkeley: University of California Press.

Cole, Robert E. 1982. Diffusion Of Participatory Work Structures In Japan, Sweden, And The United States. In Paul S. Goodman, ed., Change In Organisations : New Perspectives on Theory, Research, And Practice, pp. 166 - 211. San Francisco: Jossey-Bass.

Cole, Robert E. 2002. From Continuous Improvement to Continuous Innovation. Total Quality Management, 13(8): 1051-1056.

Cole, Robert E., Tsuyoshi Matsumiya. 2008. "When The Pursuit of Quality Risks Innovation". The TQM Journal, 20(2): pp.130-142.

Cutcher-Gershenfeld, Joel, Thomas A. Kochan \& Verma, Anil. 1991. "Recent Developments in U.S. Employee Involvement Initiatives: Erosion or Transformation", in Donna Sockell, David Lewin \& David Lipsky, eds., Advances in Industrial \& Labor Relations, Vol. 5, JAI Press, 1-31.

Davenport, Thomas \& Short, J. 1990. The New Industrial Engineering: Information Technology and Business Process Redesign, Sloan Management Review, Summer 1990, pp 11-27.

Florida, Richard. L. 2002. The Rise of the Creative Class: And how It's Transforming Work, Leisure. New York: Basic Books.

Florida, Richard. L. 2005. Cities and the Creative Class. London: Routledge.

Hammer, M. 1990. "Reengineering Work: Don't Automate, Obliterate", Harvard Business Review, July/August, Pp. 104-112.

Hammer, M. And Champy, J. A. 1993. Reengineering The Corporation: A Manifesto For Business Revolution. Harper Business Books, New York. Isbn 0-06-662112-7.

NWPB (Niagara Workforce Planning Board). Niagara 3d: Dynamics, Diversity And Density. November 2010. Available From http://niagaraworkforceboard.ca

Porter, Michael E. 1980. Competitive Strategy, Free Press, New York. 
Porter, Michael E. 1985. Competitive Advantage, Free Press, New York.

Walton, Richard. E. 1979. Work Innovations in the United States. Harvard Business Review, 57(4): 88-98.

Walton, Richard. E. 1985. From Control to Commitment in the Workplace. Harvard Business Review, 63(2): 77-84. 